Support information for

\title{
Cytotoxic Diterpenoids from Caryopteris
}

\section{aureoglandulosa}

Xu-Dong Mao, ${ }^{\dagger}{ }^{\dagger}$ Cheng-Gang Zhang, ${ }^{\dagger}$, Ting Chen, $^{\dagger}+$ Sen-Miao Zhao, ${ }^{\dagger}{ }^{\dagger}$ and GuiXin $\mathrm{Chou}^{*, \dagger, *}$

†The MOE Key Laboratory of Standardization of Chinese Medicines and SATCM Key Laboratory of New Resources and Quality Evaluation of Chinese Medicines, Institute of Chinese Materia Medica (ICMM), Shanghai University of Traditional Chinese Medicine (SHUTCM), and 'Shanghai R\&D Center for Standardization of Chinese Medicines, Shanghai 201203, People's Republic of China.

*Corresponding author.

E-mails: chouguixinzyb@126.com (G.-X. Chou). 


\section{Table of Contents}

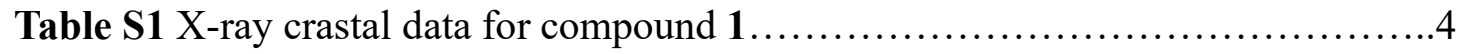

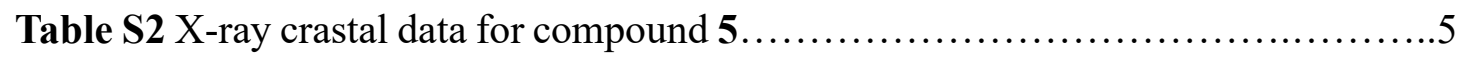

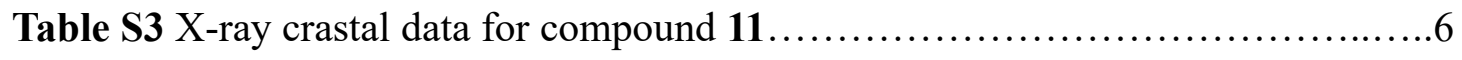

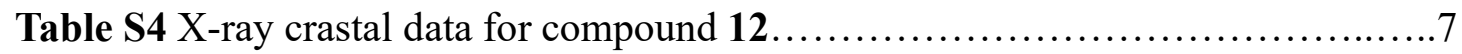

Figure S1 All isolated compounds from Caryopteris aureoglandulosa...................8

Figure S2 ${ }^{1} \mathrm{H}$ NMR spectrum $\left(400 \mathrm{MHz}, \mathrm{CDCl}_{3}\right)$ of compound $1 \ldots \ldots \ldots \ldots \ldots \ldots . . \ldots 9$

Figure $\mathbf{S 3}^{13} \mathrm{C}$ NMR spectrum $\left(100 \mathrm{MHz}, \mathrm{CDCl}_{3}\right)$ of compound 1 .................... 9

Figure S4 HSQC spectrum (400 MHz, $\left.\mathrm{CDCl}_{3}\right)$ of compound 1.................... 10

Figure $\mathbf{S 5} \mathrm{HMBC}$ spectrum $\left(400 \mathrm{MHz}, \mathrm{CDCl}_{3}\right)$ of compound $1 \ldots \ldots \ldots \ldots \ldots \ldots . \ldots 10$

Figure $\mathbf{S 6}{ }^{1} \mathrm{H}-{ }^{1} \mathrm{H}$ COSY spectrum $\left(400 \mathrm{MHz}, \mathrm{CDCl}_{3}\right)$ of compound $1 \ldots \ldots \ldots \ldots \ldots . . . . .11$

Figure S7 NOESY spectrum ( $\left.400 \mathrm{MHz}, \mathrm{CDCl}_{3}\right)$ of compound $1 \ldots \ldots \ldots \ldots \ldots \ldots \ldots \ldots$

Figure S8 HR-ESI-MS spectrum of compound 1 ............................. 12

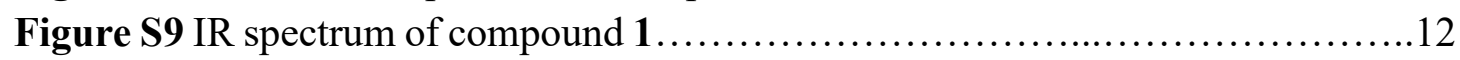

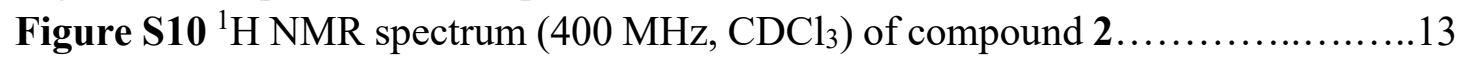

Figure $\mathbf{S 1 1}{ }^{13} \mathrm{C}$ NMR spectrum $\left(100 \mathrm{MHz}, \mathrm{CDCl}_{3}\right)$ of compound $2 \ldots \ldots \ldots \ldots \ldots \ldots . . . . . .13$

Figure S12 HSQC spectrum (400 MHz, $\left.\mathrm{CDCl}_{3}\right)$ of compound 2..................14

Figure $\mathbf{S 1 3} \mathrm{HMBC}$ spectrum $\left(400 \mathrm{MHz}, \mathrm{CDCl}_{3}\right)$ of compound $2 \ldots \ldots \ldots \ldots \ldots \ldots . . . . . .14$

Figure $\mathbf{S 1 4}{ }^{1} \mathrm{H}-{ }^{1} \mathrm{H}$ COSY spectrum (400 MHz, $\mathrm{CDCl}_{3}$ ) of compound $2 \ldots \ldots \ldots \ldots \ldots . . . . . .15$

Figure S15 NOESY spectrum ( $400 \mathrm{MHz}, \mathrm{CDCl}_{3}$ ) of compound 2 .................15

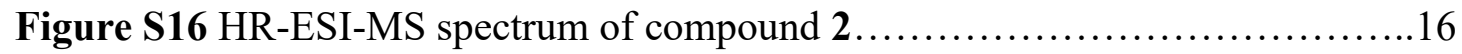

Figure S17 IR spectrum of compound 2 . ..................................16

Figure $\mathbf{S 1 8}{ }^{1} \mathrm{H}$ NMR spectrum $\left(400 \mathrm{MHz}, \mathrm{CDCl}_{3}\right)$ of compound $3 \ldots \ldots \ldots \ldots \ldots \ldots . \ldots 17$

Figure $\mathbf{S 1 9}{ }^{13} \mathrm{C}$ NMR spectrum $\left(100 \mathrm{MHz}, \mathrm{CDCl}_{3}\right)$ of compound $3 \ldots \ldots \ldots \ldots \ldots \ldots . . . . . .17$

Figure S20 HSQC spectrum (400 MHz, $\left.\mathrm{CDCl}_{3}\right)$ of compound 3..................18

Figure S21 HMBC spectrum (400 MHz, $\mathrm{CDCl}_{3}$ ) of compound 3..................18

Figure S22 ${ }^{1} \mathrm{H}-{ }^{1} \mathrm{H}$ COSY spectrum $\left(400 \mathrm{MHz}, \mathrm{CDCl}_{3}\right)$ of compound $3 \ldots \ldots \ldots \ldots . . . .19$

Figure S23 NOESY spectrum (400 MHz, $\mathrm{CDCl}_{3}$ ) of compound 3.................. 19

Figure S24 HR-ESI-MS spectrum of compound 3 ...........................20

Figure S25 IR spectrum of compound 3 .................................20

Figure $\mathbf{S 2 6}{ }^{1} \mathrm{H}$ NMR spectrum $\left(400 \mathrm{MHz}, \mathrm{CDCl}_{3}\right)$ of compound $4 \ldots \ldots \ldots \ldots \ldots \ldots . . . . .21$

Figure $\mathbf{S 2 7}{ }^{13} \mathrm{C}$ NMR spectrum $\left(100 \mathrm{MHz}, \mathrm{CDCl}_{3}\right)$ of compound $4 \ldots \ldots \ldots \ldots \ldots \ldots . . .21$

Figure S28 HSQC spectrum ( $\left.400 \mathrm{MHz}, \mathrm{CDCl}_{3}\right)$ of compound $4 \ldots \ldots \ldots \ldots \ldots \ldots . . . . .22$

Figure $\mathbf{S 2 9} \mathrm{HMBC}$ spectrum $\left(400 \mathrm{MHz}, \mathrm{CDCl}_{3}\right)$ of compound $4 \ldots \ldots \ldots \ldots \ldots \ldots . . . . .22$

Figure $\mathbf{S 3 0}{ }^{1} \mathrm{H}-{ }^{1} \mathrm{H}$ COSY spectrum $\left(400 \mathrm{MHz}, \mathrm{CDCl}_{3}\right)$ of compound $4 \ldots \ldots \ldots \ldots . .23$

Figure S31 NOESY spectrum ( $\left.400 \mathrm{MHz}, \mathrm{CDCl}_{3}\right)$ of compound $4 \ldots \ldots \ldots \ldots \ldots \ldots . . \ldots 23$

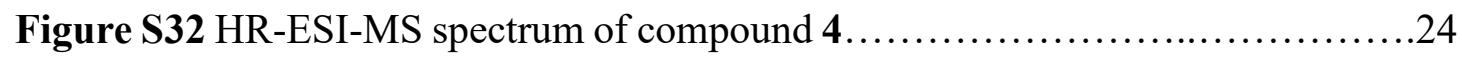

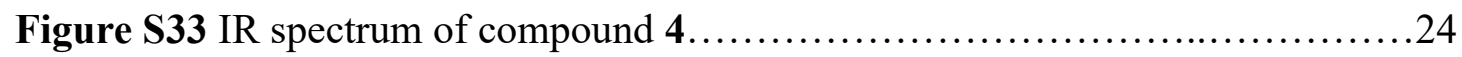

Figure S34 ${ }^{1} \mathrm{H}$ NMR spectrum $\left(400 \mathrm{MHz}, \mathrm{CDCl}_{3}\right.$ ) of compound $\mathbf{5} \ldots \ldots \ldots \ldots \ldots . . . . .25$

Figure $\mathbf{S 3 5}{ }^{13} \mathrm{C} \mathrm{NMR}$ spectrum $\left(100 \mathrm{MHz}, \mathrm{CDCl}_{3}\right)$ of compound $\mathbf{5} \ldots \ldots \ldots \ldots \ldots . . . . .25$

Figure S36 HSQC spectrum (400 MHz, $\left.\mathrm{CDCl}_{3}\right)$ of compound $\mathbf{5} \ldots \ldots \ldots \ldots \ldots \ldots . . \ldots 26$

Figure $\mathbf{S 3 7} \mathrm{HMBC}$ spectrum $\left(400 \mathrm{MHz}, \mathrm{CDCl}_{3}\right.$ ) of compound $5 \ldots \ldots \ldots \ldots \ldots \ldots . . \ldots 26$

Figure $\mathbf{S 3 8}{ }^{1} \mathrm{H}_{-}{ }^{1} \mathrm{H}$ COSY spectrum $\left(400 \mathrm{MHz}, \mathrm{CDCl}_{3}\right)$ of compound $\mathbf{5} \ldots \ldots \ldots \ldots \ldots . .27$ 
Figure S39 NOESY spectrum (400 MHz, $\mathrm{CDCl}_{3}$ ) of compound $\mathbf{5} \ldots \ldots \ldots \ldots \ldots \ldots . .27$

Figure S40 HR-ESI-MS spectrum of compound 5 ..........................28

Figure S41 IR spectrum of compound 5.................................28

Figure $\mathbf{S 4 2}{ }^{1} \mathrm{H}$ NMR spectrum $\left(400 \mathrm{MHz}, \mathrm{CDCl}_{3}\right)$ of compound $\mathbf{6} \ldots \ldots \ldots \ldots \ldots \ldots . . . . . . . .29$

Figure $\mathbf{S 4 3}{ }^{13} \mathrm{C}$ NMR spectrum $\left(100 \mathrm{MHz}, \mathrm{CDCl}_{3}\right)$ of compound $\mathbf{6} \ldots \ldots \ldots \ldots \ldots . . . . .29$

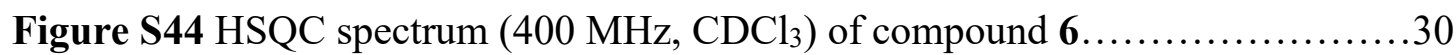

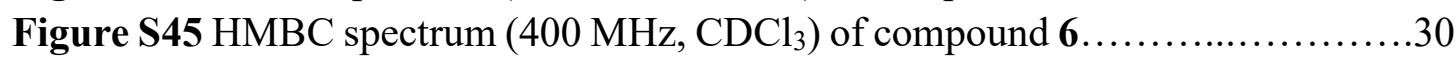

Figure $\mathbf{S 4 6}{ }^{1} \mathrm{H}-{ }^{1} \mathrm{H}$ COSY spectrum $\left(400 \mathrm{MHz}, \mathrm{CDCl}_{3}\right)$ of compound $\mathbf{6} \ldots \ldots \ldots \ldots . \ldots 31$

Figure S47 NOESY spectrum ( $\left.400 \mathrm{MHz}, \mathrm{CDCl}_{3}\right)$ of compound $6 \ldots \ldots \ldots \ldots \ldots \ldots . . . . . . .1$

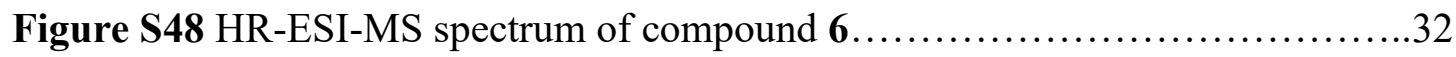

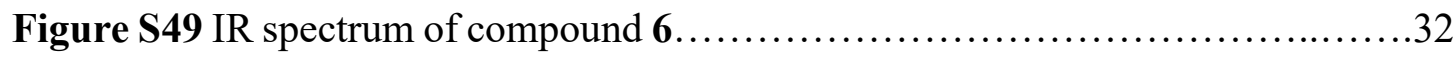

Figure S50 ${ }^{1} \mathrm{H}$ NMR spectrum (400 MHz, DMSO- $d_{6}$ ) of compound 7................33

Figure $\mathbf{S 5 1}{ }^{13} \mathrm{C}$ NMR spectrum $\left(100 \mathrm{MHz}\right.$, DMSO- $\left.d_{6}\right)$ of compound $7 \ldots \ldots \ldots \ldots . . . . .33$

Figure S52 HSQC spectrum (400 MHz, DMSO- $d_{6}$ ) of compound 7 .................34

Figure S53 HMBC spectrum (400 MHz, DMSO- $d_{6}$ ) of compound $7 \ldots \ldots \ldots \ldots \ldots . . . . . . .34$

Figure $554{ }^{1} \mathrm{H}-{ }^{1} \mathrm{H}$ COSY spectrum $\left(400 \mathrm{MHz}, \mathrm{DMSO}-d_{6}\right)$ of compound 7.............35

Figure S55 NOESY spectrum ( $400 \mathrm{MHz}$, DMSO- $d_{6}$ ) of compound 7.................35

Figure S56 HR-ESI-MS spectrum of compound 7 ............................. 36

Figure S57 IR spectrum of compound 7 ....................................... 
Table S1 X-ray crastal data for compound 1

\begin{tabular}{|c|c|c|}
\hline Identification code & mjr18011_0m & \\
\hline Empirical formula & $\mathrm{C}_{20} \mathrm{H}_{18} \mathrm{O}_{5}$ & \\
\hline Formula weight & 338.34 & \\
\hline Temperature & $296 \mathrm{~K}$ & \\
\hline Wavelength & $1.34139 \AA$ & \\
\hline Crystal system & Monoclinic & \\
\hline Space group & $\mathrm{C} 1 \mathrm{C} 1$ & \\
\hline \multirow[t]{3}{*}{ Unit cell dimensions } & $a=18.5220(3) \AA$ & $\alpha=90^{\circ}$. \\
\hline & $\mathrm{b}=13.0651(2) \AA$ & $\beta=103.7600(10)^{\circ}$ \\
\hline & $\mathrm{c}=7.04120(10) \AA$ & $\gamma=90^{\circ}$. \\
\hline Volume & $1655.01(4) \AA^{3}$ & \\
\hline $\mathrm{Z}$ & 4 & \\
\hline Density (calculated) & $1.358 \mathrm{Mg} / \mathrm{m}^{3}$ & \\
\hline Absorption coefficient & $0.516 \mathrm{~mm}^{-1}$ & \\
\hline $\mathrm{F}(000)$ & 712 & \\
\hline Crystal size & $0.2 \times 0.02 \times 0.01 \mathrm{~mm}^{3}$ & \\
\hline Theta range for data collection & 7.069 to $54.863^{\circ}$. & \\
\hline \multirow[t]{2}{*}{ Index ranges } & $-22<=\mathrm{h}<=22,-15<=\mathrm{k}<=15$, & \\
\hline & $-8<=1<=7$ & \\
\hline Reflections collected & 9333 & \\
\hline Independent reflections & $2945[\mathrm{R}(\mathrm{int})=0.0411]$ & \\
\hline Completeness to theta $=53.594^{\circ}$ & $99.3 \%$ & \\
\hline Absorption correction & Semi-empirical from equivalents & \\
\hline Max. and min. transmission & 0.7508 and 0.6224 & \\
\hline Refinement method & Full-matrix least-squares on $\mathrm{F}^{2}$ & \\
\hline Data / restraints / parameters & 2945 / 2 / 230 & \\
\hline Goodness-of-fit on $\mathrm{F}^{2}$ & 1.060 & \\
\hline Final $R$ indices $[I>2 \operatorname{sigma}(I)]$ & $\mathrm{R} 1=0.0376, \mathrm{wR} 2=0.0933$ & \\
\hline $\mathrm{R}$ indices (all data) & $\mathrm{R} 1=0.0438, \mathrm{wR} 2=0.0988$ & \\
\hline Absolute structure parameter & $0.24(12)$ & \\
\hline Extinction coefficient & $\mathrm{n} / \mathrm{a}$ & \\
\hline Largest diff. peak and hole & 0.143 and -0.156 e..$\AA^{-3}$ & \\
\hline
\end{tabular}


Table S2 X-ray crastal data for compound 5

\begin{tabular}{|c|c|c|}
\hline Identification code & mjr18012_0m & \\
\hline Empirical formula & $\mathrm{C}_{20} \mathrm{H}_{30} \mathrm{O}_{4}$ & \\
\hline Formula weight & 334.44 & \\
\hline Temperature & $296 \mathrm{~K}$ & \\
\hline Wavelength & $1.34139 \AA$ & \\
\hline Crystal system & Orthorhombic & \\
\hline Space group & P 212121 & \\
\hline \multirow[t]{3}{*}{ Unit cell dimensions } & $\mathrm{a}=7.57000(10) \AA$ & $\alpha=90^{\circ}$. \\
\hline & $\mathrm{b}=10.8882(2) \AA$ & $\beta=90^{\circ}$. \\
\hline & $c=45.5723(10) \AA$ & $\gamma=90^{\circ}$. \\
\hline Volume & $3756.24(12) \AA^{3}$ & \\
\hline $\mathrm{Z}$ & 8 & \\
\hline Density (calculated) & $1.183 \mathrm{Mg} / \mathrm{m}^{3}$ & \\
\hline Absorption coefficient & $0.415 \mathrm{~mm}^{-1}$ & \\
\hline $\mathrm{F}(000)$ & 1456 & \\
\hline Crystal size & $0.05 \times 0.03 \times 0.01 \mathrm{~mm}^{3}$ & \\
\hline Theta range for data collection & 3.375 to $54.939^{\circ}$. & \\
\hline \multirow[t]{2}{*}{ Index ranges } & $-9<=\mathrm{h}<=7,-13<=\mathrm{k}<=13$, & \\
\hline & $-55<=1<=54$ & \\
\hline Reflections collected & 32530 & \\
\hline Independent reflections & $7131[\mathrm{R}(\mathrm{int})=0.0661]$ & \\
\hline Completeness to theta $=53.594^{\circ}$ & $99.9 \%$ & \\
\hline Absorption correction & Semi-empirical from equivalents & \\
\hline Max. and min. transmission & 0.7508 and 0.5992 & \\
\hline Refinement method & Full-matrix least-squares on $\mathrm{F}^{2}$ & \\
\hline Data / restraints / parameters & $7131 / 0 / 445$ & \\
\hline Goodness-of-fit on $\mathrm{F}^{2}$ & 1.001 & \\
\hline Final $\mathrm{R}$ indices $[\mathrm{I}>2 \operatorname{sigma}(\mathrm{I})]$ & $\mathrm{R} 1=0.0575, \mathrm{wR} 2=0.1318$ & \\
\hline $\mathrm{R}$ indices (all data) & $\mathrm{R} 1=0.1108, \mathrm{wR} 2=0.1607$ & \\
\hline Absolute structure parameter & $-0.05(15)$ & \\
\hline Extinction coefficient & $\mathrm{n} / \mathrm{a}$ & \\
\hline Largest diff. peak and hole & 0.199 and -0.189 e. $\AA^{-3}$ & \\
\hline
\end{tabular}


Table S3 X-ray crastal data for compound $\mathbf{1 1}$

\begin{tabular}{|c|c|c|}
\hline Identification code & 22019692_0m & \\
\hline Empirical formula & $\mathrm{C}_{19} \mathrm{H}_{14} \mathrm{O}_{7}$ & \\
\hline Formula weight & 354.30 & \\
\hline Temperature & $277.0 \mathrm{~K}$ & \\
\hline Crystal system & Orthorhombic & \\
\hline Space group & P 212121 & \\
\hline \multirow[t]{3}{*}{ Unit cell dimensions } & $a=8.4122(5) \AA$ & $\alpha=90^{\circ}$. \\
\hline & $\mathrm{b}=20.1750(11) \AA$ & $\beta=90^{\circ}$. \\
\hline & $c=26.6799(16) \AA$ & $\gamma=90^{\circ}$ \\
\hline Volume & $4528.0(5) \AA^{3}$ & \\
\hline $\mathrm{Z}$ & 12 & \\
\hline Density (calculated) & $1.559 \mathrm{Mg} / \mathrm{m}^{3}$ & \\
\hline Absorption coefficient & $1.019 \mathrm{~mm}^{-1}$ & \\
\hline $\mathrm{F}(000)$ & 2208.0 & \\
\hline Crystal size & $0.15 \times 0.06 \times 0.04 \mathrm{~mm}^{3}$ & \\
\hline Radiation & $\operatorname{CuK} \alpha(\lambda=1.54178)$ & \\
\hline Theta range for data collection & 5.492 to $149.056^{\circ}$. & \\
\hline \multirow[t]{2}{*}{ Index ranges } & $-10<=\mathrm{h}<=10,-24<=\mathrm{k}<=25$ & \\
\hline & $-33<=1<=31$ & \\
\hline Reflections collected & 49200 & \\
\hline \multirow[t]{2}{*}{ Independent reflections } & $8932[\mathrm{R}(\mathrm{int})=0.0589$, & \\
\hline & $\mathrm{R}($ sigma $)=0.0372]$ & \\
\hline Data/restraints/parameters & $8932 / 0 / 712$ & \\
\hline Goodness-of-fit on $\mathrm{F}^{2}$ & 1.067 & \\
\hline Final $\mathrm{R}$ indices $[\mathrm{I}>2 \operatorname{sigma}(\mathrm{I})]$ & $\mathrm{R} 1=0.0498, \mathrm{wR} 2=0.1489$ & \\
\hline $\mathrm{R}$ indices (all data) & $\mathrm{R} 1=0.0600, \mathrm{wR} 2=0.1775$ & \\
\hline Largest diff. peak and hole & $0.69 /-0.54$ e. $\AA^{-3}$ & \\
\hline Flack parameter & $-0.05(5)$ & \\
\hline
\end{tabular}


Table S4 X-ray crastal data for compound $\mathbf{1 2}$

\begin{tabular}{|c|c|c|}
\hline Identification code & 22019728_0m & \\
\hline Empirical formula & $\mathrm{C}_{38} \mathrm{H}_{28} \mathrm{O}_{13}$ & \\
\hline Formula weight & 692.60 & \\
\hline Temperature & $297 \mathrm{~K}$ & \\
\hline Crystal system & Monoclinic & \\
\hline Space group & P 21 & \\
\hline \multirow[t]{3}{*}{ Unit cell dimensions } & $\mathrm{a}=11.7598(12) \AA$ & $\alpha=90^{\circ}$. \\
\hline & $\mathrm{b}=6.7923(5) \AA$ & $\beta=94.713(8)^{\circ}$. \\
\hline & $c=19.840(2) \AA$ & $\gamma=90^{\circ}$ \\
\hline Volume & $1579.4(3) \AA^{3}$ & \\
\hline $\mathrm{Z}$ & 2 & \\
\hline Density (calculated) & $1.456 \mathrm{Mg} / \mathrm{m}^{3}$ & \\
\hline Absorption coefficient & $0.935 \mathrm{~mm}^{-1}$ & \\
\hline $\mathrm{F}(000)$ & 720.0 & \\
\hline Crystal size & $0.08 \times 0.02 \times 0.01 \mathrm{~mm}^{3}$ & \\
\hline Radiation & $\operatorname{CuK} \alpha(\lambda=1.54178)$ & \\
\hline Theta range for data collection & 7.542 to $133.762^{\circ}$ & \\
\hline \multirow[t]{2}{*}{ Index ranges } & $-12<=\mathrm{h}<=14,-6<=\mathrm{k}<=8$, & \\
\hline & $-22<=1<=23$ & \\
\hline Reflections collected & 8911 & \\
\hline \multirow[t]{2}{*}{ Independent reflections } & $4607[\mathrm{R}(\mathrm{int})=0.0704$ & \\
\hline & $\mathrm{R}($ sigma $)=0.1013]$ & \\
\hline Data/restraints/parameters & $4607 / 1 / 467$ & \\
\hline Goodness-of-fit on $\mathrm{F}^{2}$ & 1.029 & \\
\hline Final R indices $[\mathrm{I}>2 \operatorname{sigma}(\mathrm{I})]$ & $\mathrm{R} 1=0.0816, \mathrm{wR} 2=0.2089$ & \\
\hline $\mathrm{R}$ indices (all data) & $\mathrm{R} 1=0.1371, \mathrm{wR} 2=0.2450$ & \\
\hline Largest diff. peak and hole & $0.27 /-0.30 \mathrm{e} . \AA^{-3}$ & \\
\hline Flack parameter & $1.2(8)$ & \\
\hline
\end{tabular}


<smiles>Cc1cc2c(o1)C(=O)c1cc3c(c(O)c1C2=O)C(=O)CCCC3(C)C</smiles>

1<smiles>CC1(F)C(=O)CC[C@@]2(C)[C@@H]1CCC1=C/C(=C\C(=O)O)CC[C@@H]12</smiles>

5<smiles>Cc1cc2c(o1)C(=O)c1cc3c(cc1C2=O)C(C)(C)[C@H](O)CC3</smiles>

2<smiles>COC(=O)C1=CC=CC2=C(CC[C@@H](C)[C]2CCC2=CC(=O)OC2)C1</smiles><smiles>Cc1cc2c(o1)C(=O)c1cc3c(cc1C2=O)C(C)(CO)CCC3</smiles>

3<smiles>CC1Oc2c(O)c3c(c(O)c2[C@@H]1O)C(=O)C[C@H]1C(C)(C)CCC[C@]31C</smiles>
4<smiles>C=C1C(=O)C[C@@]2(C)C(=CC(=O)c3c(O)c4c(c(O)c32)OC(C)C4)C(C)=C1C</smiles><smiles>CC12CCC(O1)c1c(cc(O)c3c1C(=O)c1oc(CO)cc1C3=O)C2=O</smiles>

11<smiles>CC1=C2CC(O1)c1c(cc(O)c3c1C(=O)c1oc(C)cc1C3=O)C2=O</smiles>

12<smiles>C=C[C@]1(C)C=C2CCC3[C@H](C)CCC[C@]3(C)[C@H]2CC1</smiles>

13<smiles>C=C[C@]1(C)CCC2=C(C1)C(=O)CC1[C@@](C)(C(=O)O)CCC[C@@]21C</smiles>

14<smiles>C=C/C(C)=C/C[C@H]1C(=C)CC[C@H](C(=C)C)[C@]1(C)CCC(=O)O</smiles>

15<smiles>C=C1CC[C@H]2C(C)(C)[C@@H](O)CC[C@]2(C)[C@H]1C/C=C(\C)C=O</smiles>

16

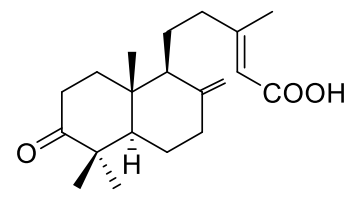

17<smiles>C[C@H]1CCC2(O)C(C(=O)O)=CCC[C@H]2[C@H]1CCC1=CCOC1=O</smiles>

18

Figure S1 All isolated compounds from Caryopteris aureoglandulosa 
<smiles>Cc1cc2c(o1)C(=O)c1cc3c(c(O)c1C2=O)C(=O)CCCC3(C)C</smiles>

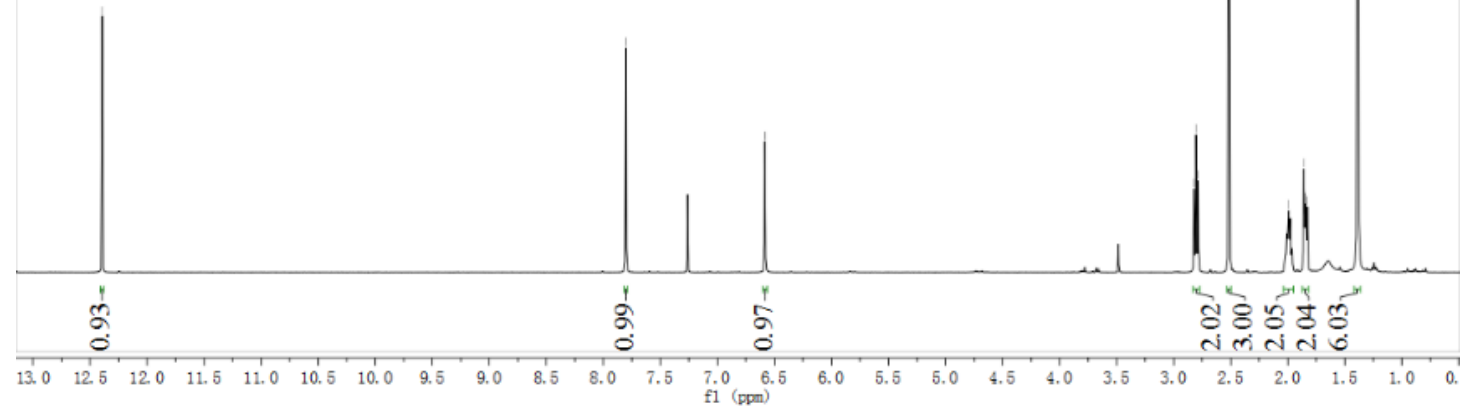

Figure S2 ${ }^{1} \mathrm{H}$ NMR spectrum $\left(400 \mathrm{MHz}, \mathrm{CDCl}_{3}\right)$ of compound 1

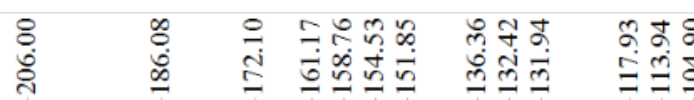

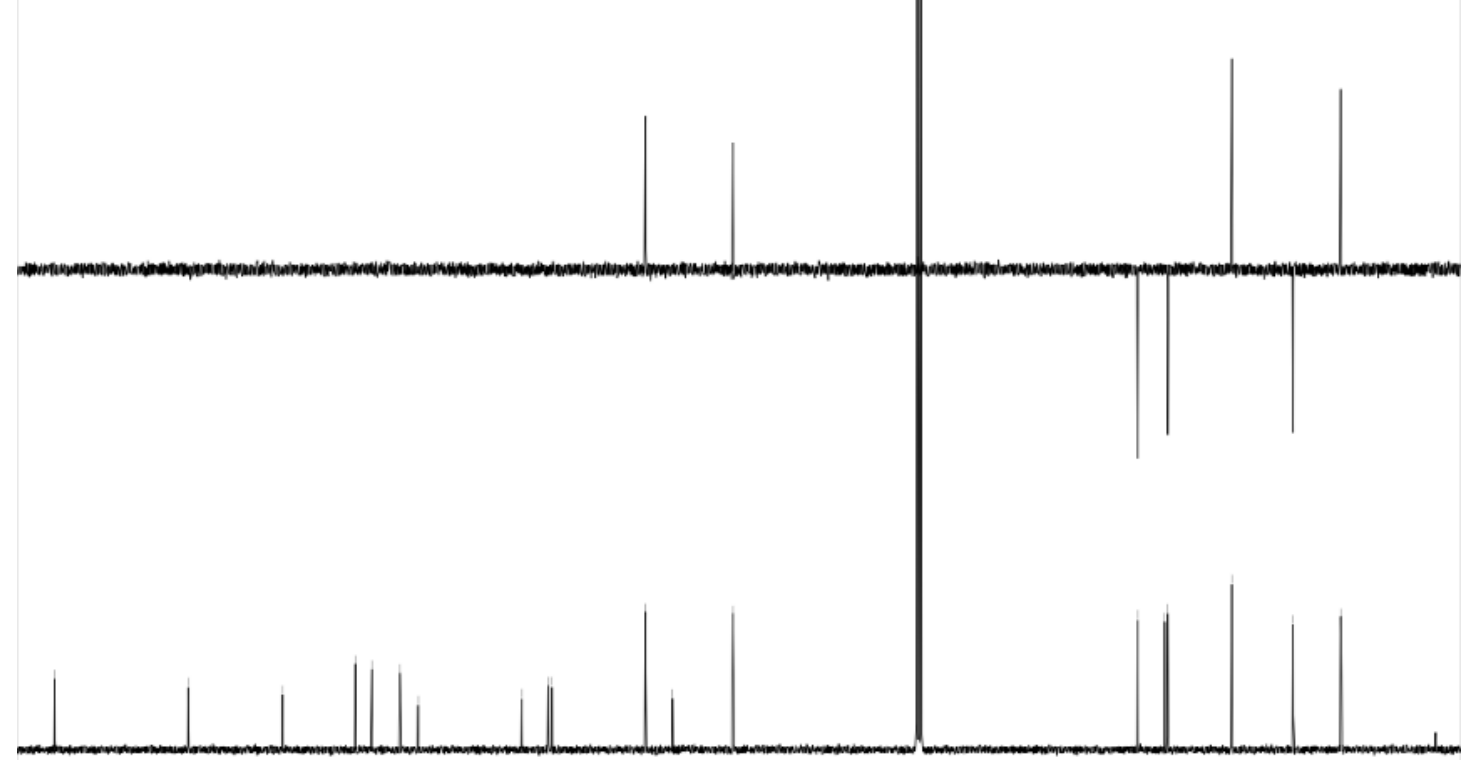

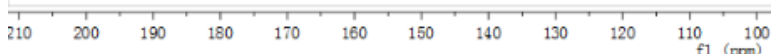

Figure $\mathbf{S 3}{ }^{13} \mathrm{C}$ NMR spectrum $\left(100 \mathrm{MHz}, \mathrm{CDCl}_{3}\right)$ of compound $\mathbf{1}$ 


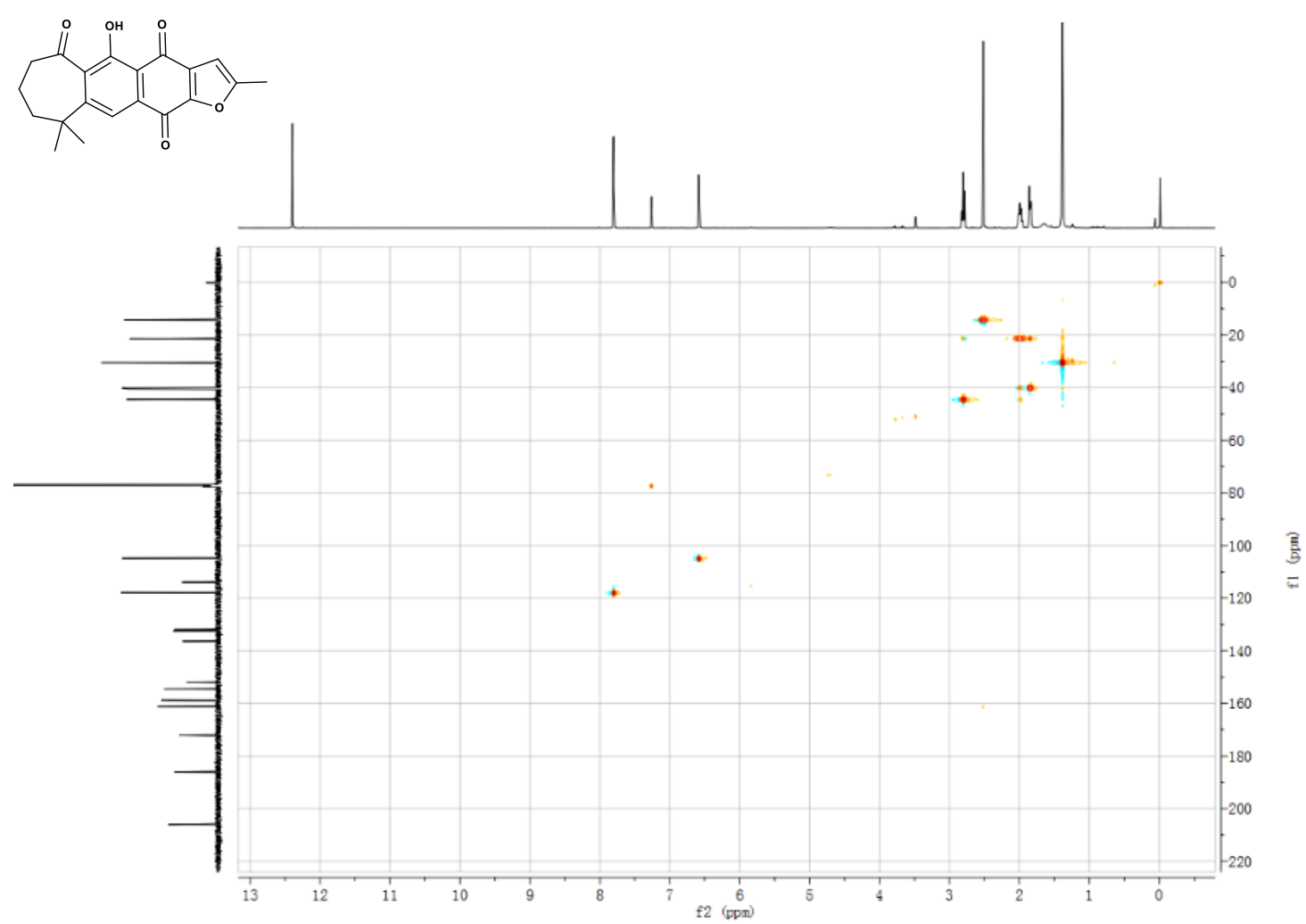

Figure S4 HSQC spectrum (400 MHz, $\mathrm{CDCl}_{3}$ ) of compound $\mathbf{1}$

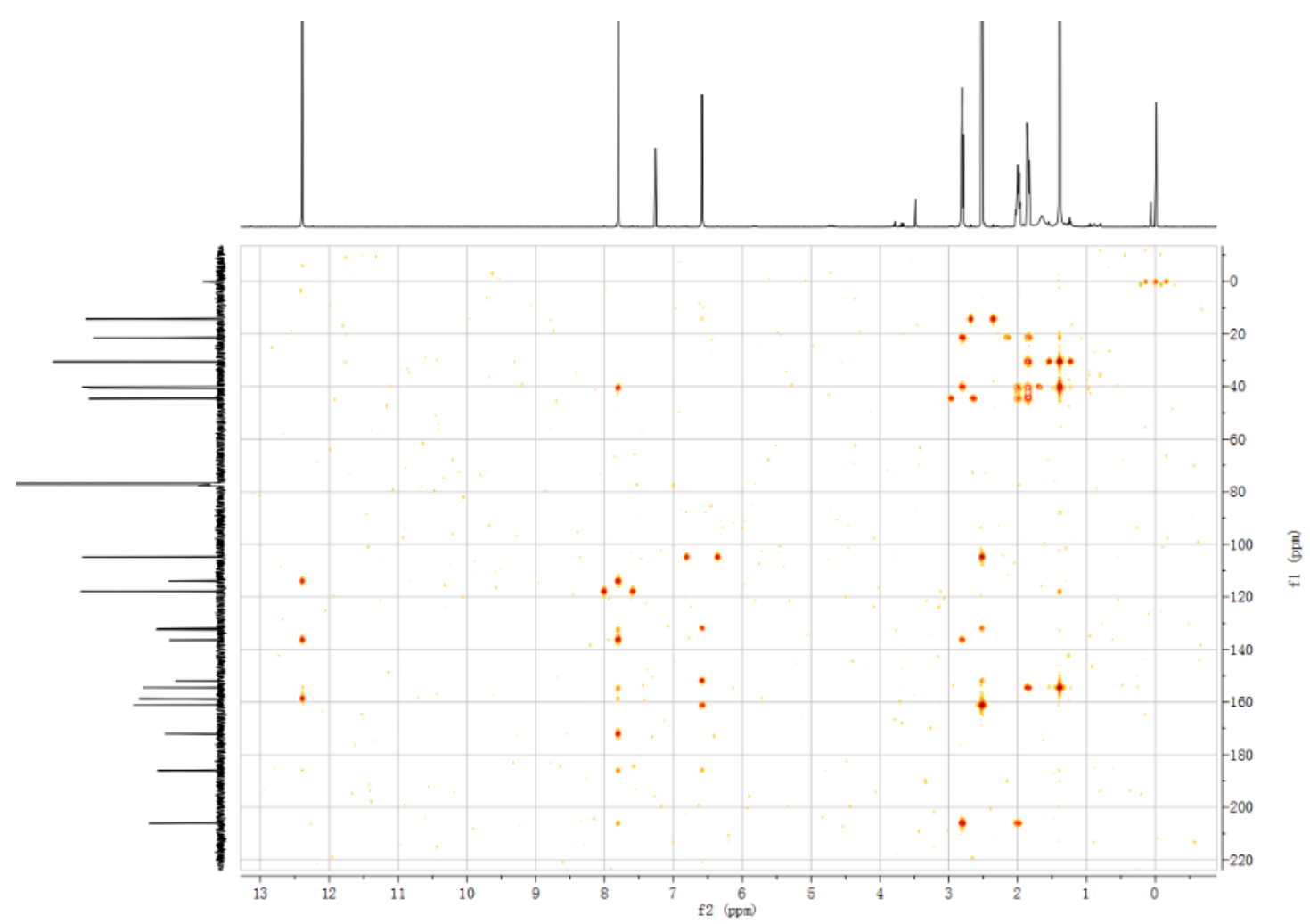

Figure S5 $\mathrm{HMBC}$ spectrum $\left(400 \mathrm{MHz}, \mathrm{CDCl}_{3}\right)$ of compound 1 


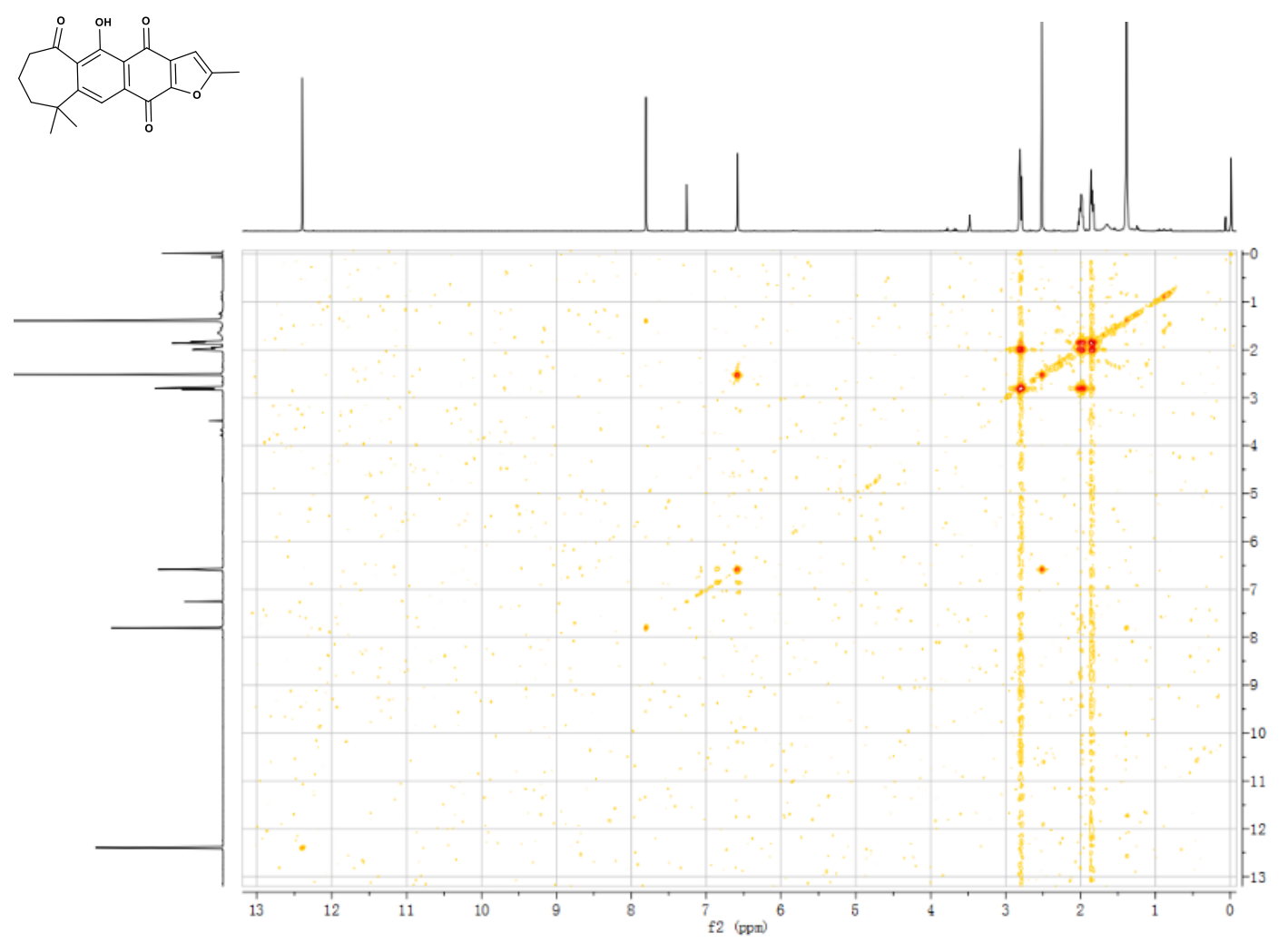

$\frac{1}{5}$

Figure S6 ${ }^{1} \mathrm{H}-{ }^{1} \mathrm{H}$ COSY spectrum $\left(400 \mathrm{MHz}, \mathrm{CDCl}_{3}\right)$ of compound 1

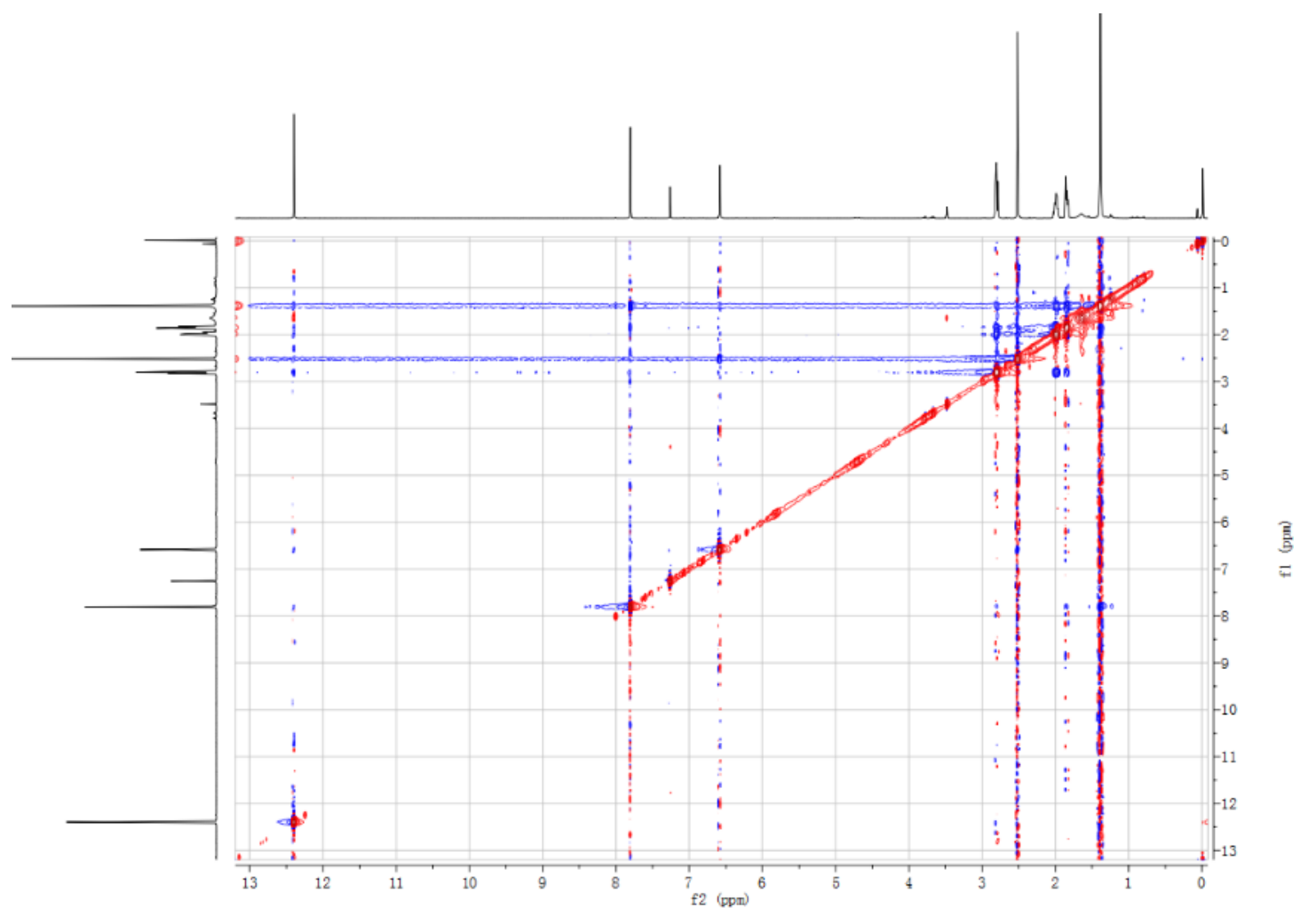

Figure S7 NOESY spectrum (400 MHz, $\mathrm{CDCl}_{3}$ ) of compound 1 


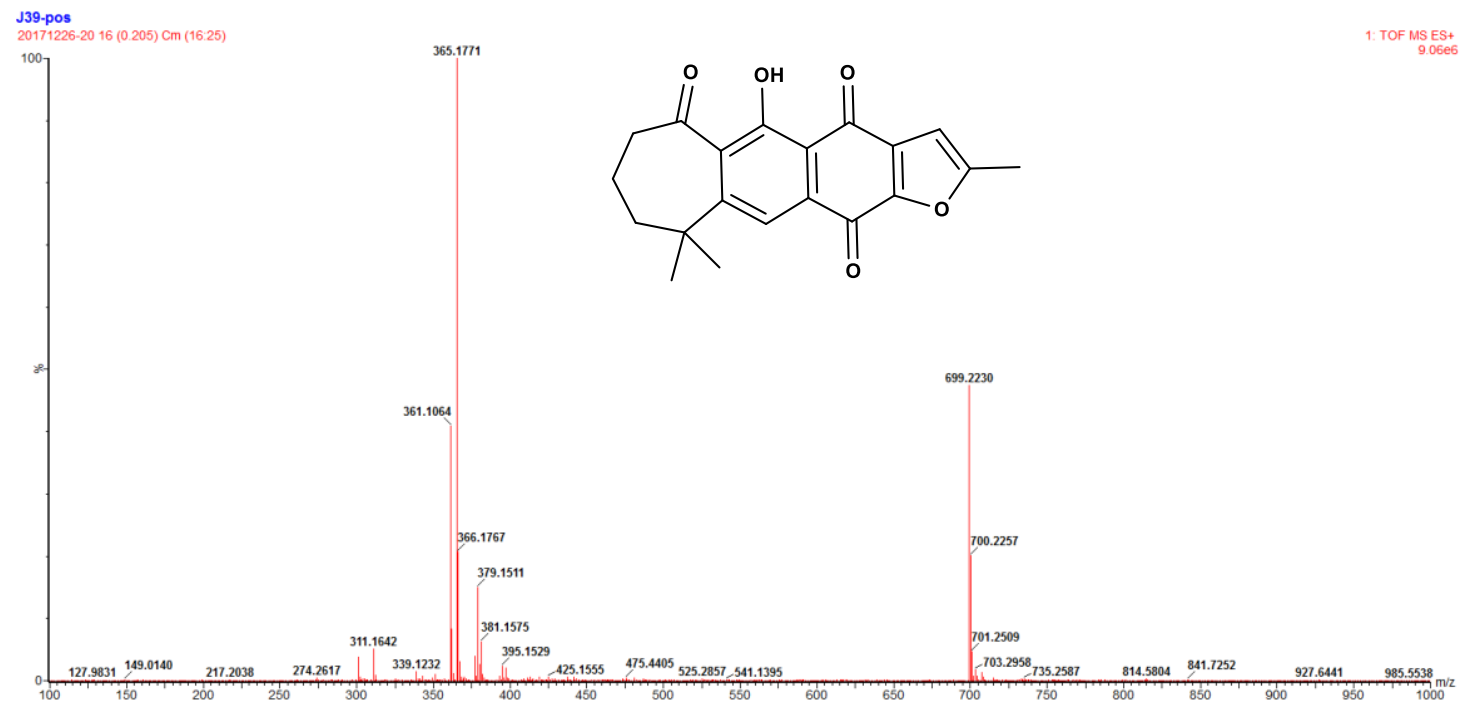

Figure S8 HR-ESI-MS spectrum of compound 1

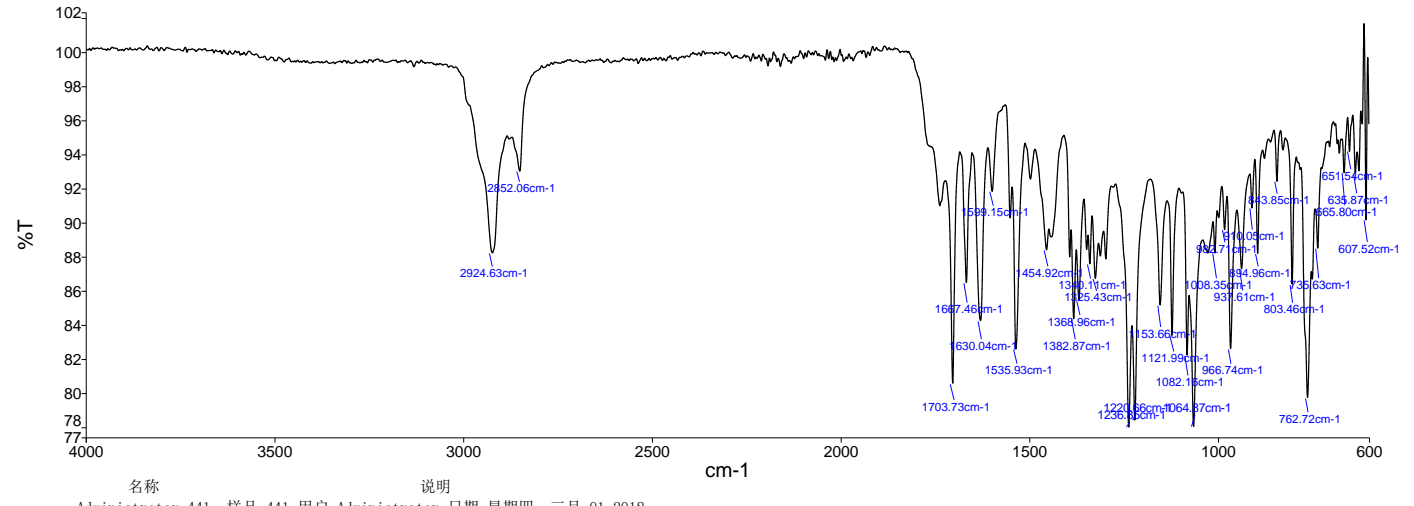

Figure S9 IR spectrum of compound 1 
<smiles>Cc1cc2c(o1)C(=O)c1cc3c(cc1C2=O)C(C)(C)[C@H](O)CC3</smiles>

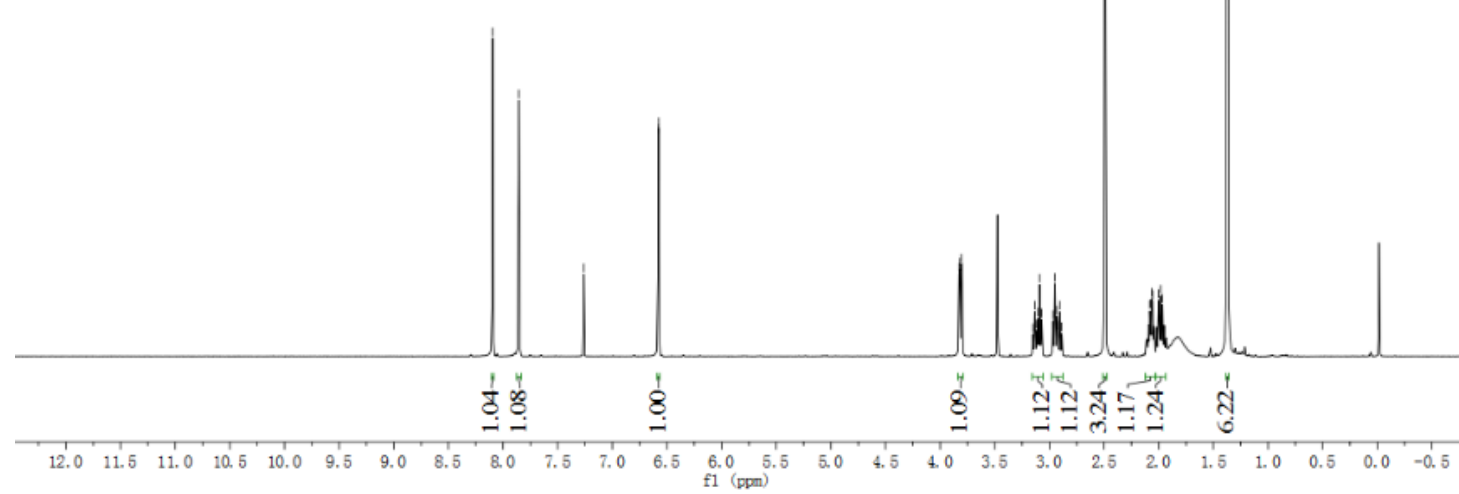

Figure $\mathbf{S 1 0}{ }^{1} \mathrm{H}$ NMR spectrum $\left(400 \mathrm{MHz}, \mathrm{CDCl}_{3}\right)$ of compound 2

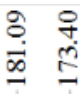

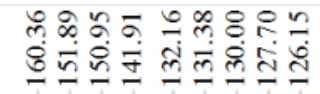
$\frac{0}{8}$
\&. 유요
लेतेंत्त
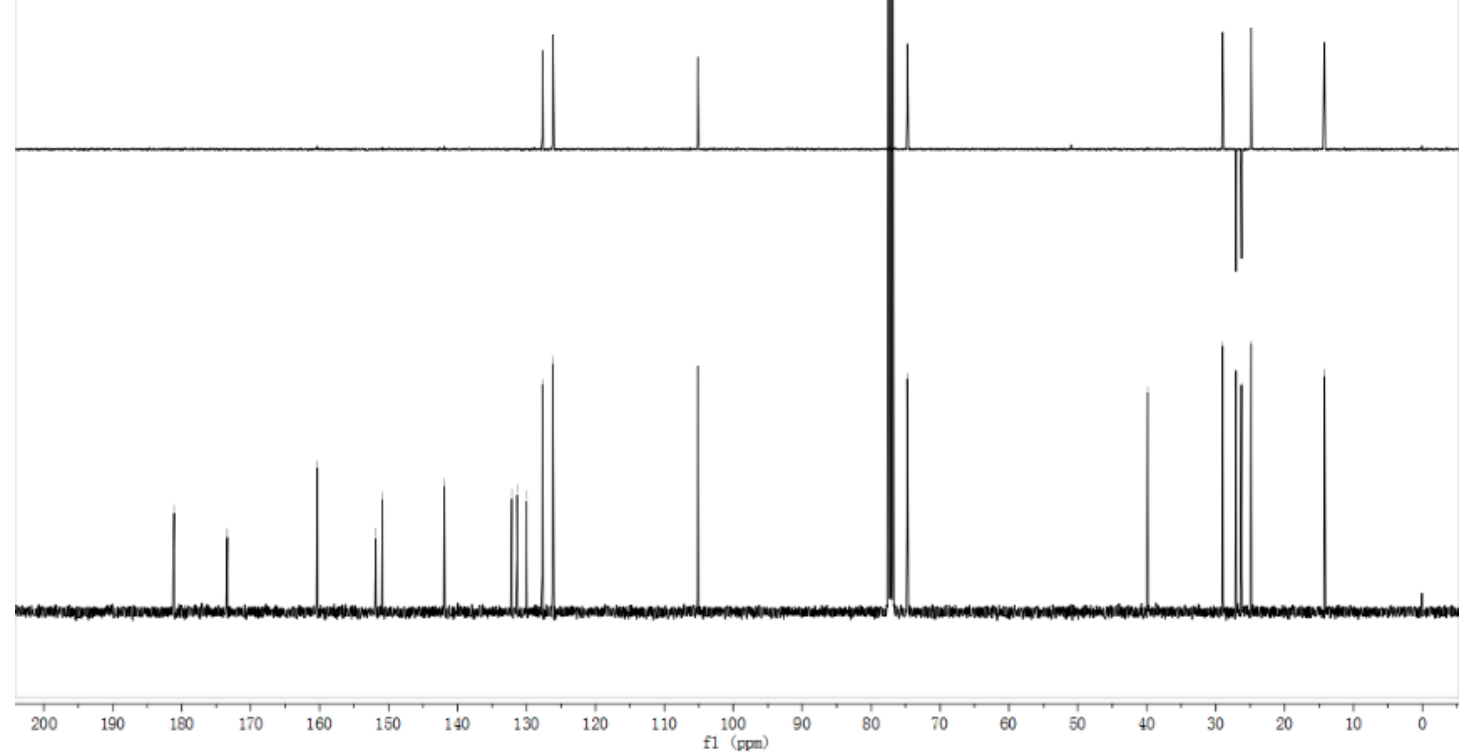

Figure $\mathbf{S 1 1}{ }^{13} \mathrm{C}$ NMR spectrum $\left(100 \mathrm{MHz}, \mathrm{CDCl}_{3}\right)$ of compound 2 
<smiles>Cc1cc2c(o1)C(=O)c1cc3c(cc1C2=O)C(C)(C)[C@H](C)CC3</smiles>

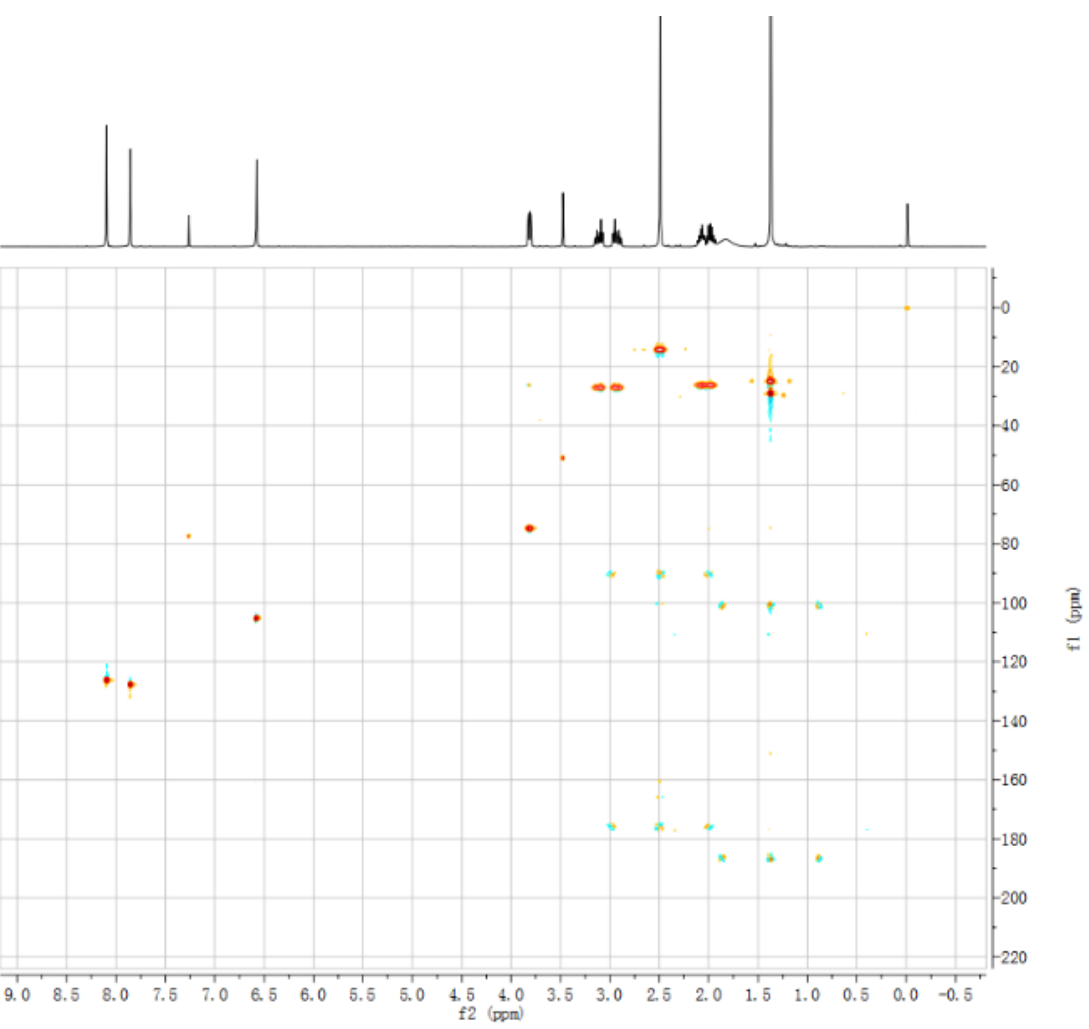

Figure S12 HSQC spectrum ( $400 \mathrm{MHz}, \mathrm{CDCl}_{3}$ ) of compound 2

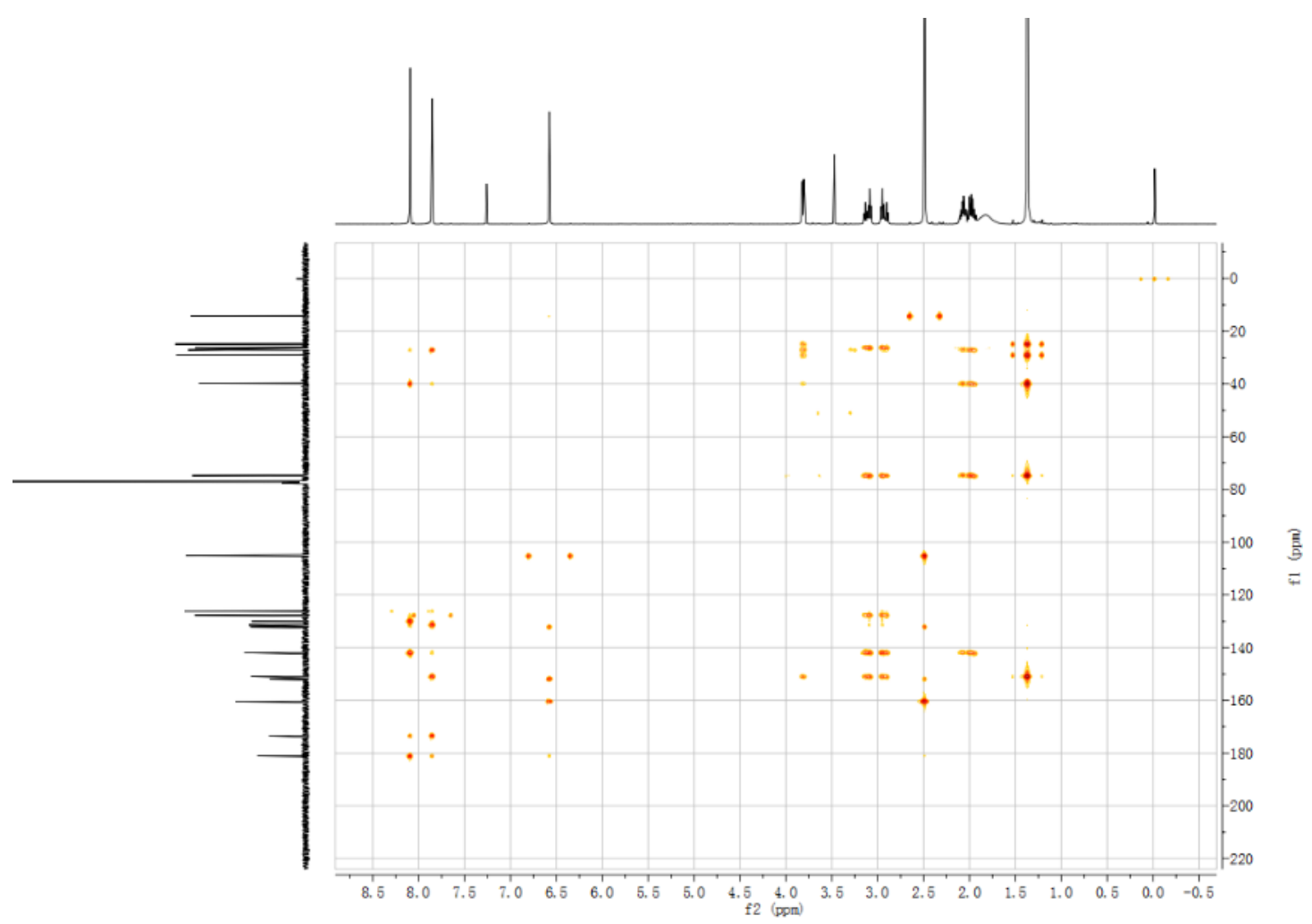

Figure S13 HMBC spectrum (400 MHz, $\left.\mathrm{CDCl}_{3}\right)$ of compound 2 


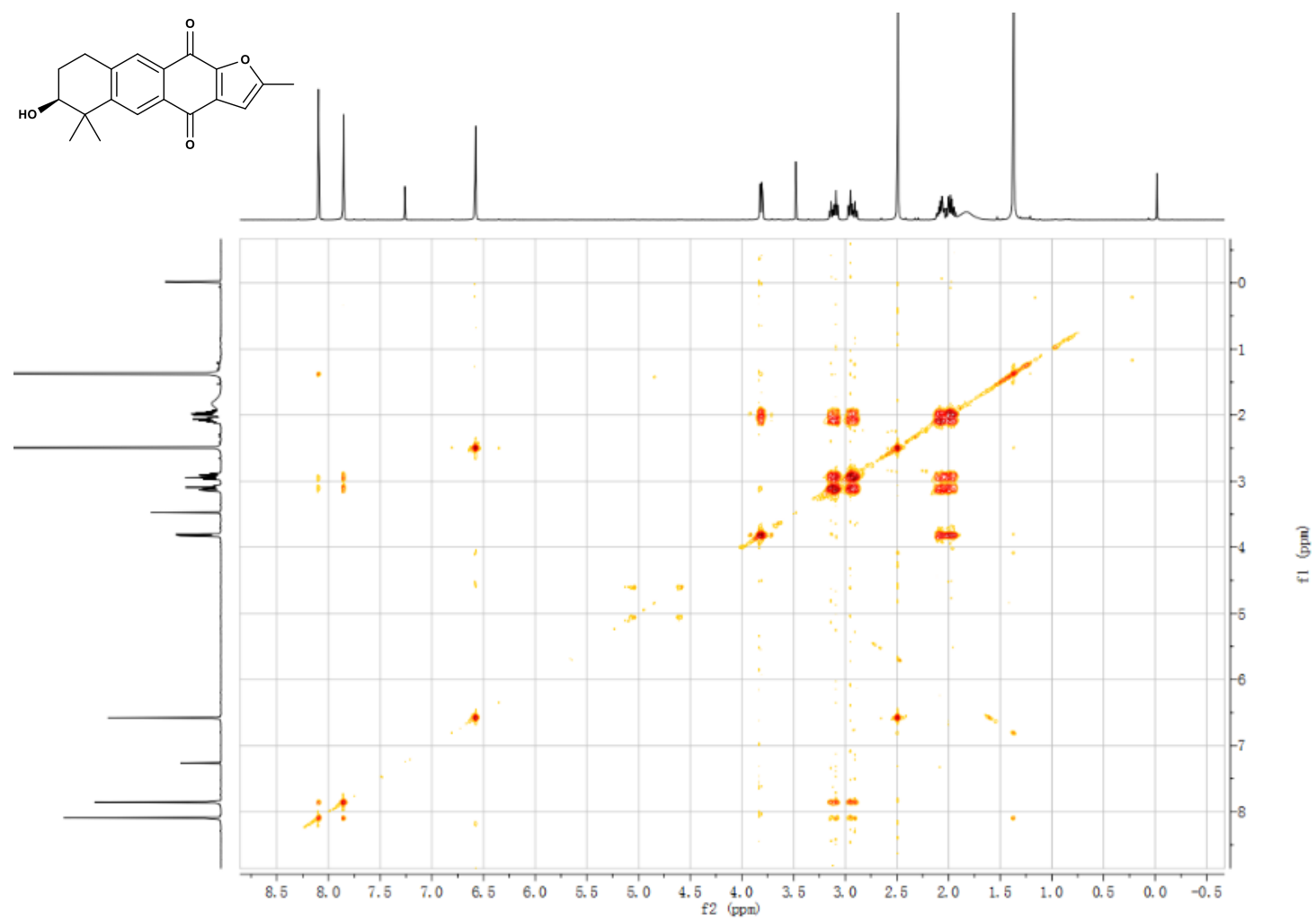

Figure $\mathbf{S 1 4}{ }^{1} \mathrm{H}-{ }^{1} \mathrm{H}$ COSY spectrum $\left(400 \mathrm{MHz}, \mathrm{CDCl}_{3}\right)$ of compound 2

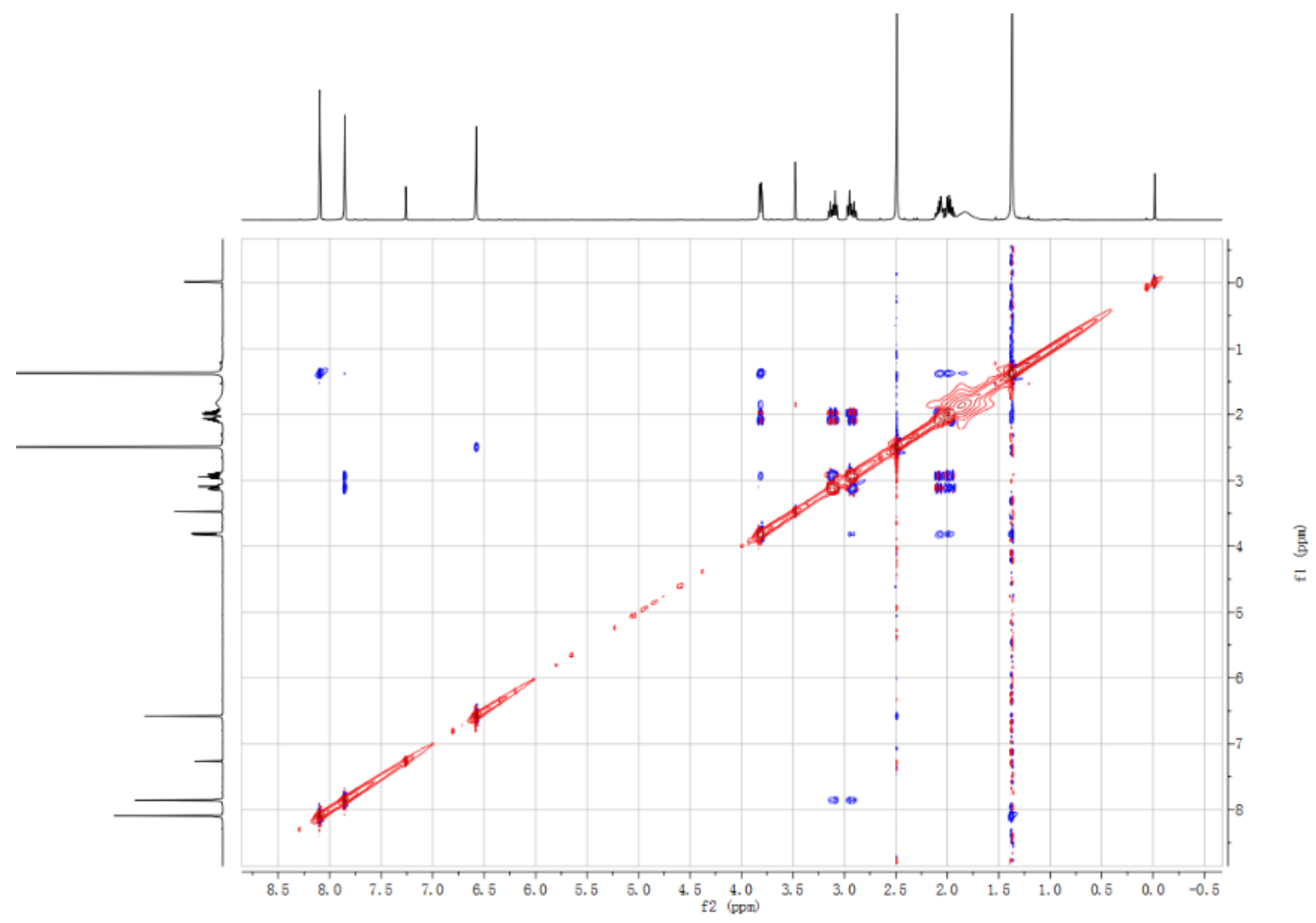

Figure S15 NOESY spectrum $\left(400 \mathrm{MHz}, \mathrm{CDCl}_{3}\right)$ of compound 2 


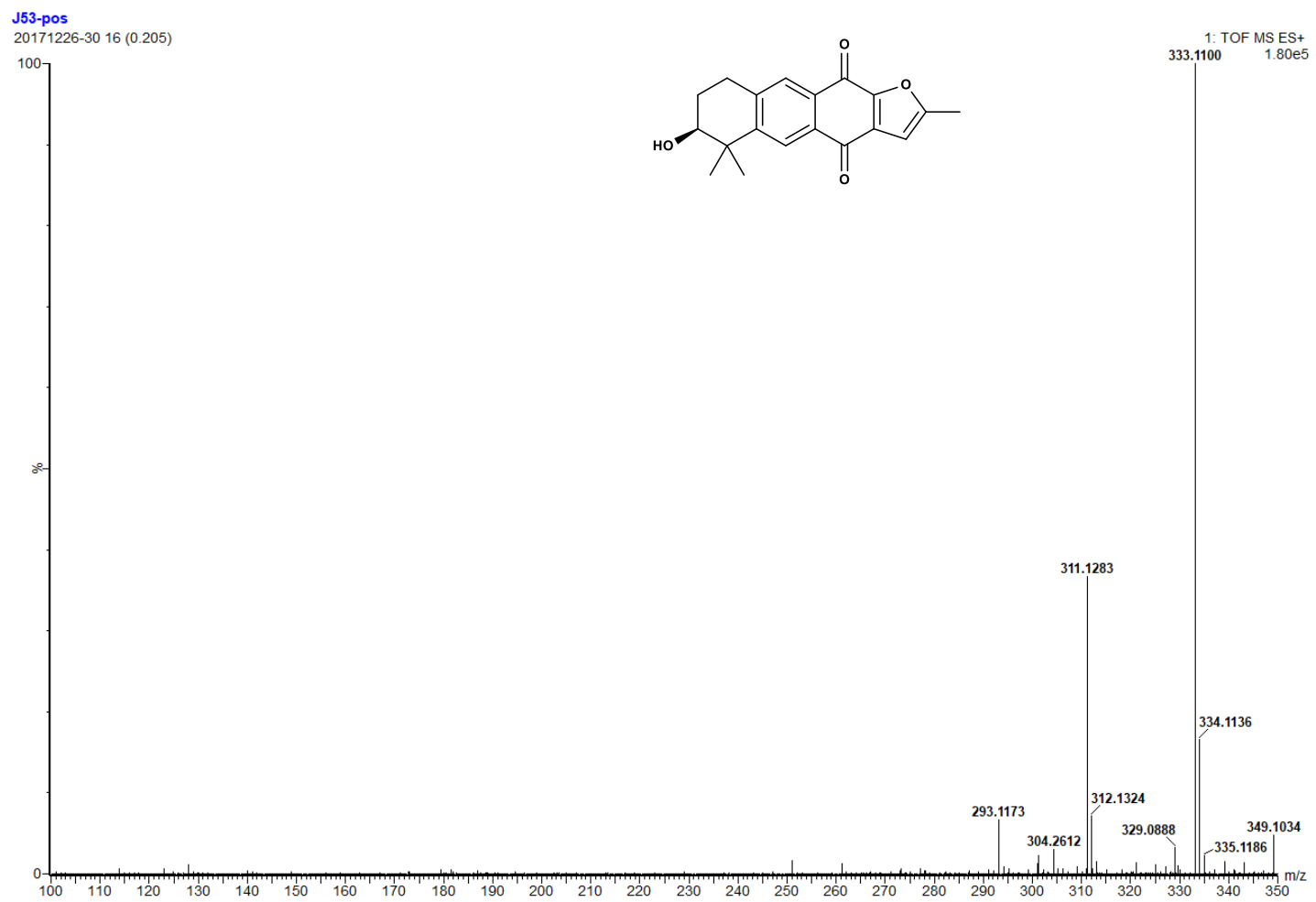

Figure S16 HR-ESI-MS spectrum of compound 2

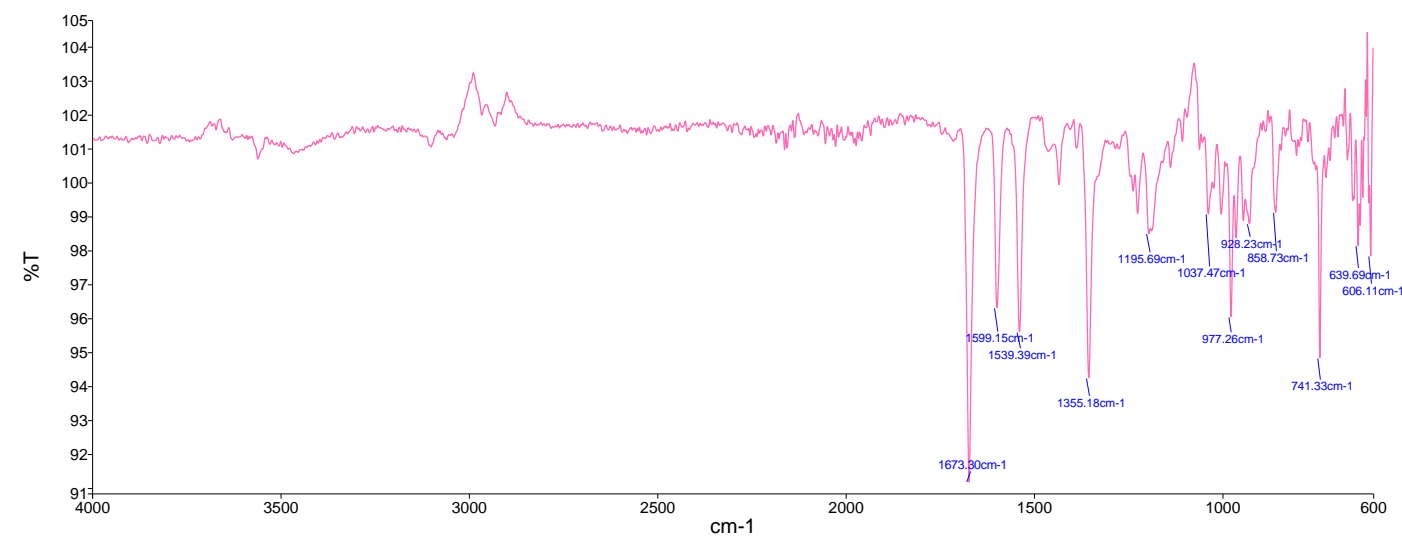

Figure S17 IR spectrum of compound 2 


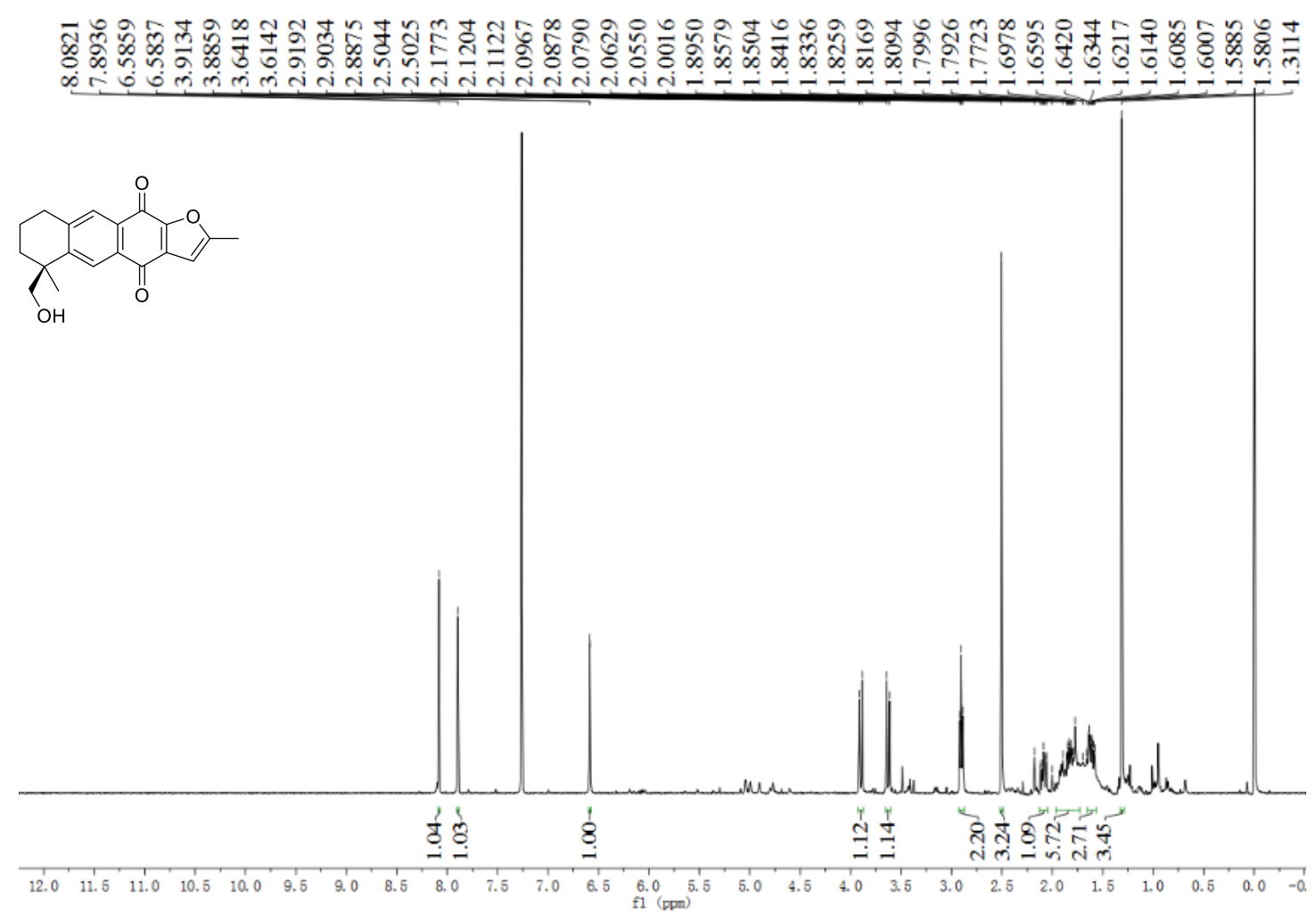

Figure $\mathbf{S 1 8}{ }^{1} \mathrm{H}$ NMR spectrum $\left(400 \mathrm{MHz}, \mathrm{CDCl}_{3}\right)$ of compound 3

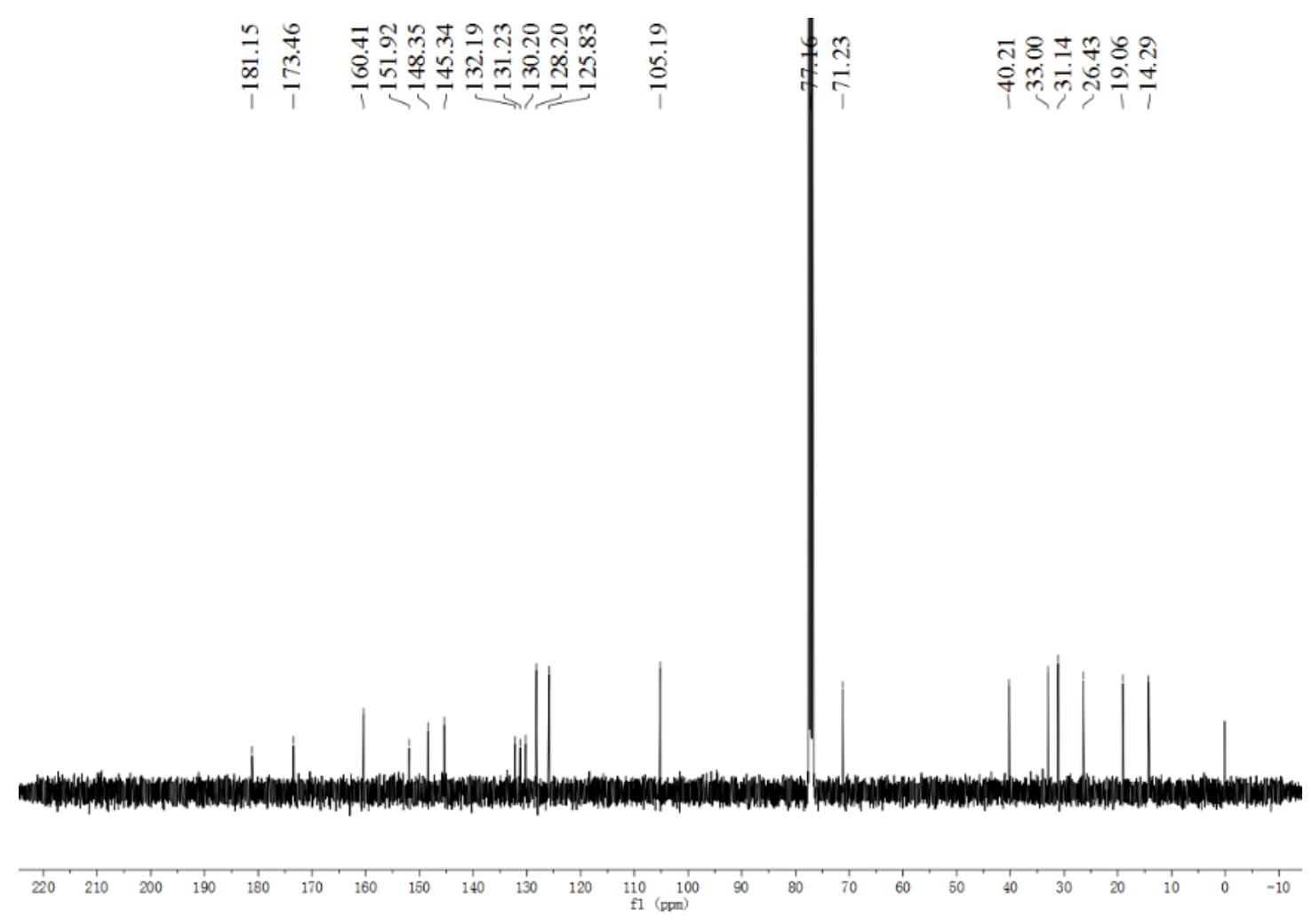

Figure $\mathbf{S 1 9}{ }^{13} \mathrm{C}$ NMR spectrum $\left(100 \mathrm{MHz}, \mathrm{CDCl}_{3}\right)$ of compound 3 


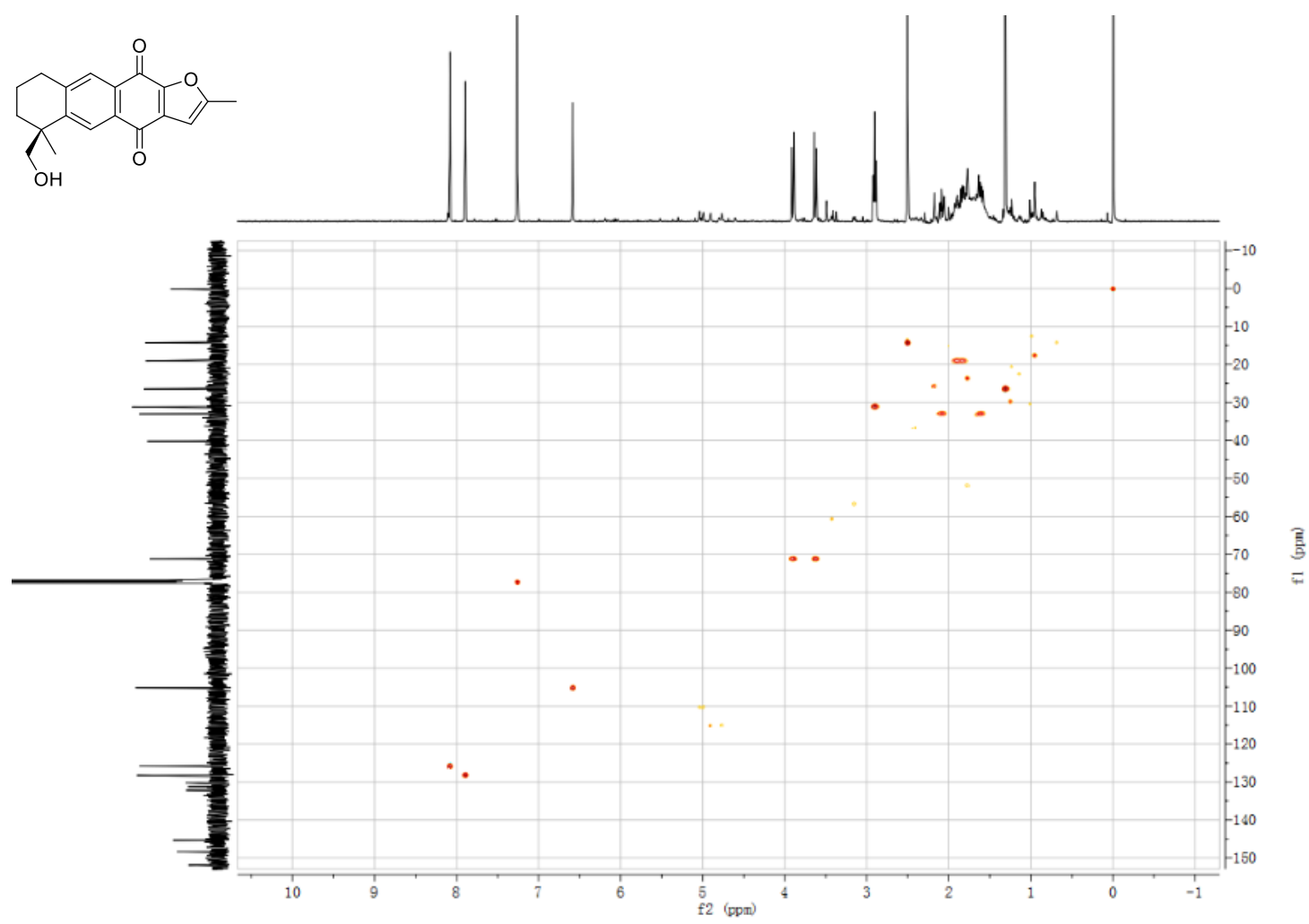

Figure S20 HSQC spectrum (400 MHz, $\mathrm{CDCl}_{3}$ ) of compound 3

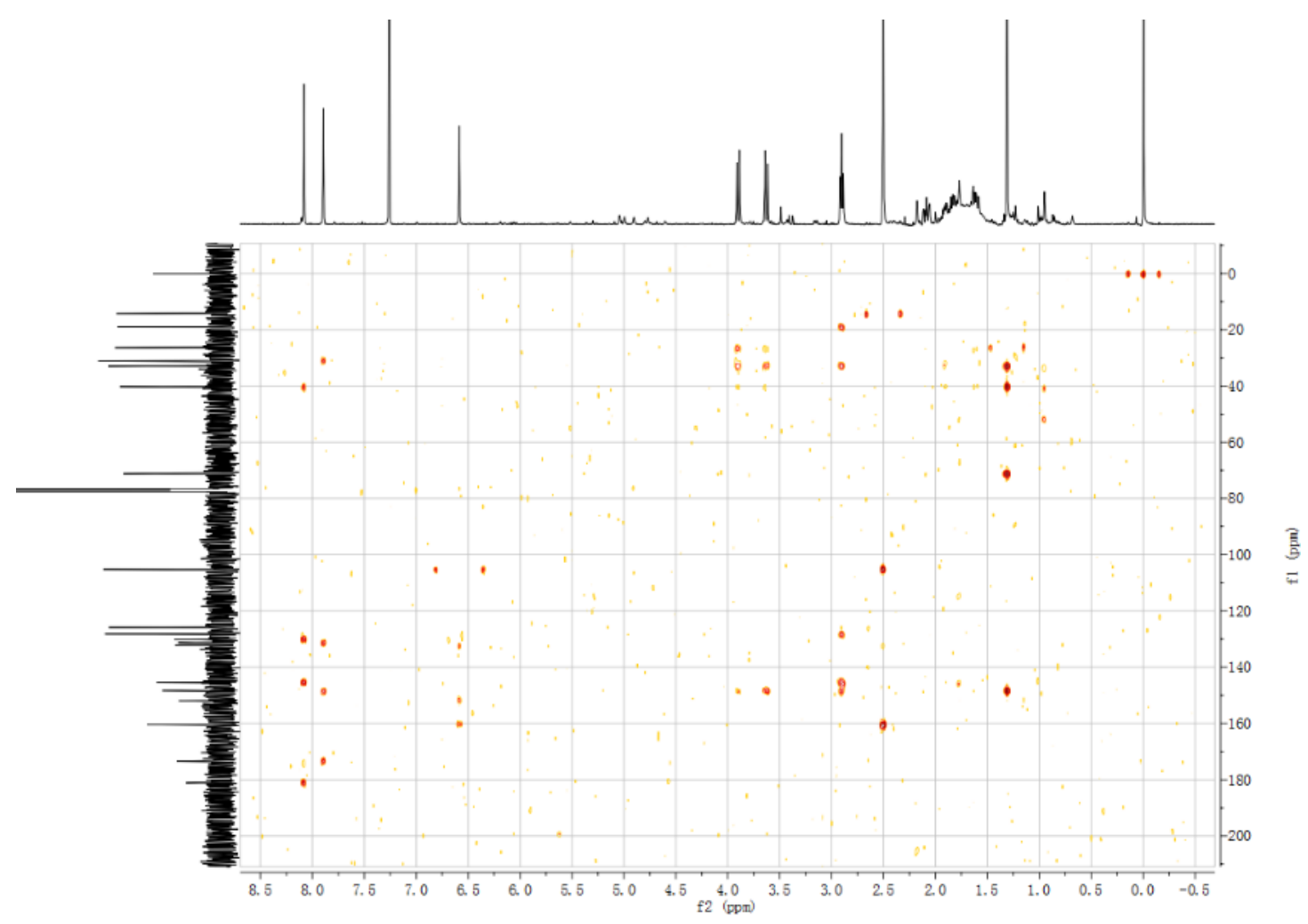

Figure S21 HMBC spectrum (400 MHz, $\left.\mathrm{CDCl}_{3}\right)$ of compound 3 


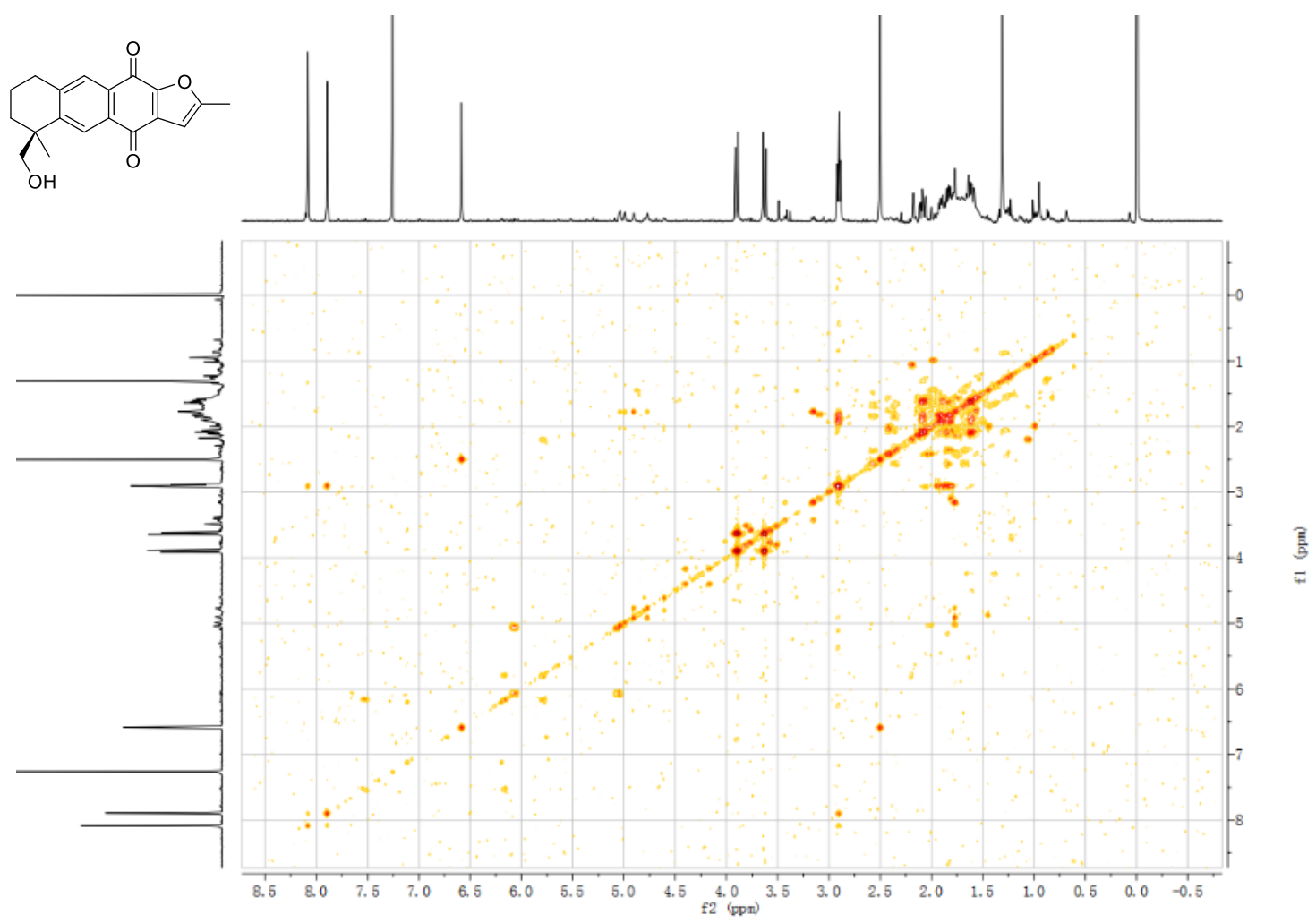

Figure $\mathbf{S 2 2}{ }^{1} \mathrm{H}-{ }^{1} \mathrm{H}$ COSY spectrum $\left(400 \mathrm{MHz}, \mathrm{CDCl}_{3}\right)$ of compound $\mathbf{3}$

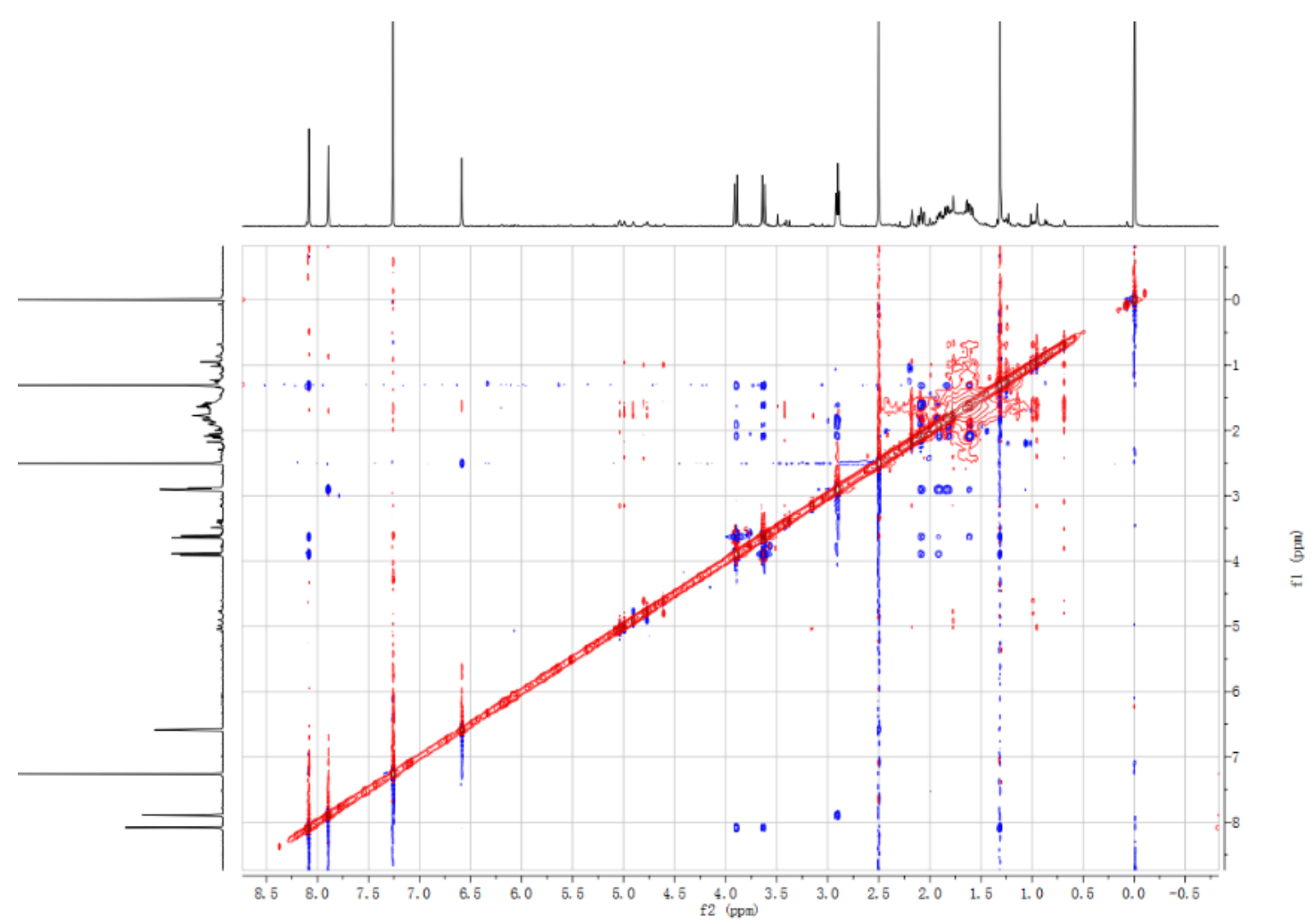

Figure S23 NOESY spectrum $\left(400 \mathrm{MHz}, \mathrm{CDCl}_{3}\right)$ of compound 3 


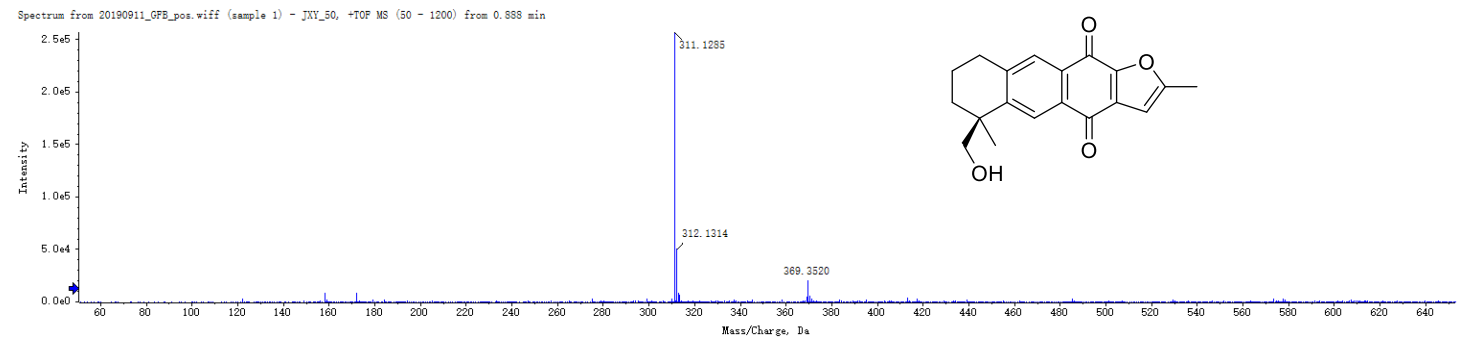

Figure S24 HR-ESI-MS spectrum of compound 3

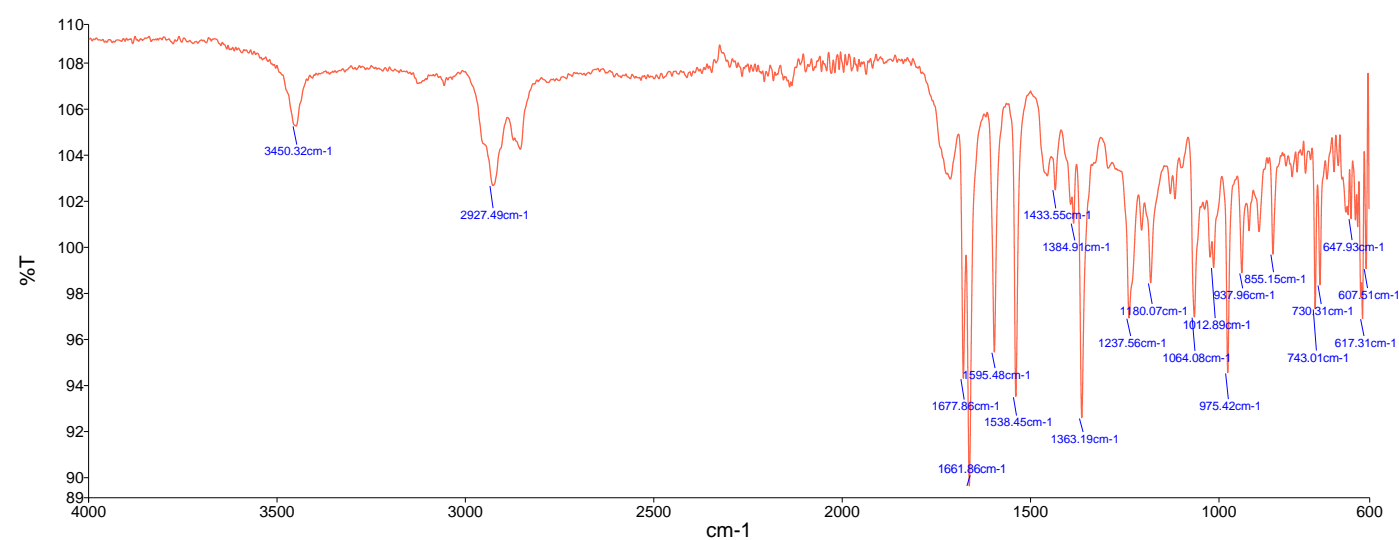

Figure S25 IR spectrum of compound 3 

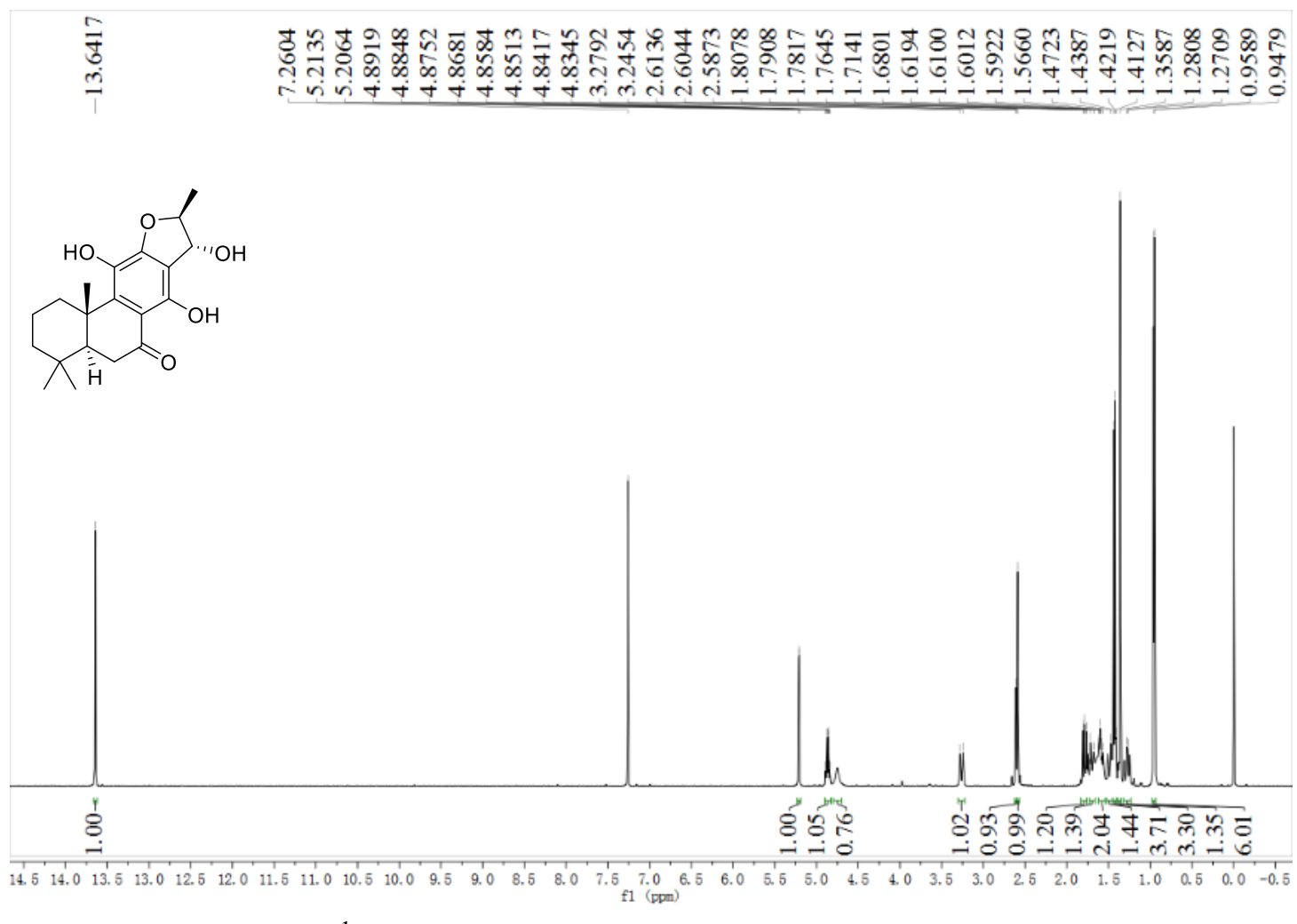

Figure $\mathbf{S 2 6}{ }^{1} \mathrm{H}$ NMR spectrum $\left(400 \mathrm{MHz}, \mathrm{CDCl}_{3}\right)$ of compound 4

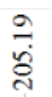

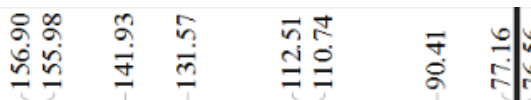

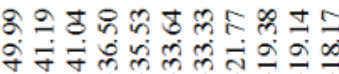

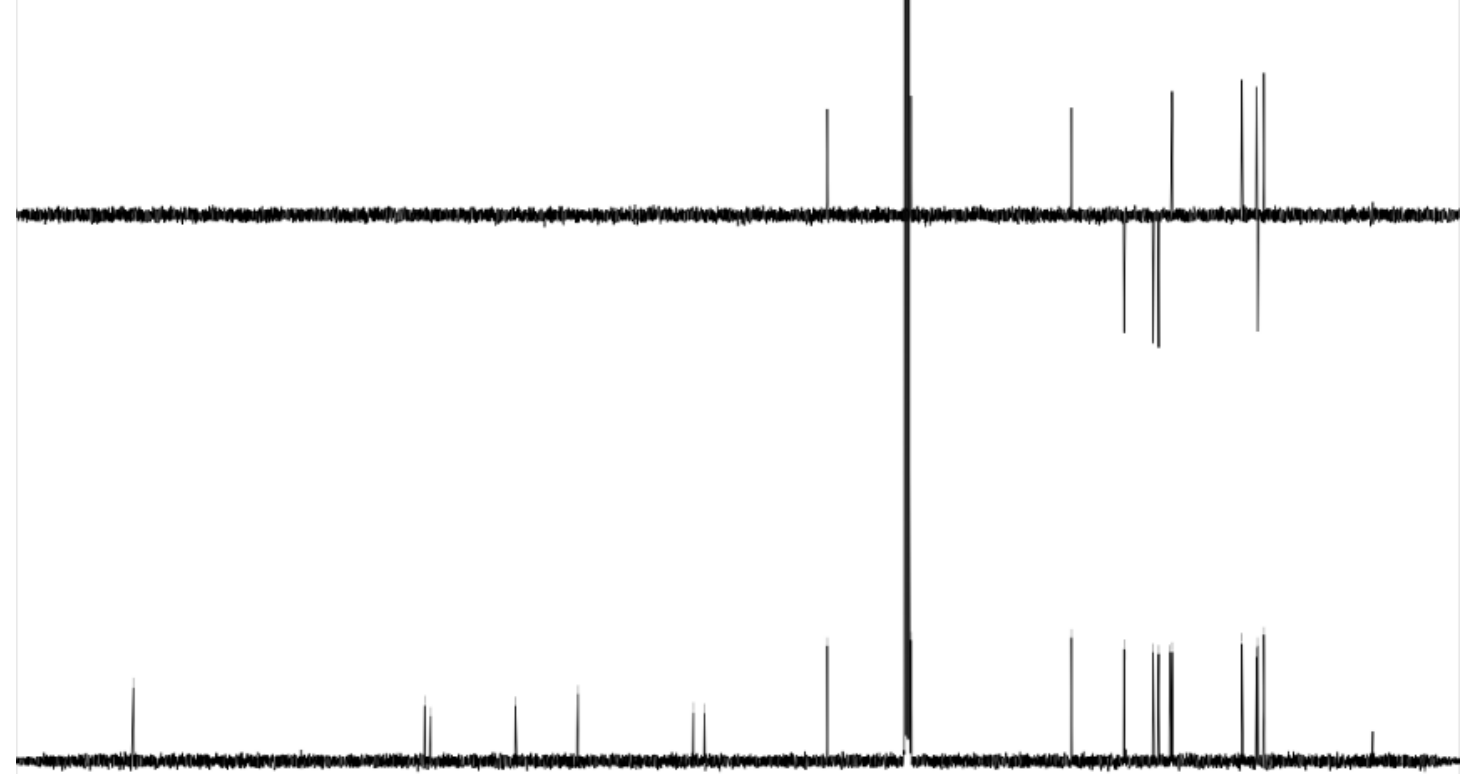

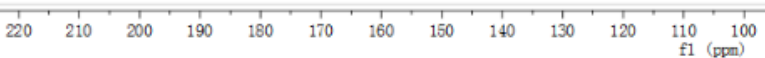

Figure S27 ${ }^{13} \mathrm{C}$ NMR spectrum $\left(100 \mathrm{MHz}, \mathrm{CDCl}_{3}\right)$ of compound 4 

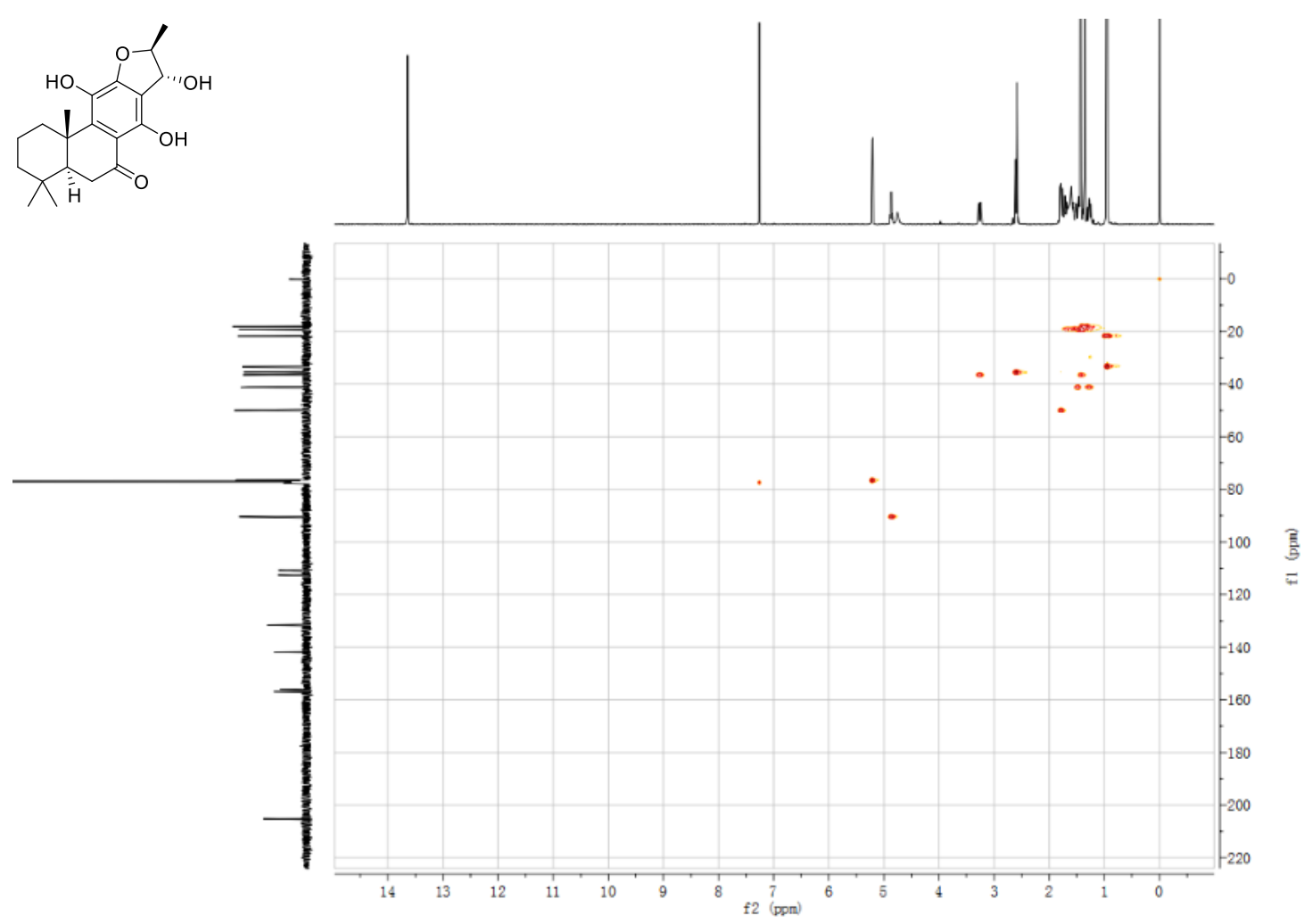

Figure S28 HSQC spectrum ( $400 \mathrm{MHz}, \mathrm{CDCl}_{3}$ ) of compound 4

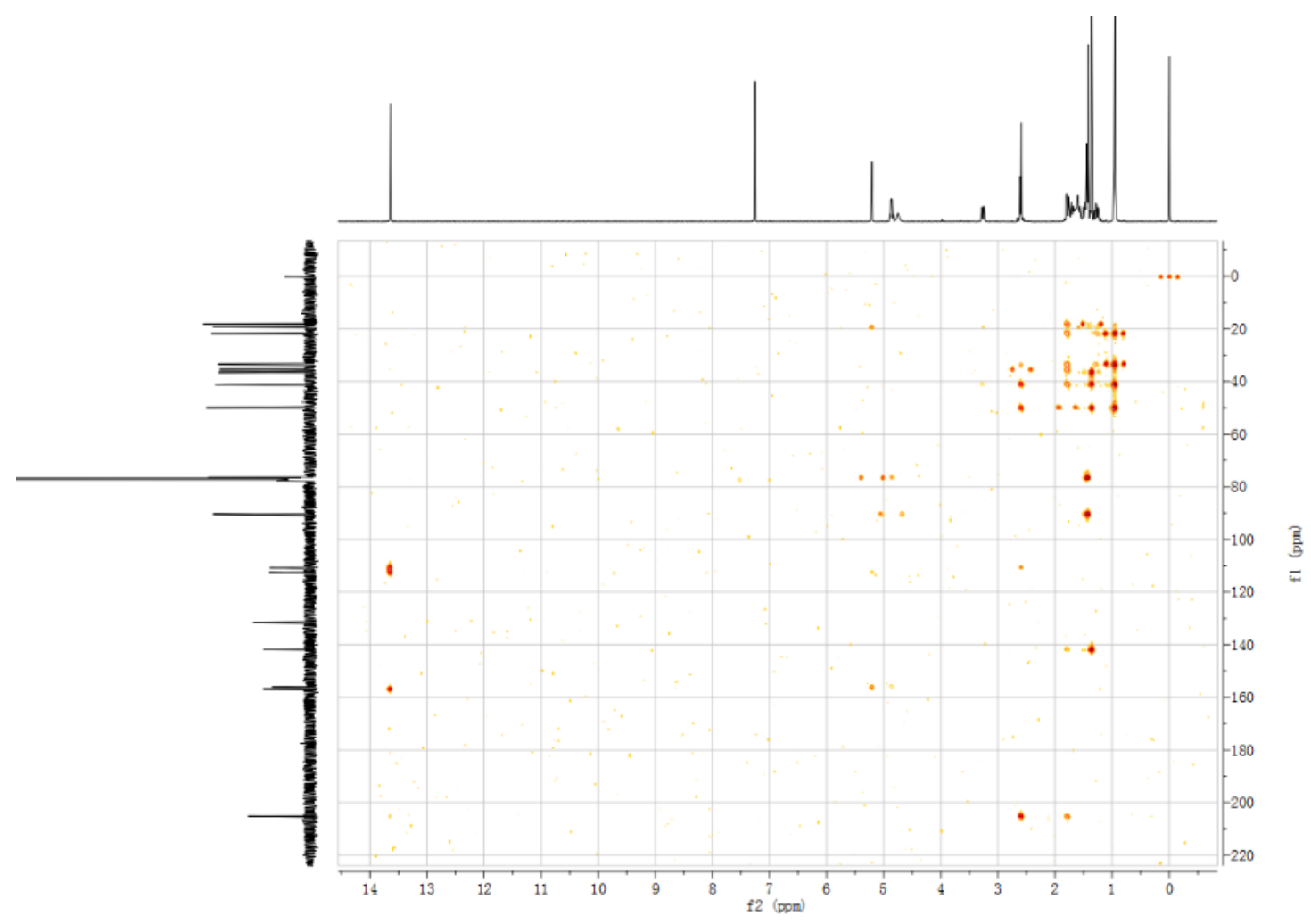

Figure S29 $\mathrm{HMBC}$ spectrum $\left(400 \mathrm{MHz}, \mathrm{CDCl}_{3}\right)$ of compound 4 

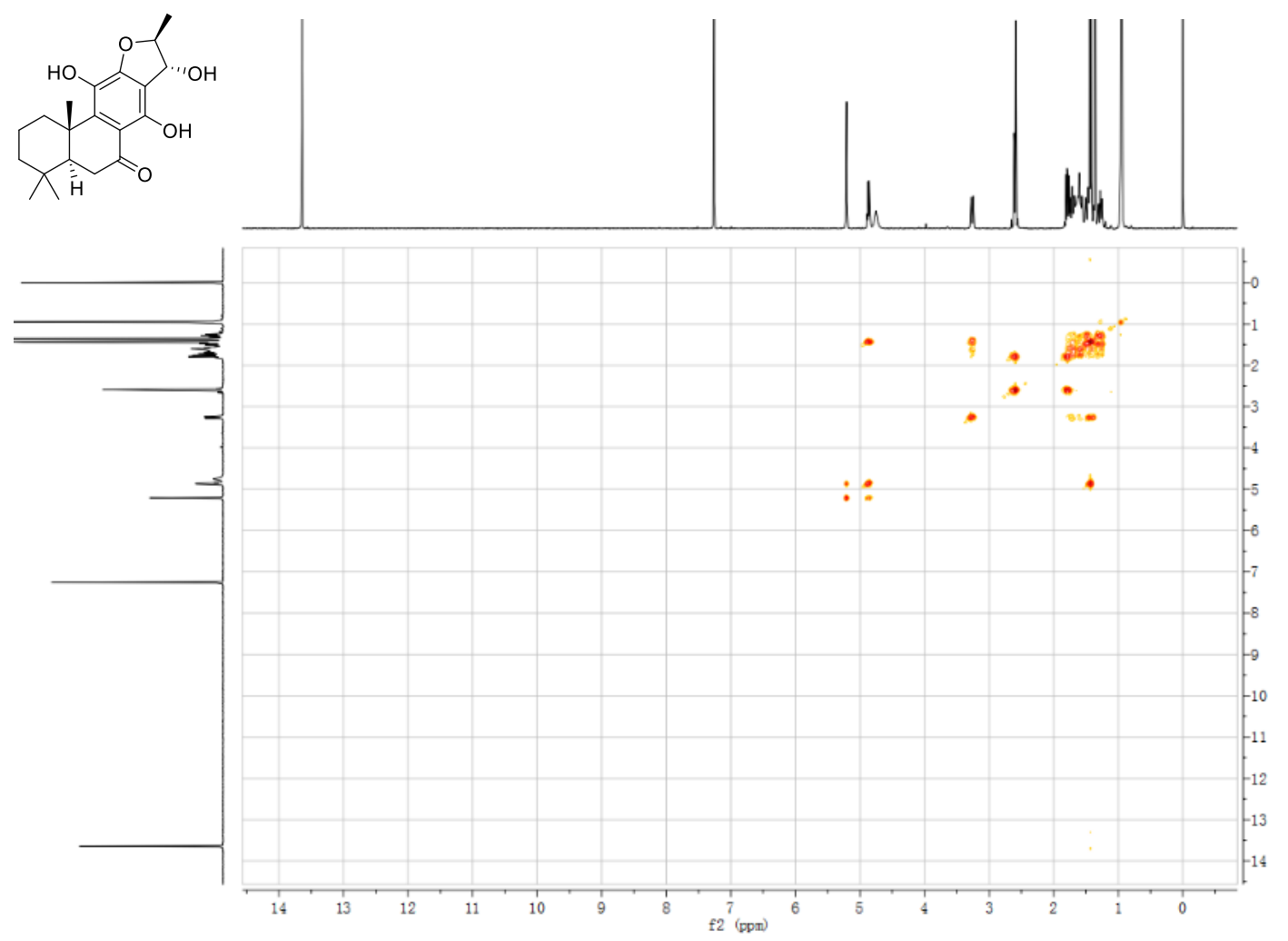

Figure S30 ${ }^{1} \mathrm{H}-{ }^{1} \mathrm{H}$ COSY spectrum $\left(400 \mathrm{MHz}, \mathrm{CDCl}_{3}\right)$ of compound 4

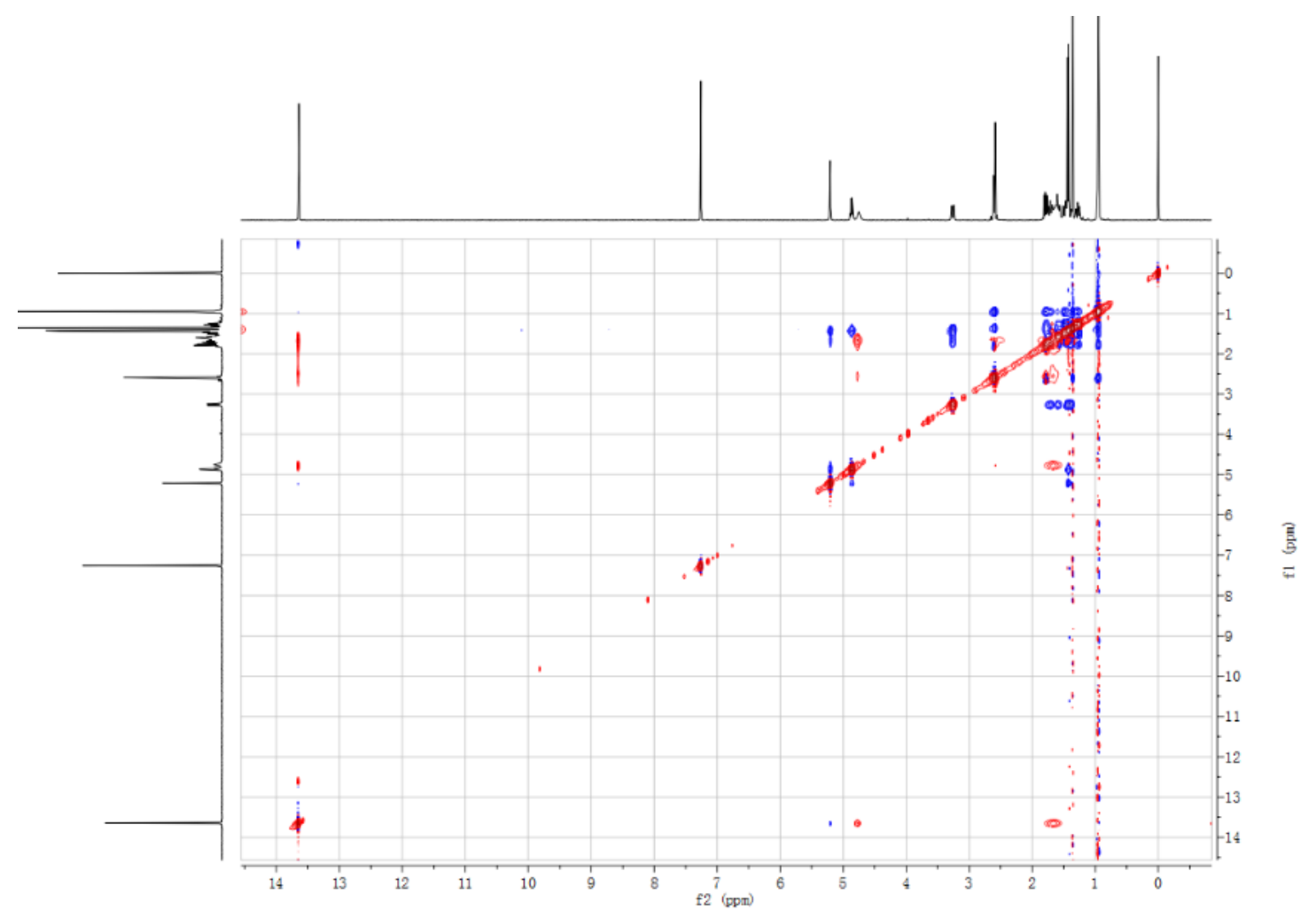

Figure S31 NOESY spectrum (400 MHz, $\mathrm{CDCl}_{3}$ ) of compound 4 


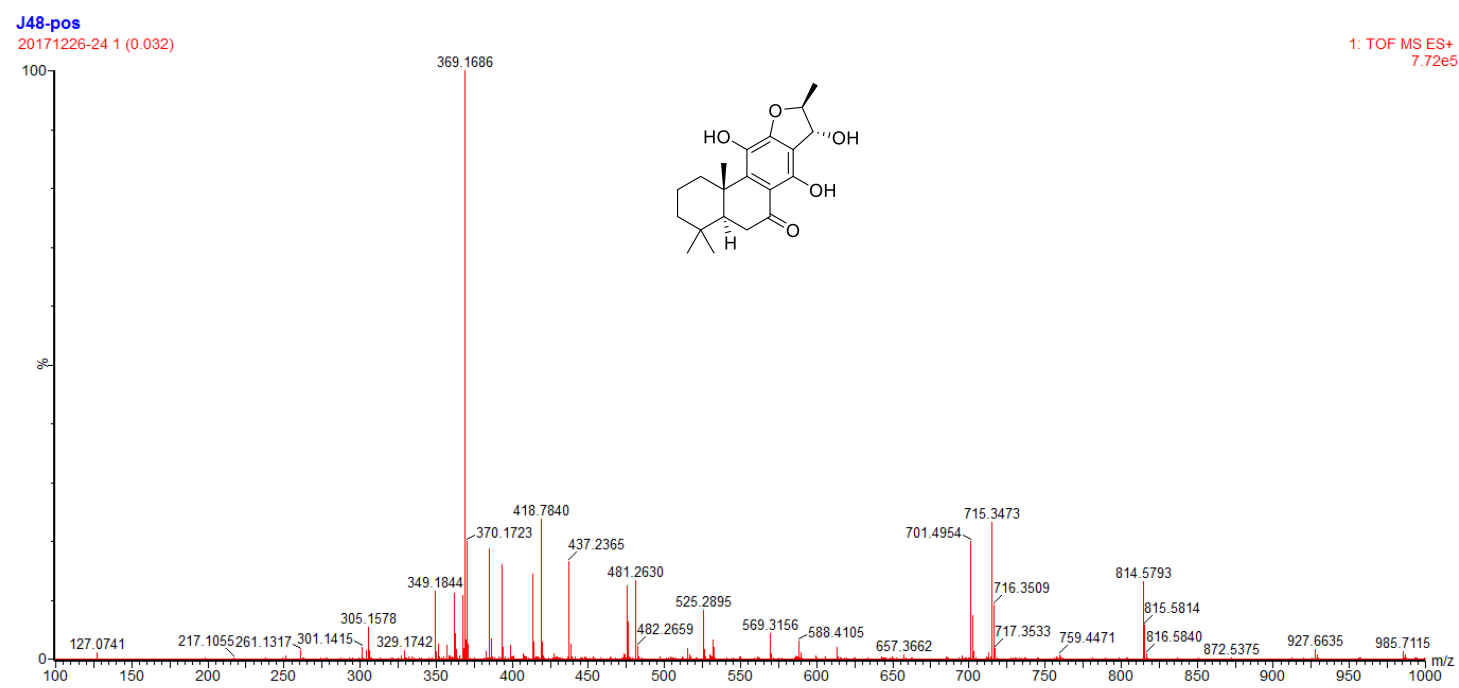

Figure S32 HR-ESI-MS spectrum of compound 4

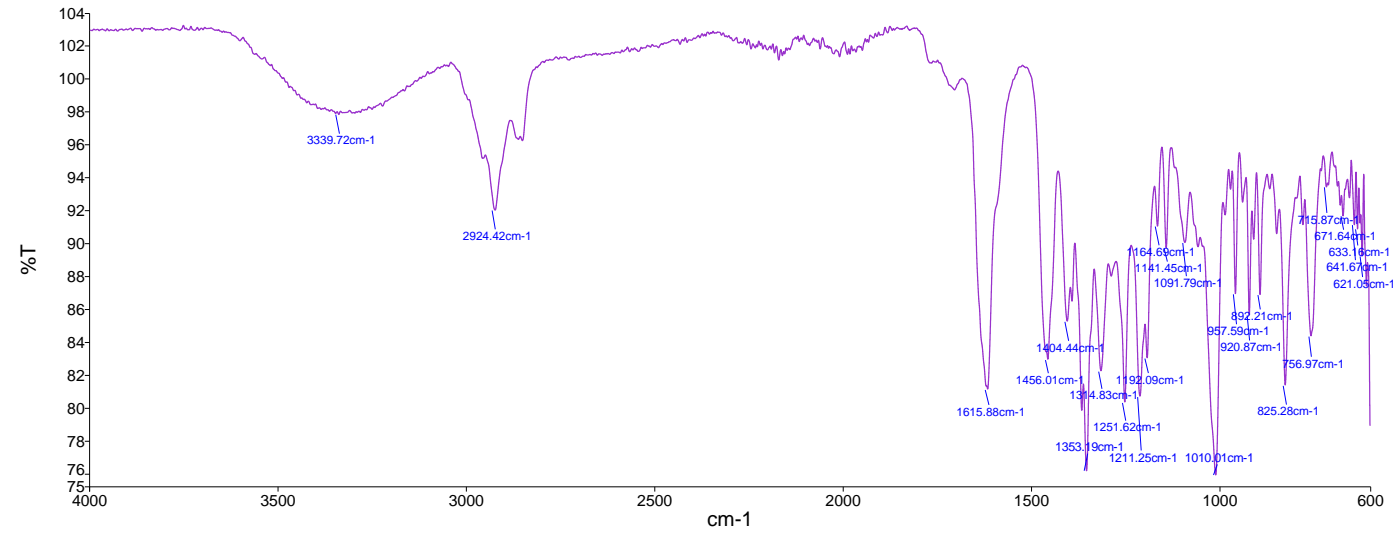

Figure S33 IR spectrum of compound 4 


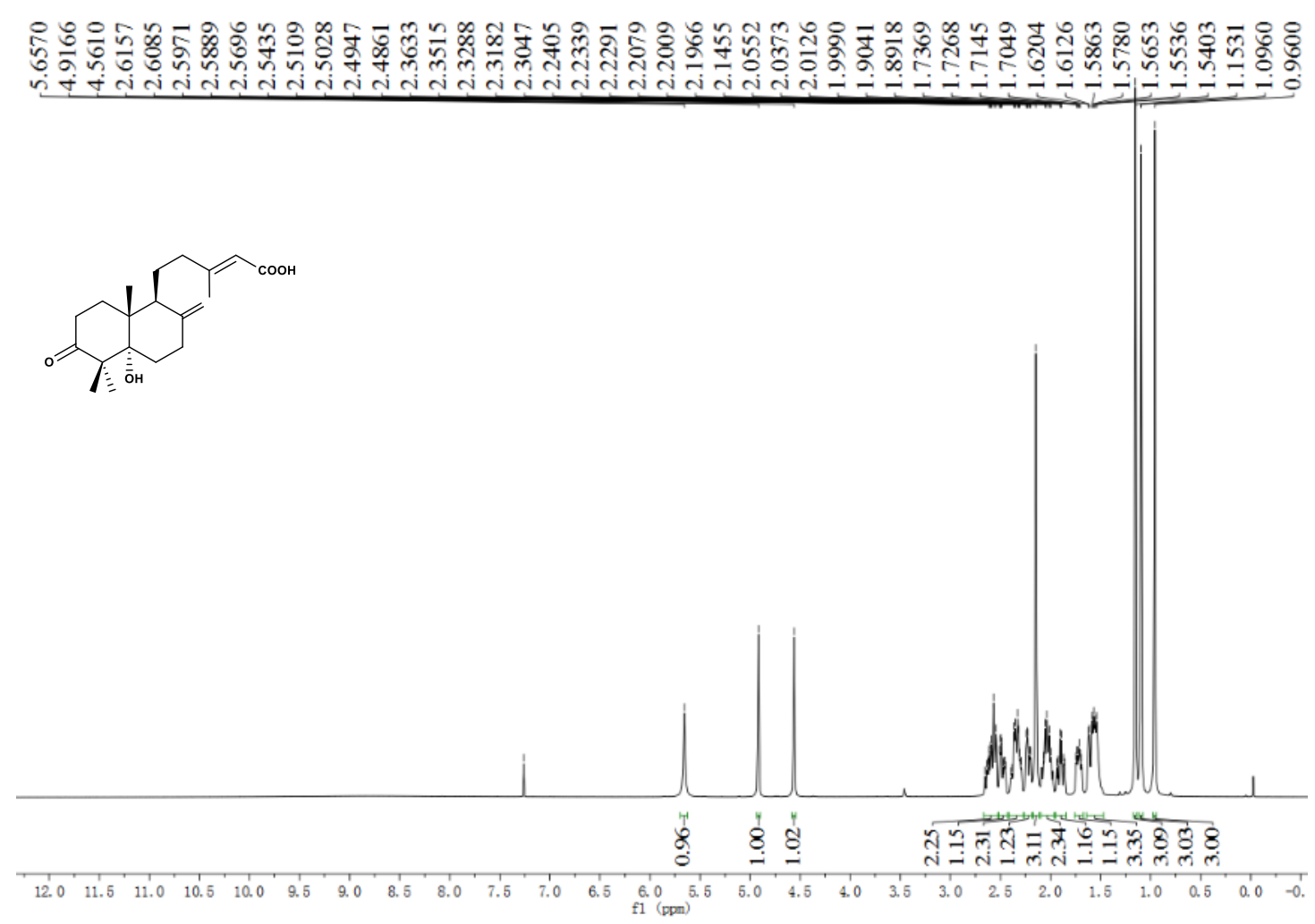

Figure $\mathbf{S 3 4}{ }^{1} \mathrm{H}$ NMR spectrum $\left(400 \mathrm{MHz}, \mathrm{CDCl}_{3}\right)$ of compound $\mathbf{5}$

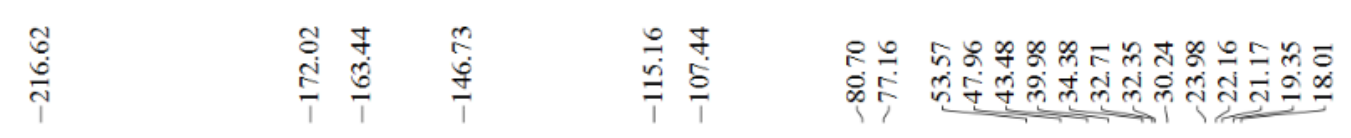

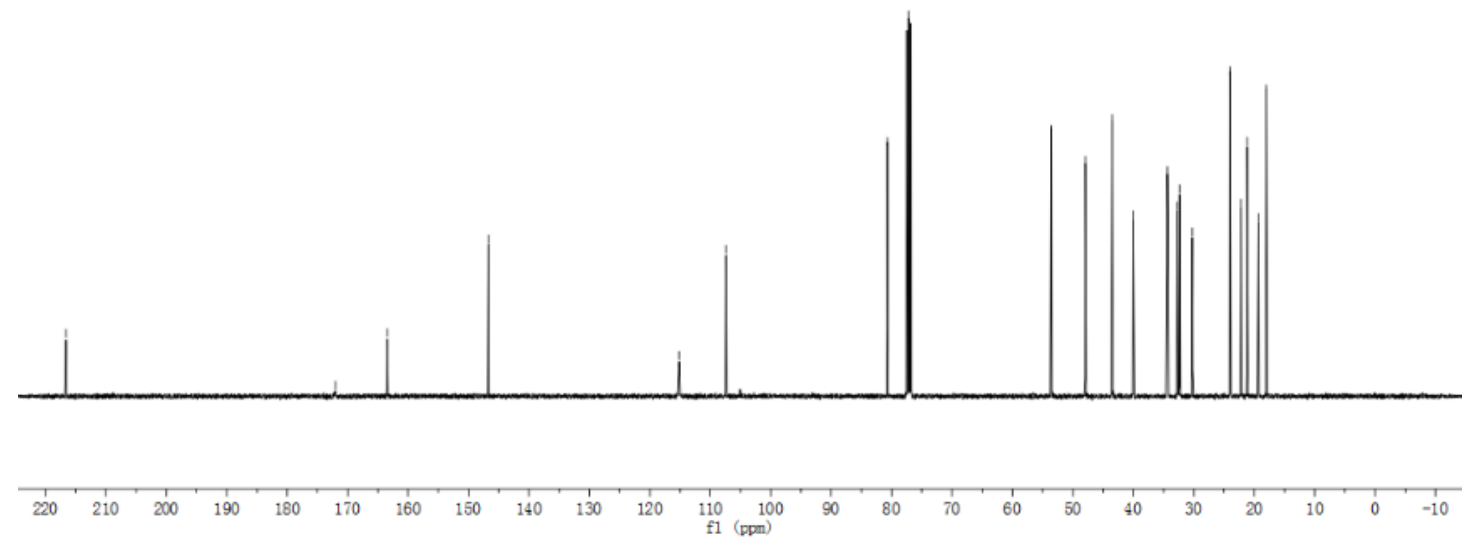

Figure $\mathbf{S 3 5}{ }^{13} \mathrm{C}$ NMR spectrum $\left(100 \mathrm{MHz}, \mathrm{CDCl}_{3}\right)$ of compound $\mathbf{5}$ 

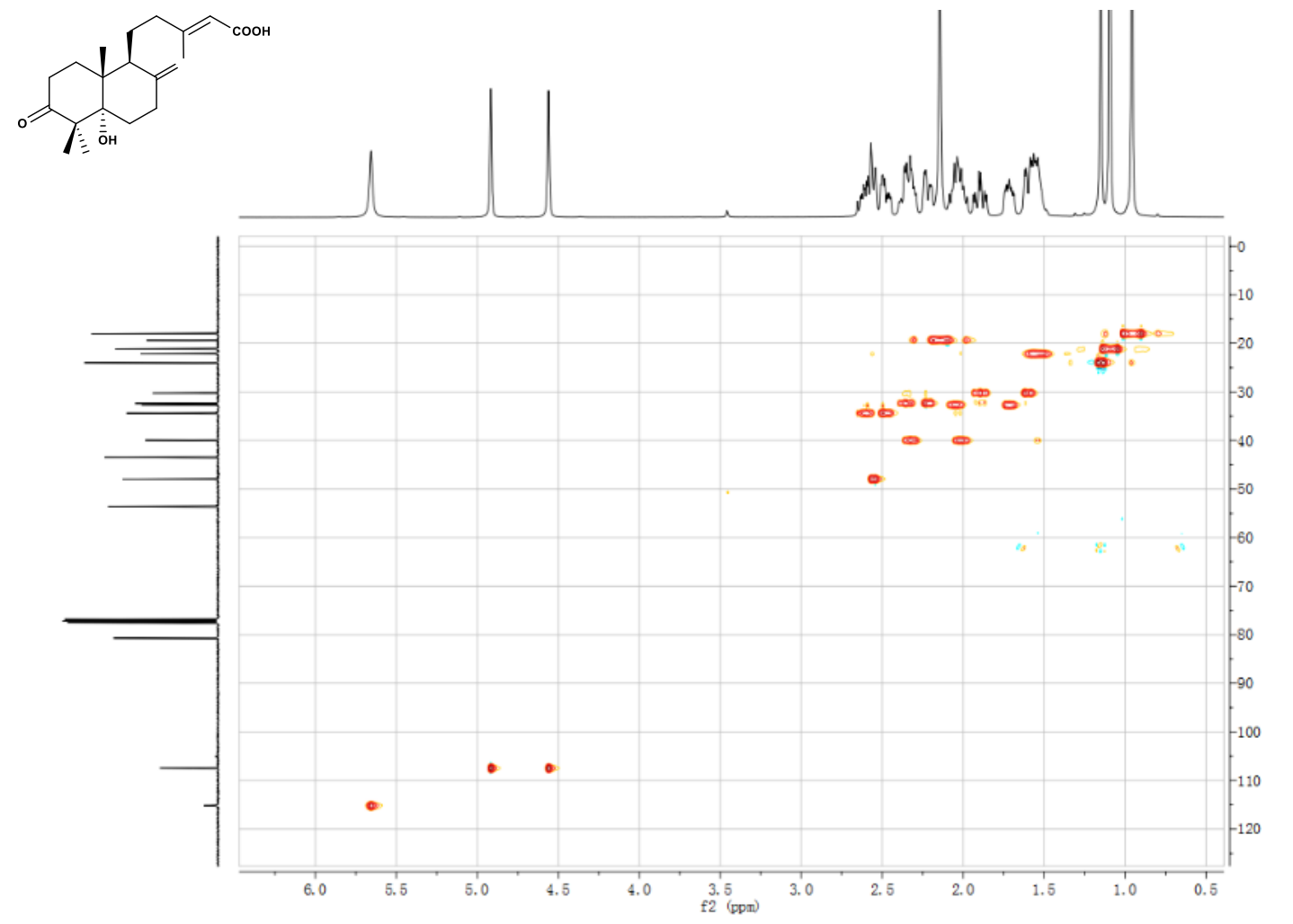

Figure S36 HSQC spectrum (400 MHz, $\mathrm{CDCl}_{3}$ ) of compound 5

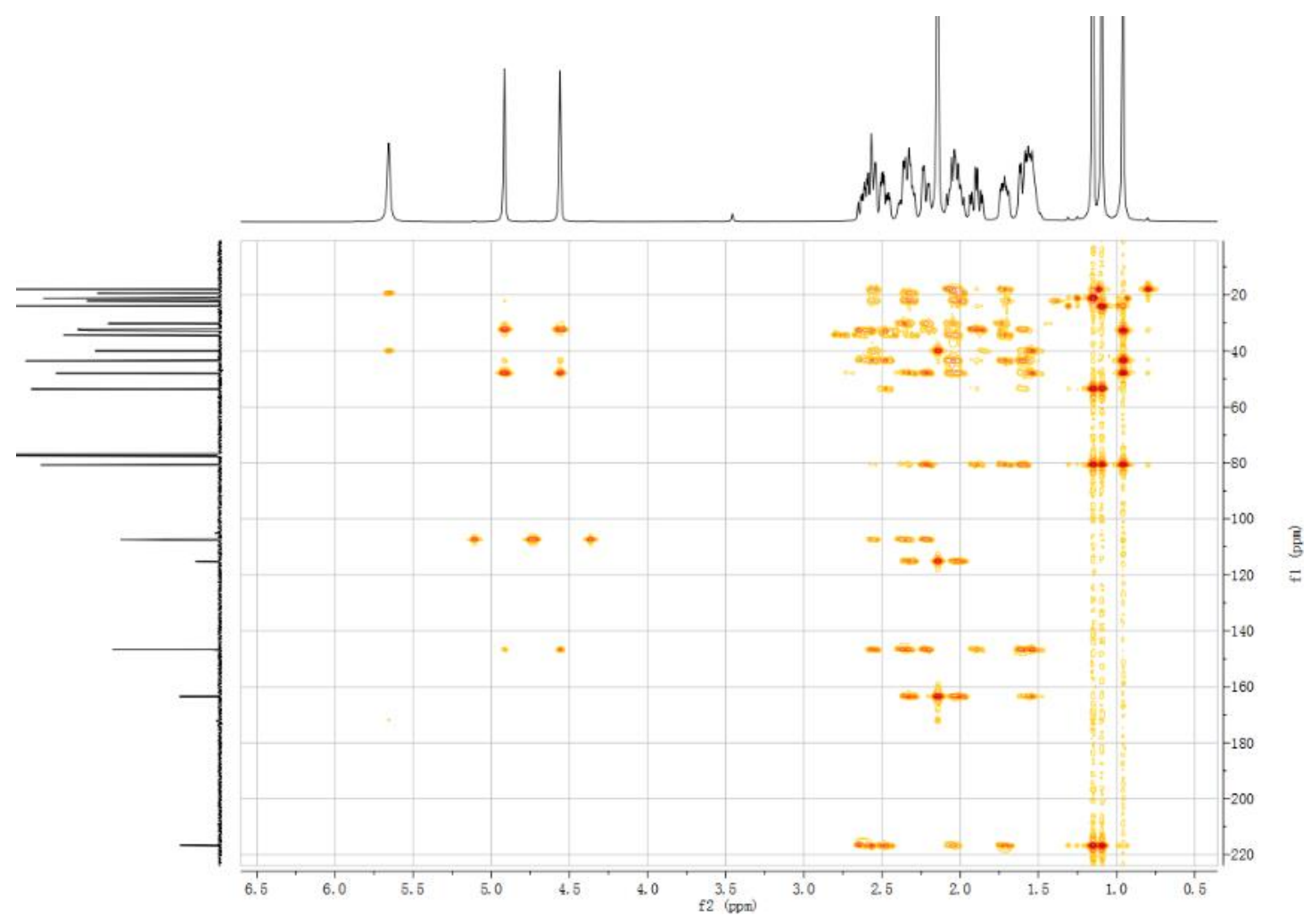

Figure S37 HMBC spectrum (400 MHz, $\left.\mathrm{CDCl}_{3}\right)$ of compound $\mathbf{5}$ 

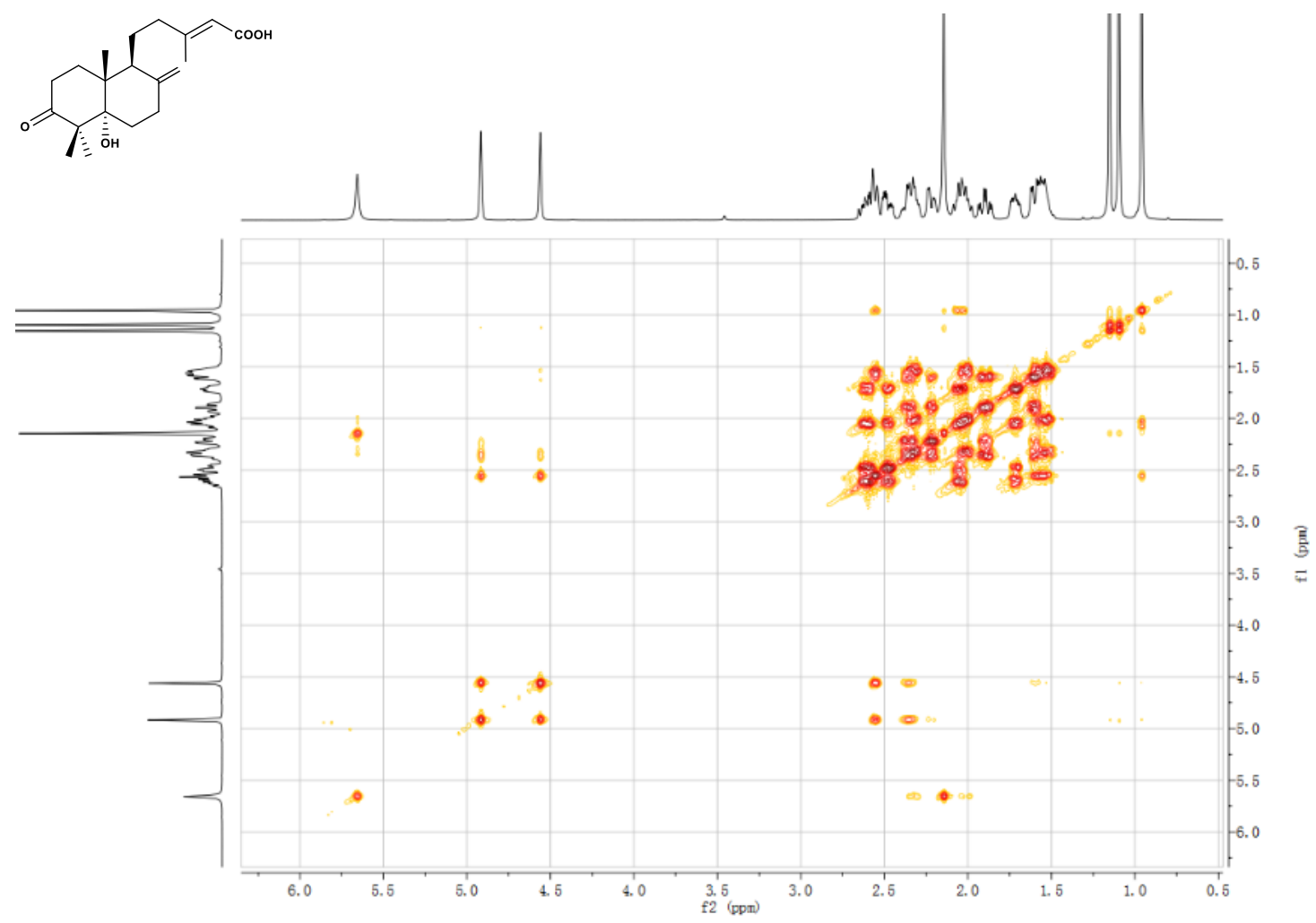

Figure $\mathbf{S 3 8}{ }^{1} \mathrm{H}-{ }^{1} \mathrm{H}$ COSY spectrum $\left(400 \mathrm{MHz}, \mathrm{CDCl}_{3}\right)$ of compound $\mathbf{5}$

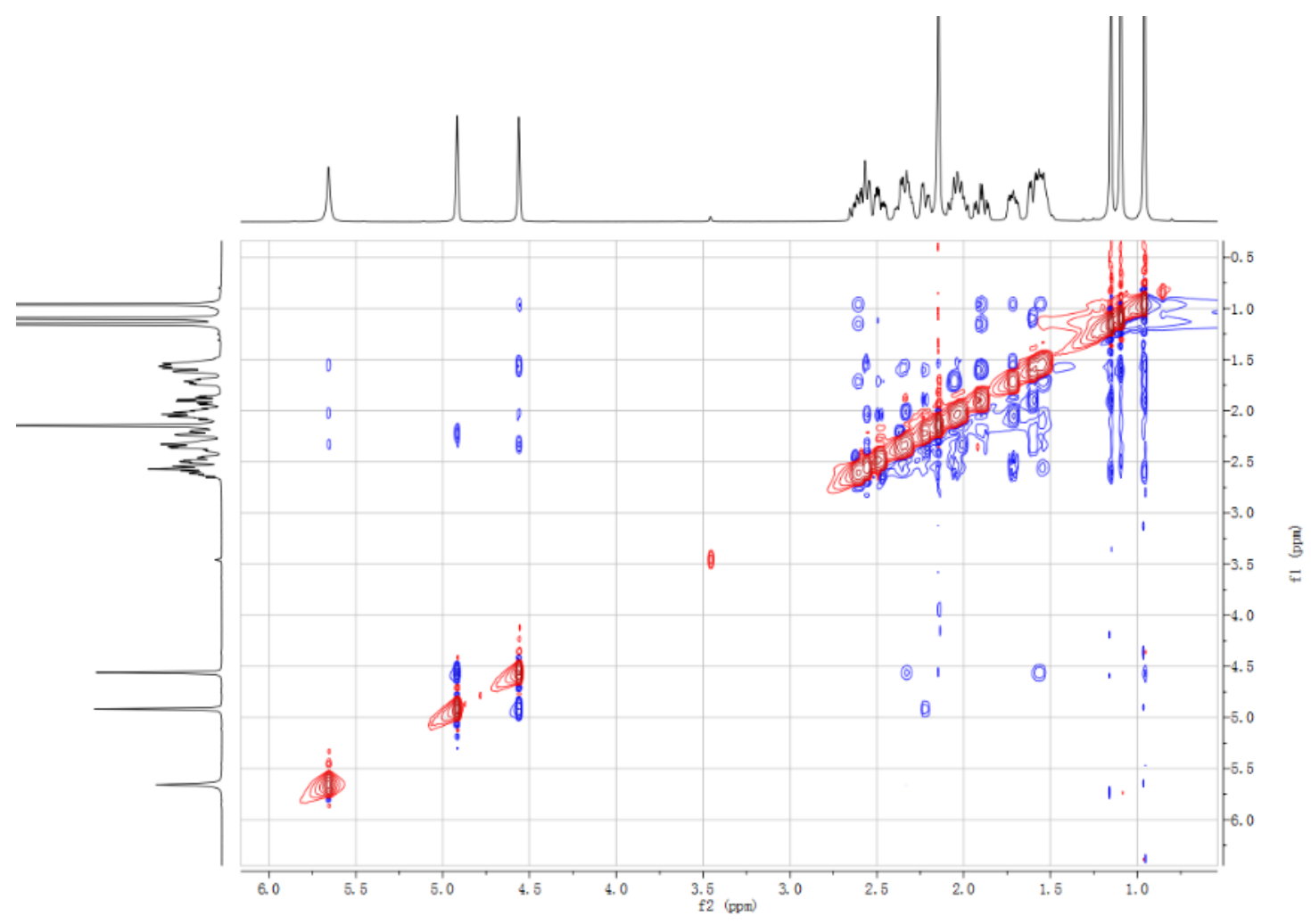

Figure S39 NOESY spectrum $\left(400 \mathrm{MHz}, \mathrm{CDCl}_{3}\right)$ of compound 5 


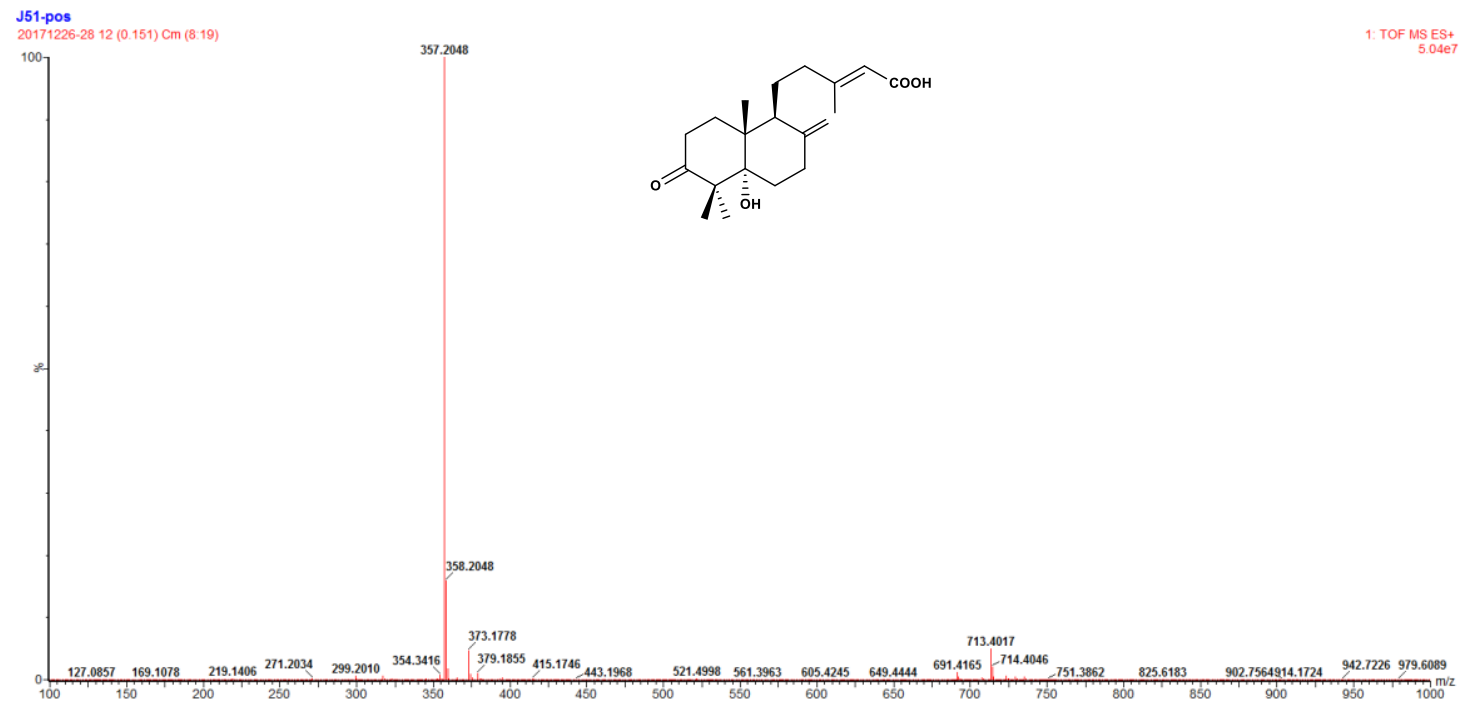

Figure S40 HR-ESI-MS spectrum of compound 5

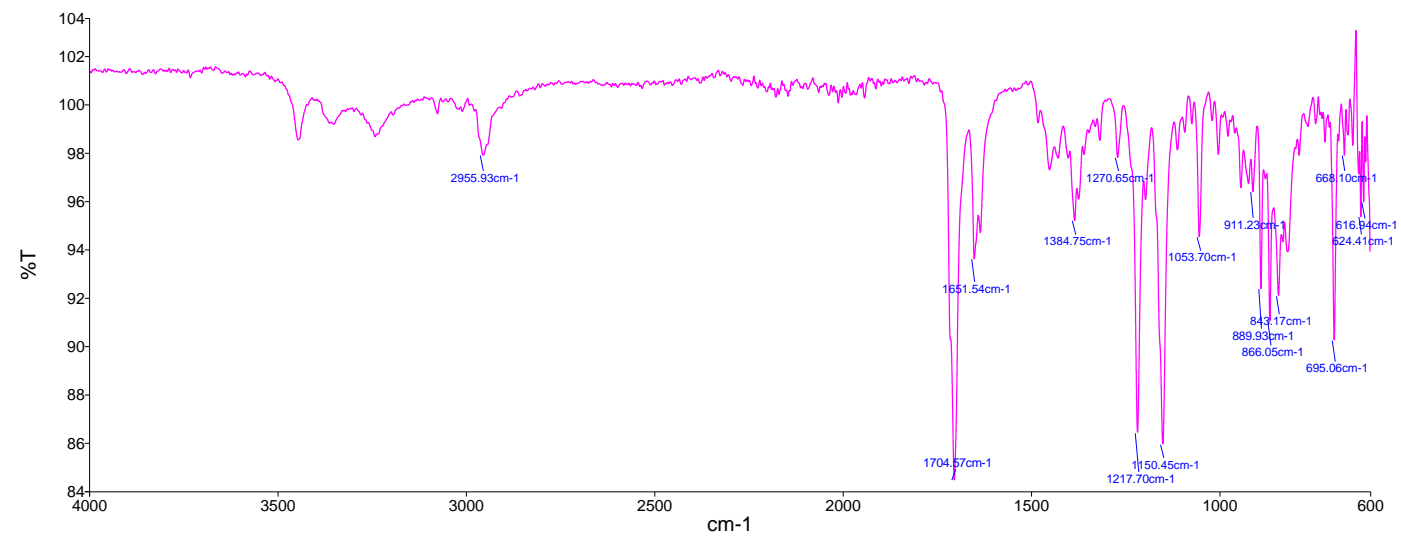

Figure S41 IR spectrum of compound 5 


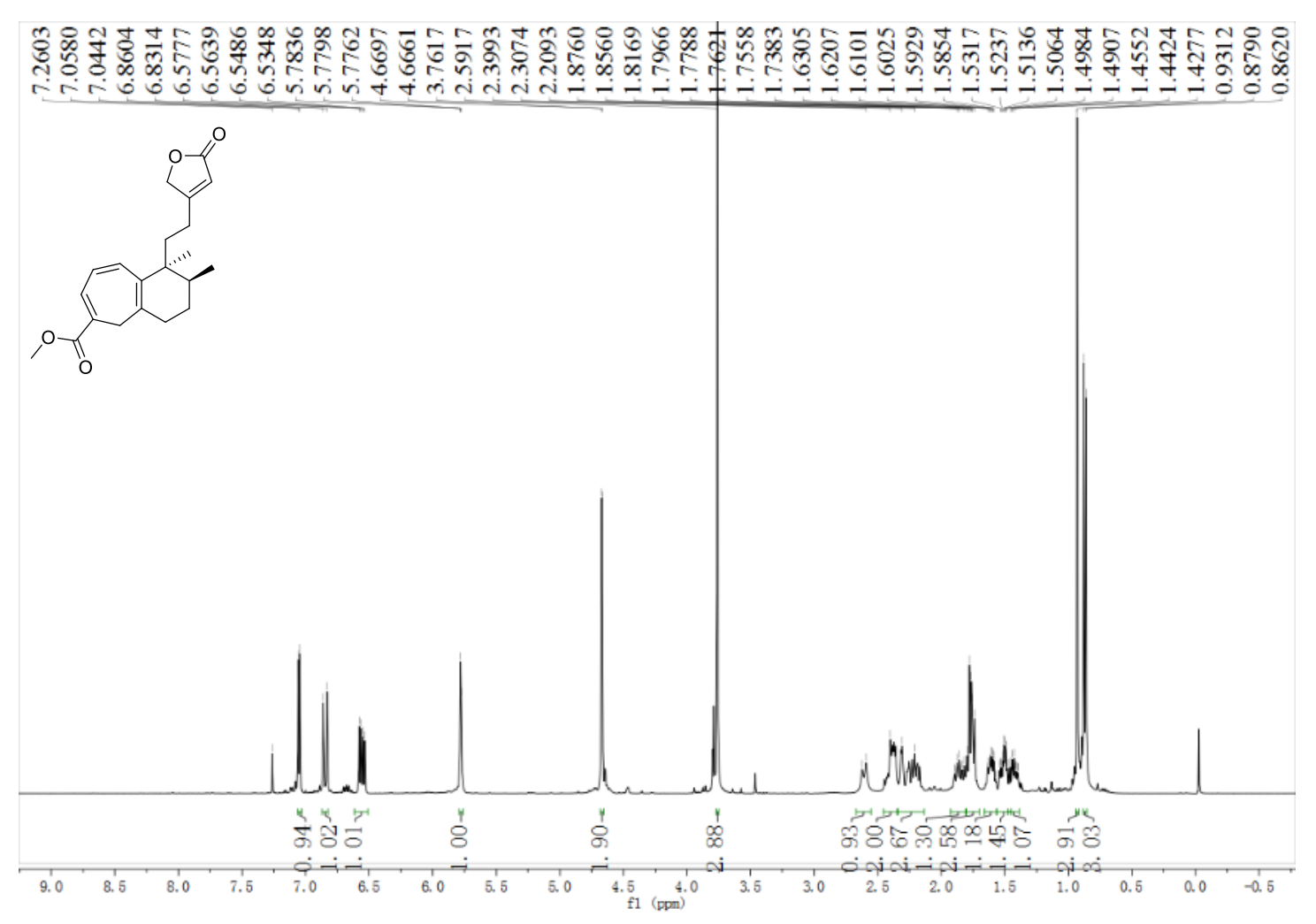

Figure $\mathbf{S 4 2}{ }^{1} \mathrm{H}$ NMR spectrum $\left(400 \mathrm{MHz}, \mathrm{CDCl}_{3}\right)$ of compound $\mathbf{6}$
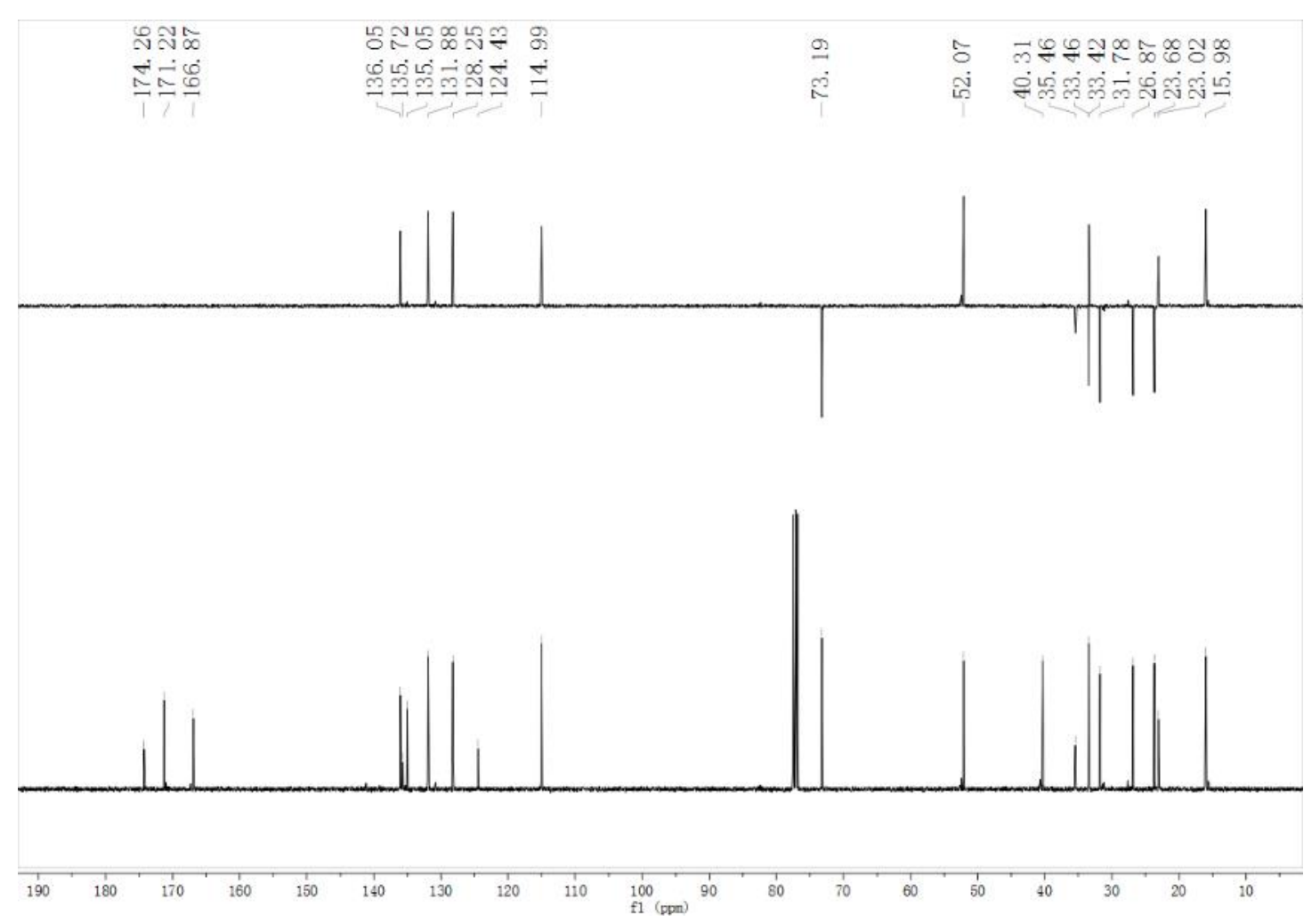

Figure $\mathbf{S 4 3}{ }^{13} \mathrm{C}$ NMR spectrum $\left(100 \mathrm{MHz}, \mathrm{CDCl}_{3}\right)$ of compound 6 


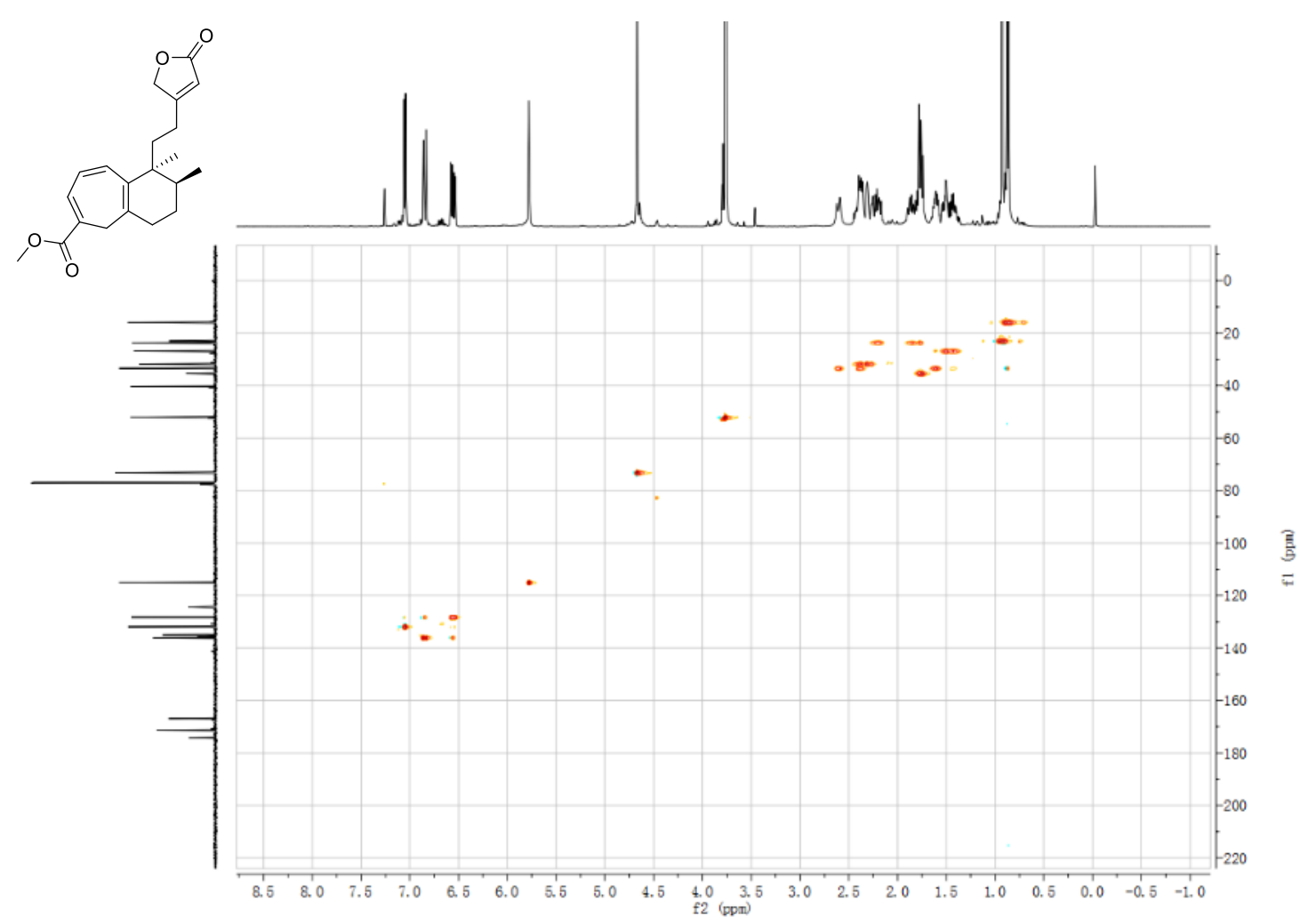

Figure S44 HSQC spectrum (400 MHz, $\mathrm{CDCl}_{3}$ ) of compound 6

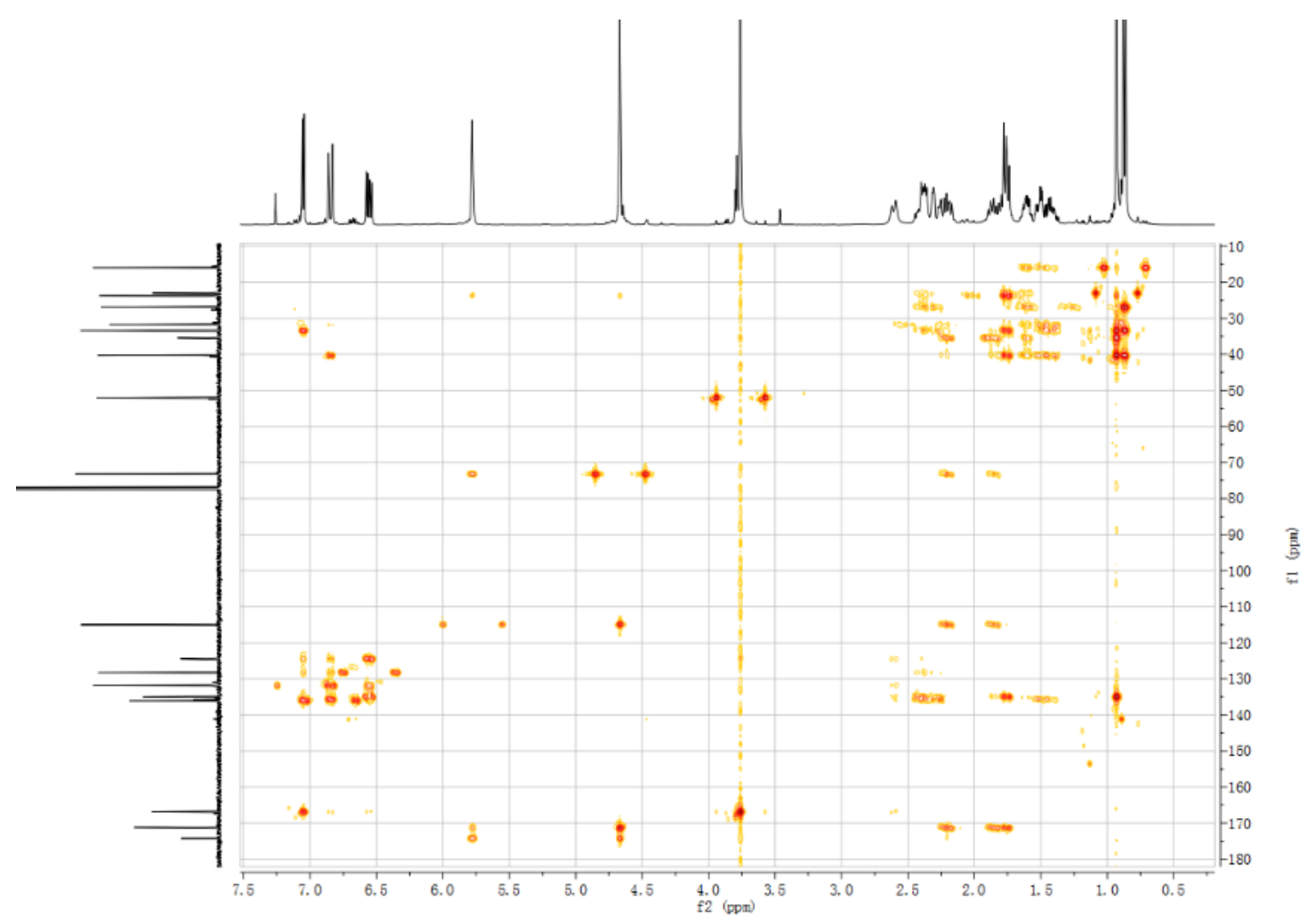

Figure S45 HMBC spectrum (400 MHz, $\left.\mathrm{CDCl}_{3}\right)$ of compound 6 


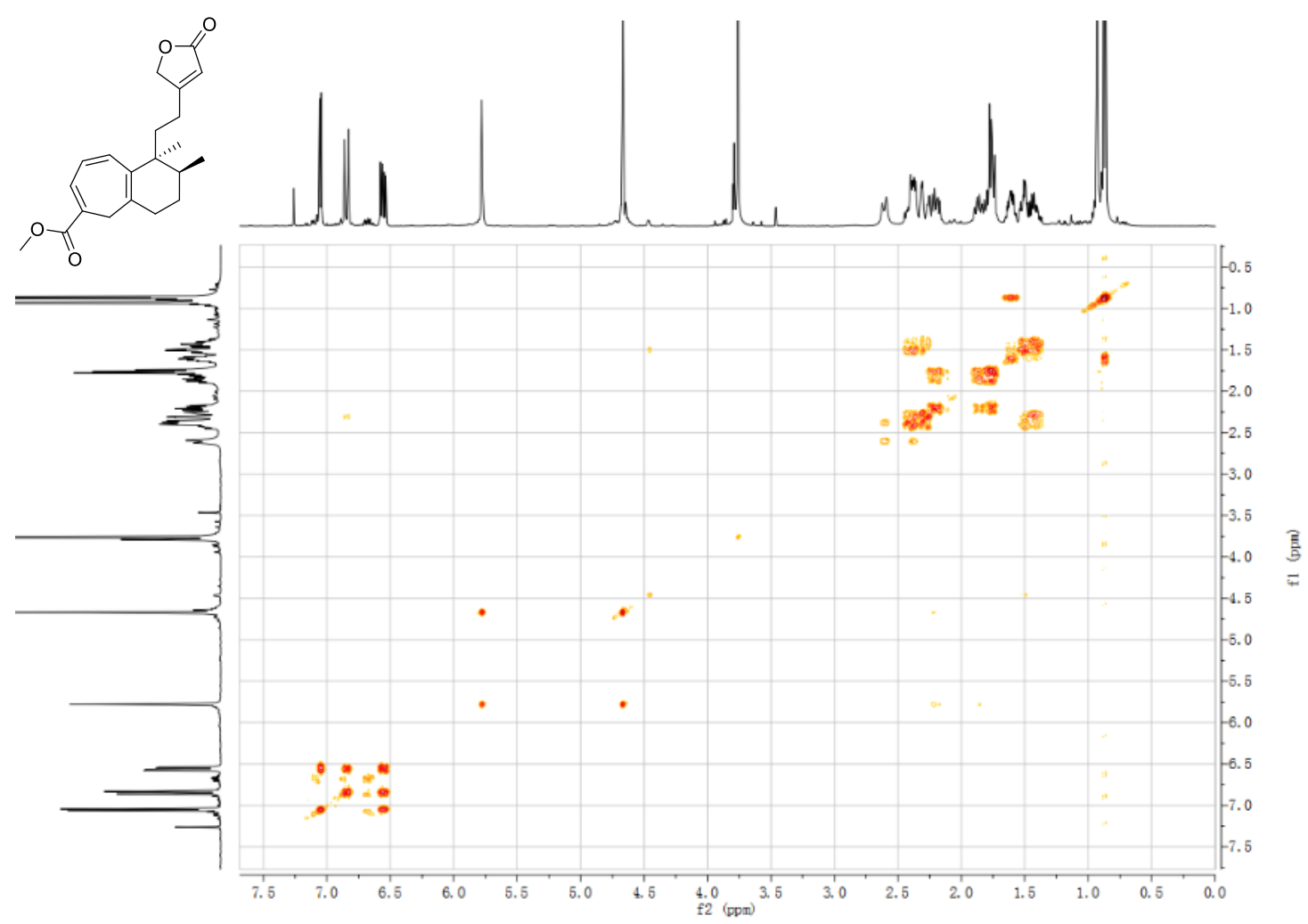

Figure $\mathbf{S 4 6}{ }^{1} \mathrm{H}-{ }^{1} \mathrm{H}$ COSY spectrum $\left(400 \mathrm{MHz}, \mathrm{CDCl}_{3}\right)$ of compound $\mathbf{6}$

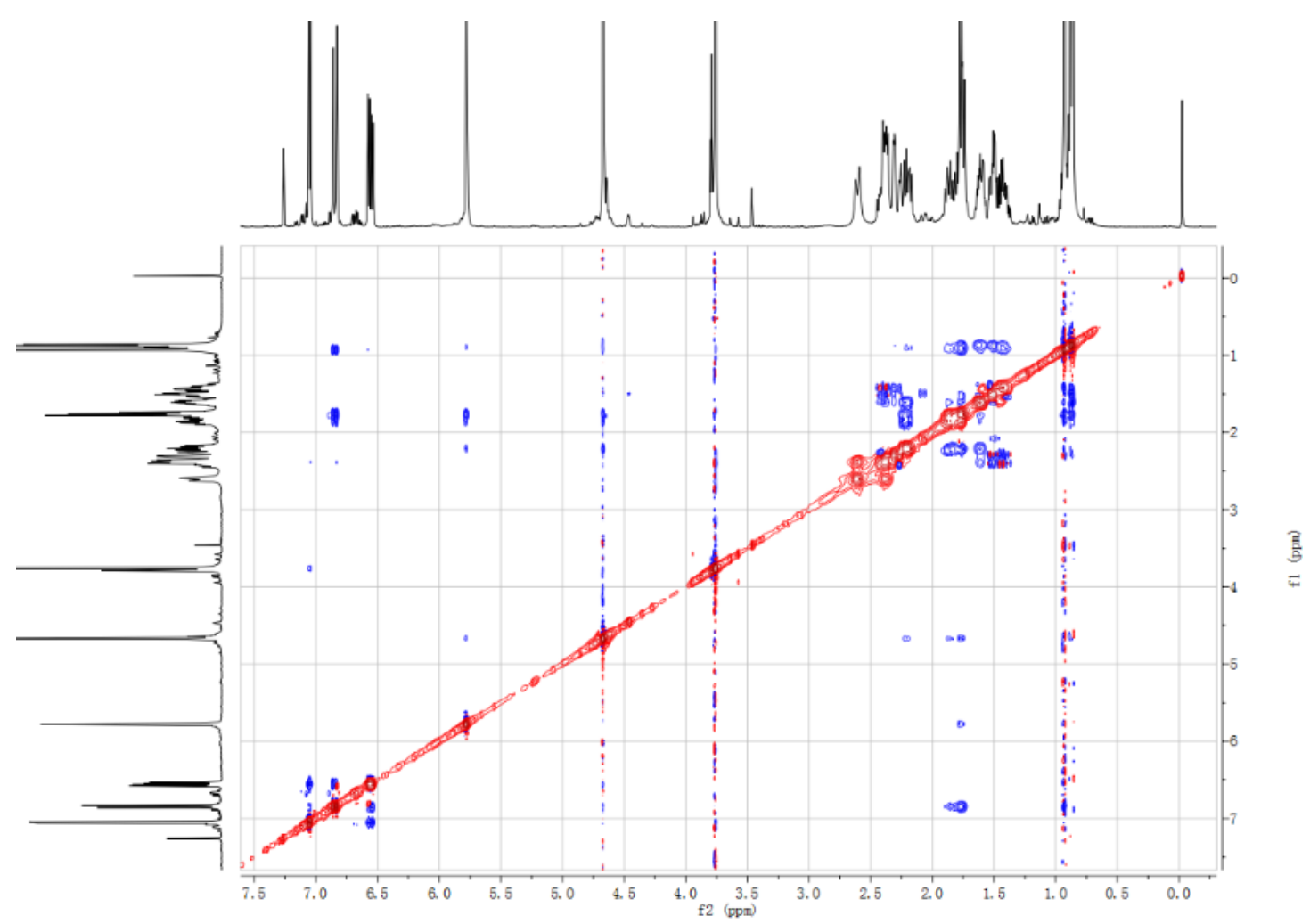

Figure S47 NOESY spectrum ( $\left.400 \mathrm{MHz}, \mathrm{CDCl}_{3}\right)$ of compound 6 


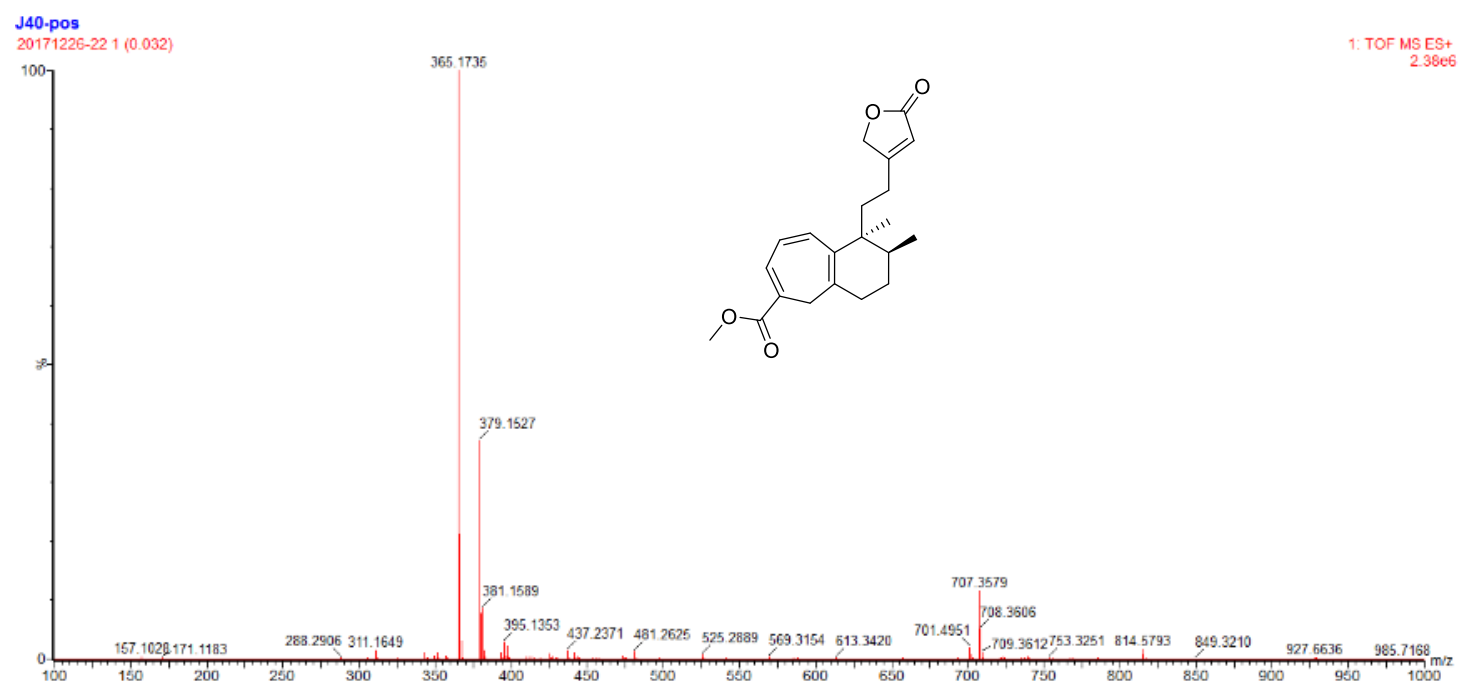

Figure S48 HR-ESI-MS spectrum of compound 6

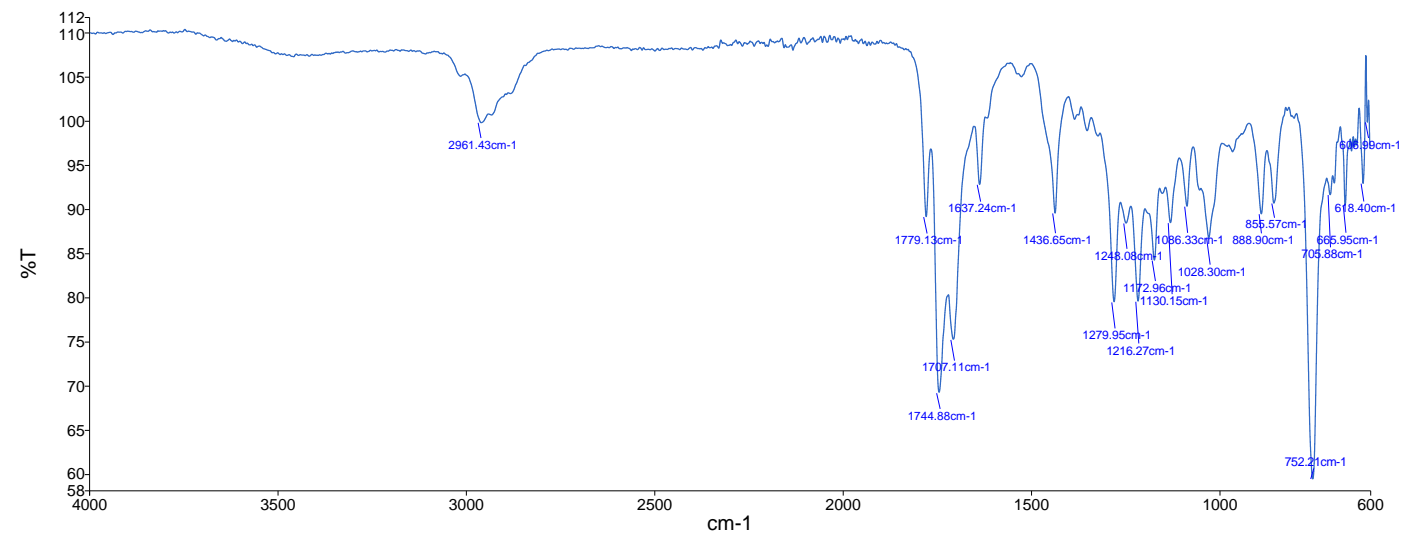

Figure S49 IR spectrum of compound 6 
<smiles>CC1=C(COC2O[C@H](CO)[C@@H](O)[C@H](O)[C@H]2O)CC[C@@]2(C)C1=CC(=O)c1c2c(O)c2oc(C)cc2c1O</smiles>

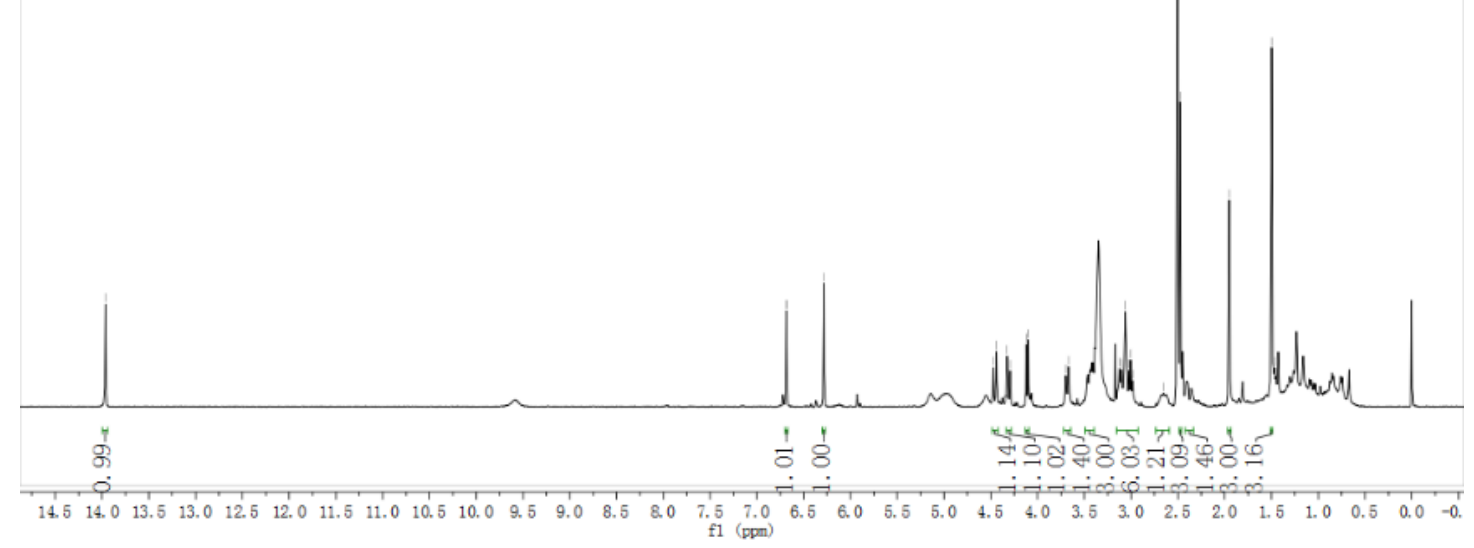

Figure S50 ${ }^{1} \mathrm{H}$ NMR spectrum (400 MHz, DMSO-d $)$ of compound 7

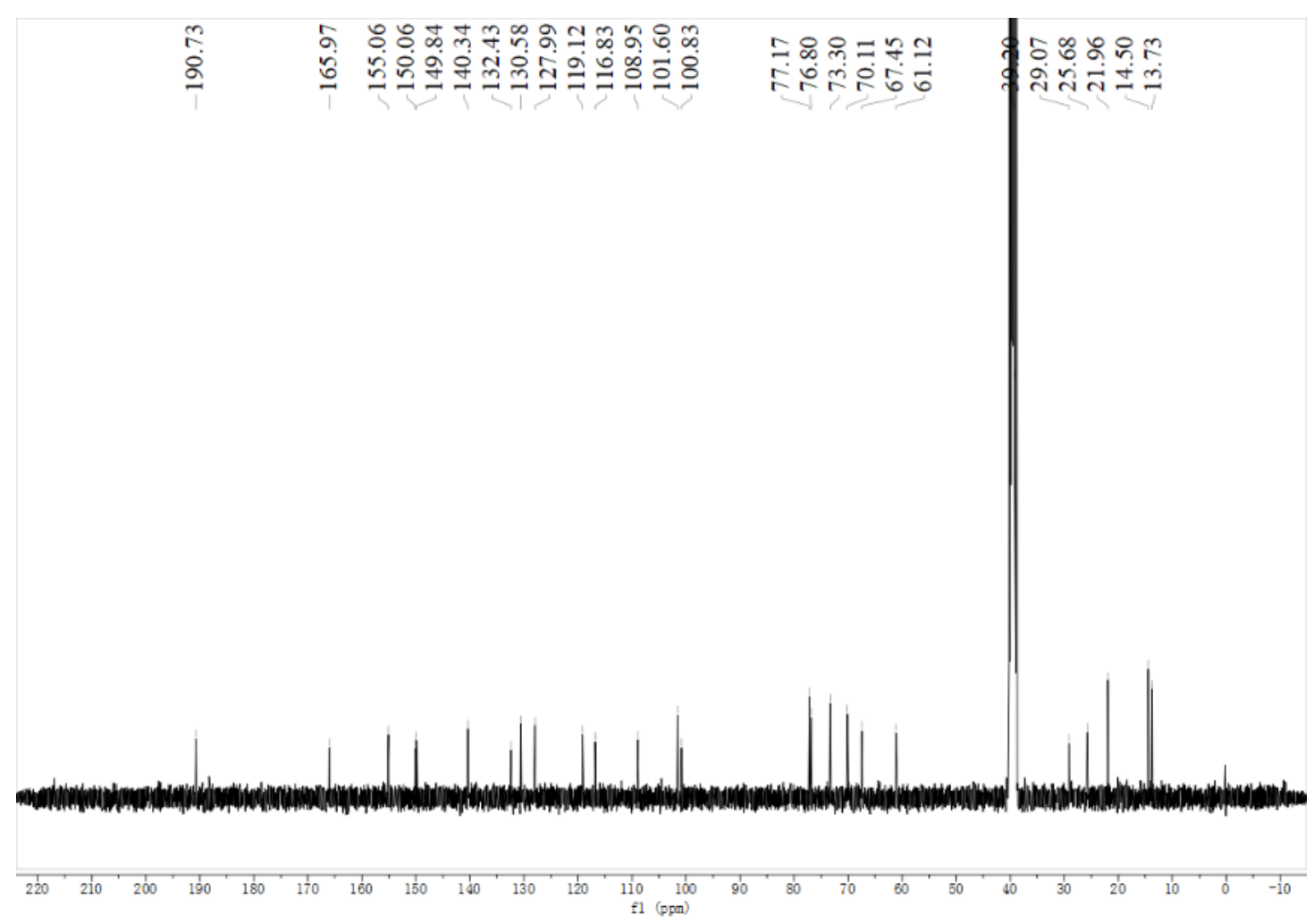

Figure S51 ${ }^{13} \mathrm{C}$ NMR spectrum (100 MHz, DMSO- $d_{6}$ ) of compound 7 


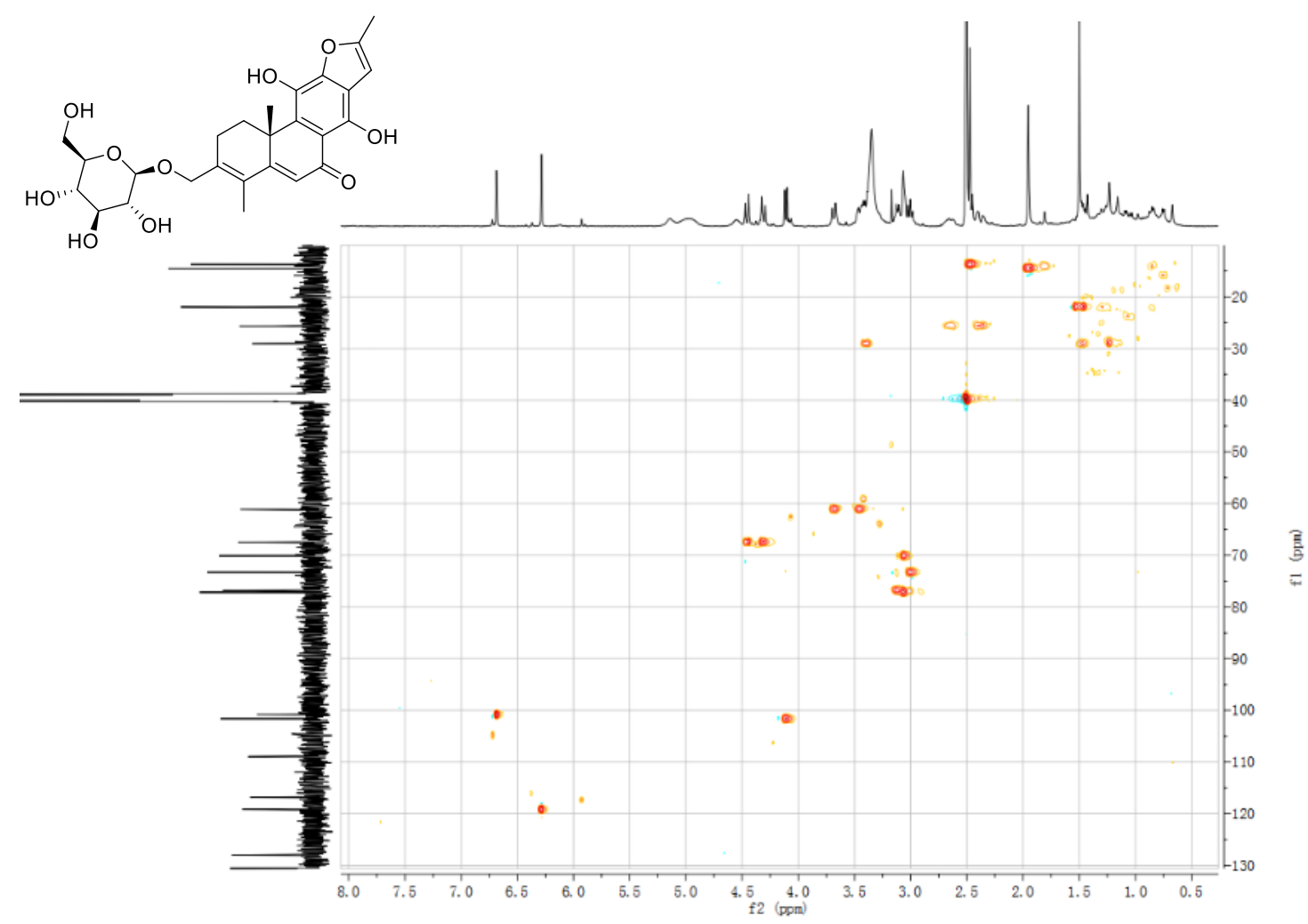

Figure S52 HSQC spectrum (400 MHz, DMSO- $d_{6}$ ) of compound 7

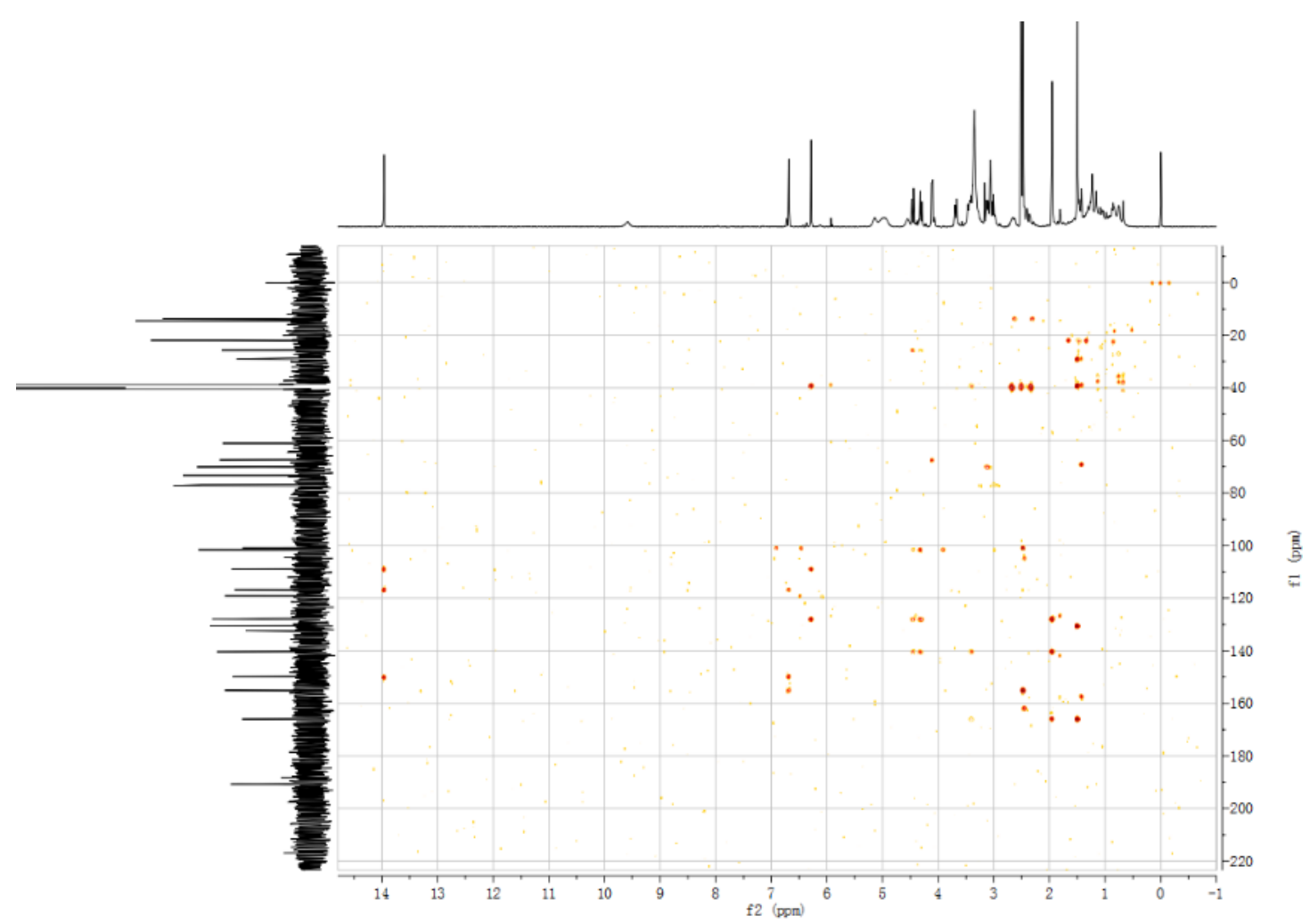

Figure S53 HMBC spectrum (400 MHz, DMSO- $\left.d_{6}\right)$ of compound 7 


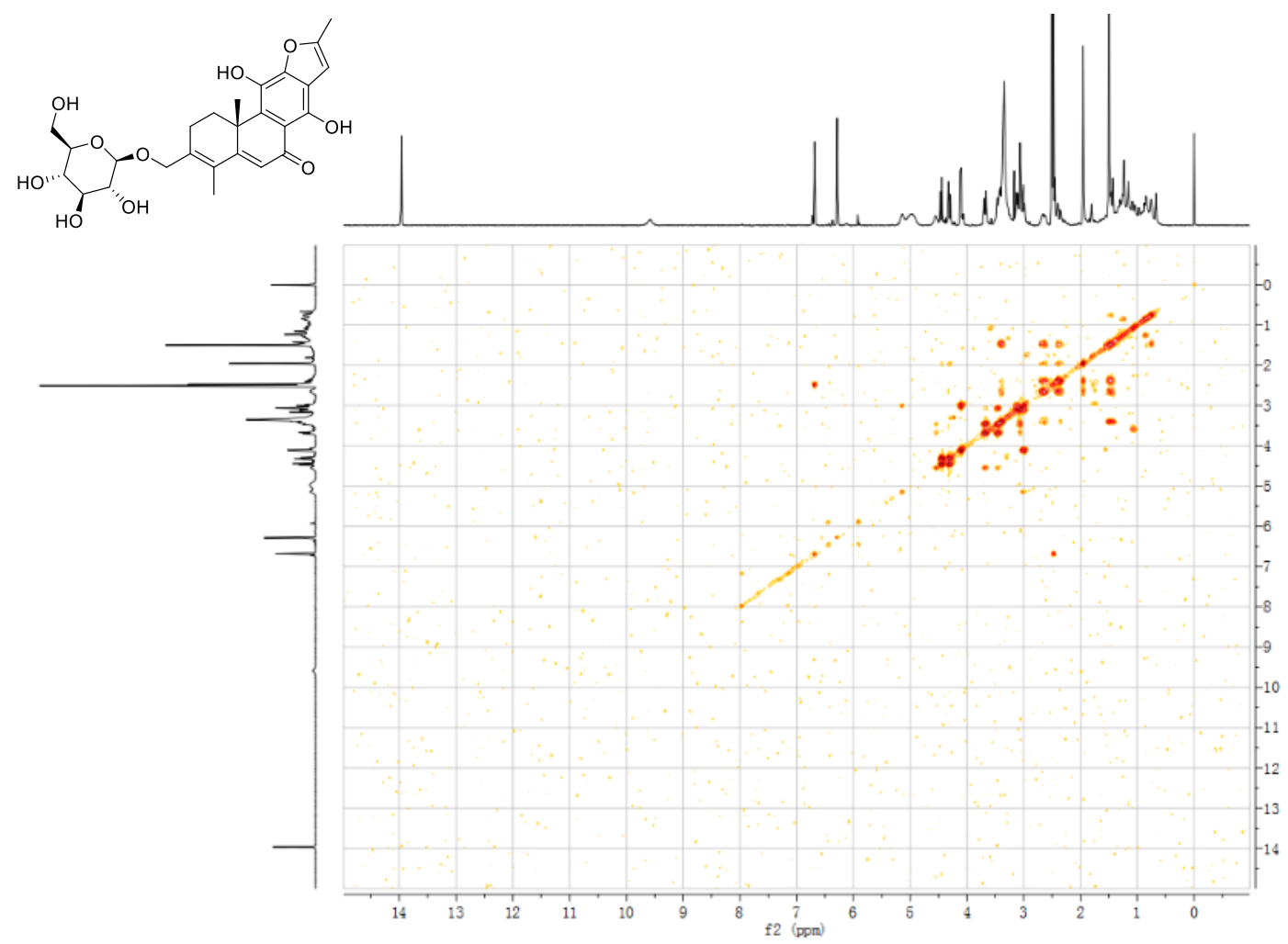

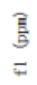

Figure S54 ${ }^{1} \mathrm{H}-{ }^{1} \mathrm{H}$ COSY spectrum (400 MHz, DMSO- $d_{6}$ ) of compound 7

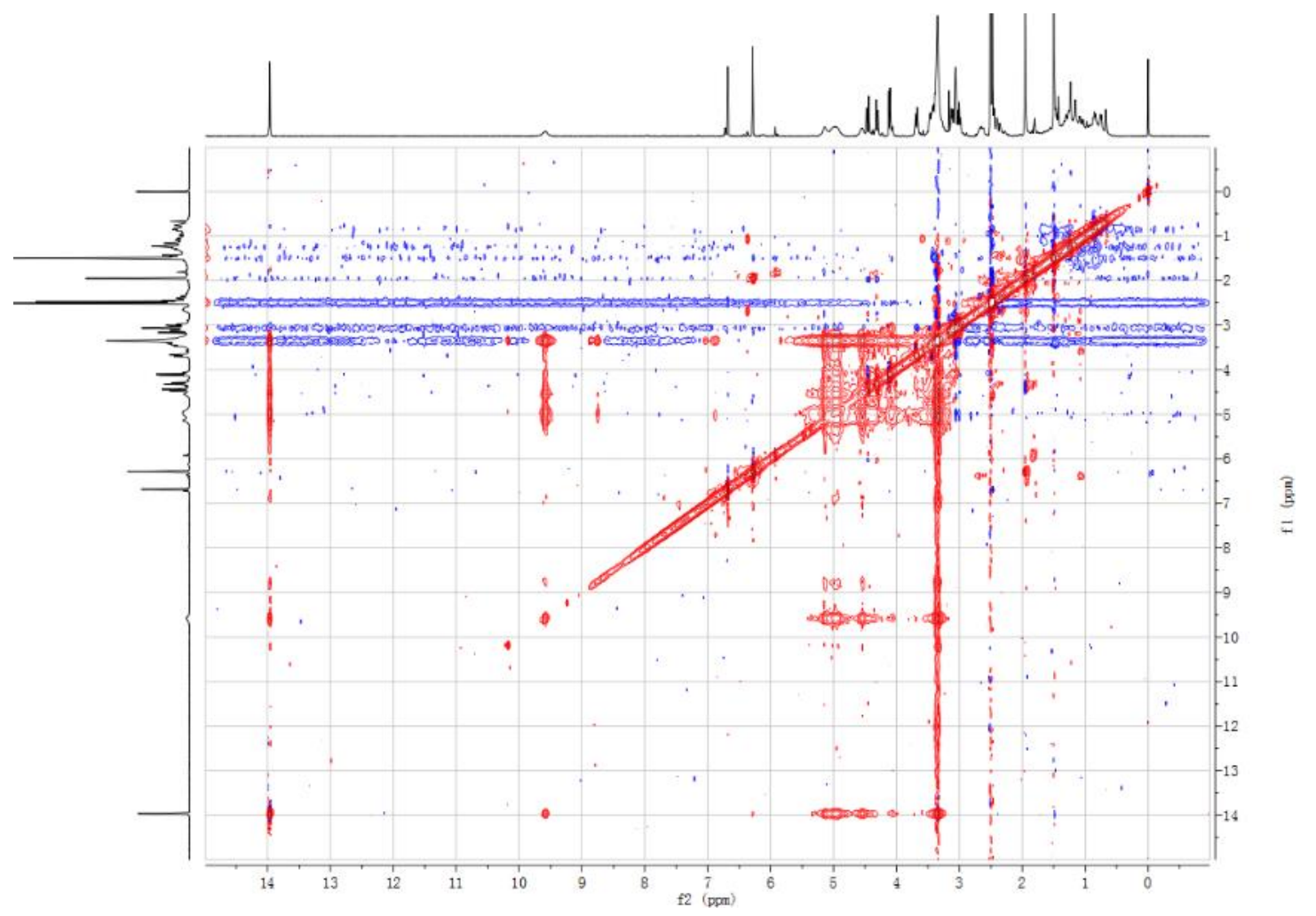

Figure S55 NOESY spectrum (400 MHz, DMSO- $d_{6}$ ) of compound 7 
J76-pos

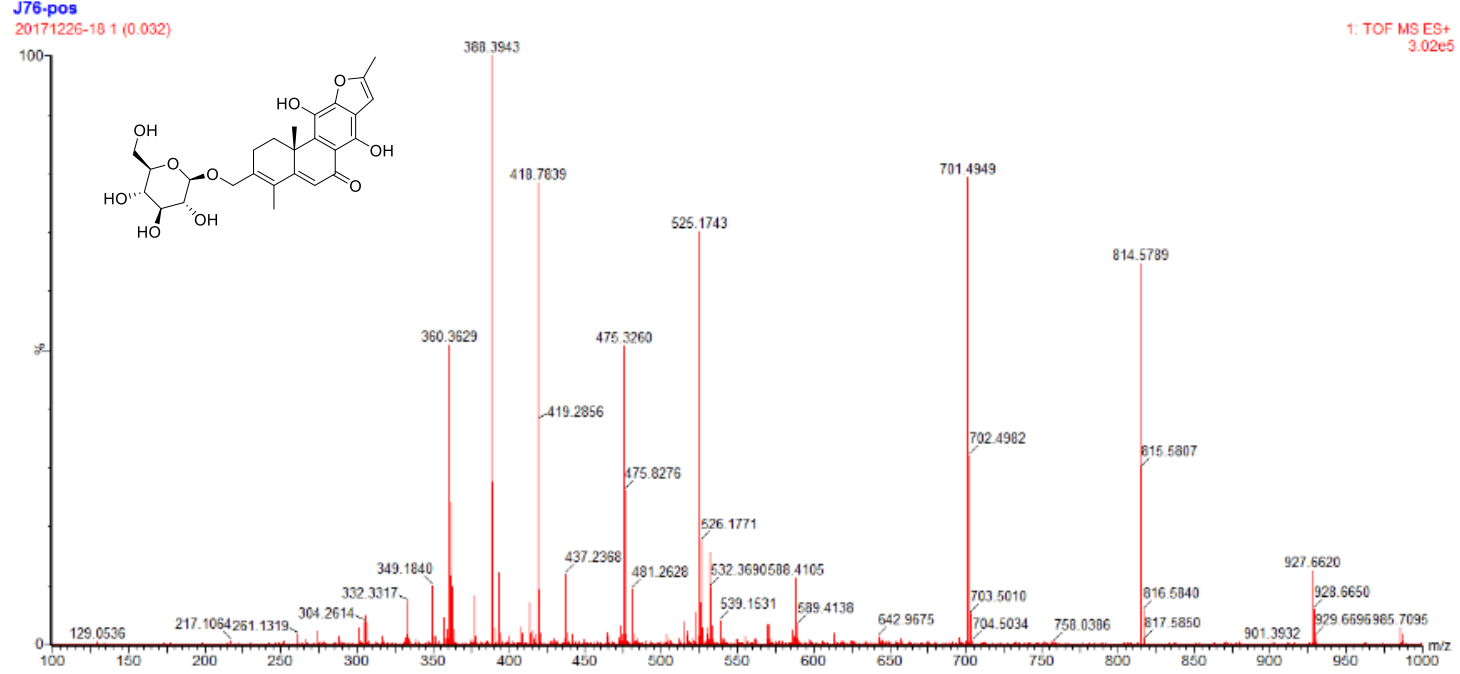

Figure S56 HR-ESI-MS spectrum of compound 7

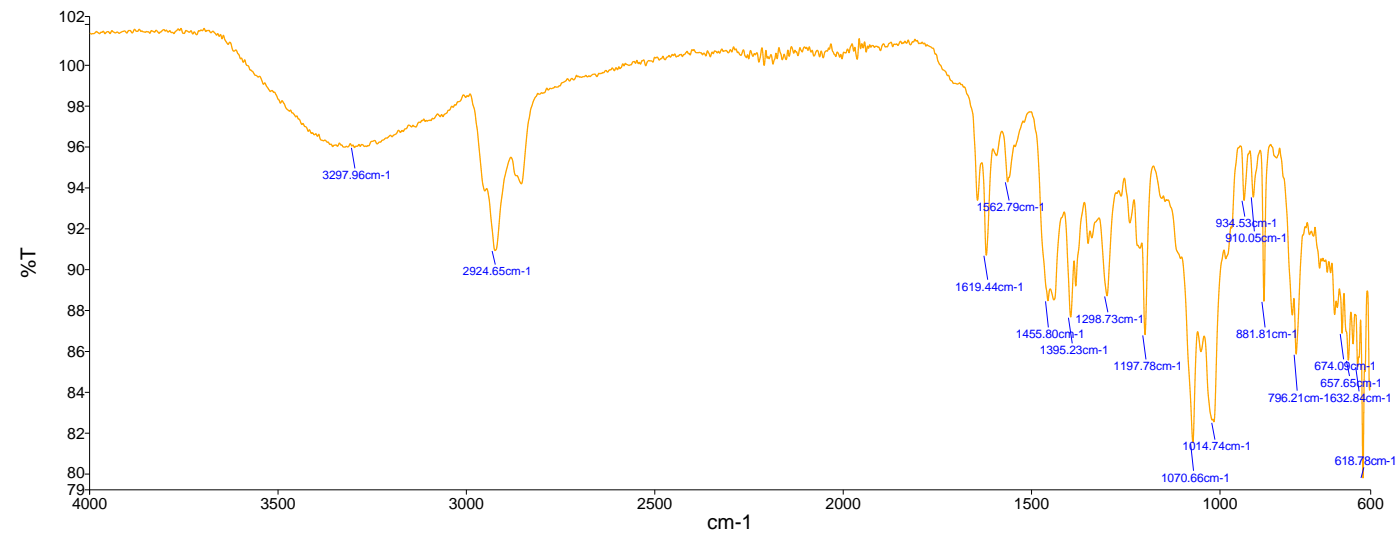

Figure S57 IR spectrum of compound 7 